\title{
Challenges of Antibacterial Discovery
}

\author{
Lynn L. Silver* \\ LL Silver Consulting, LLC, 955 S. Springfield Ave., Unit C403, Springfield, New Jersey 07081
}

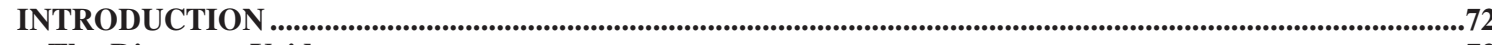

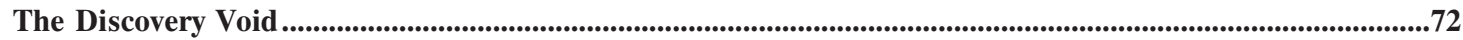

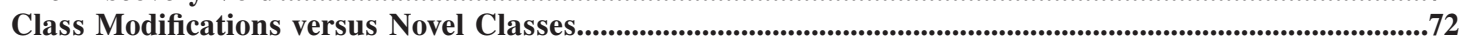

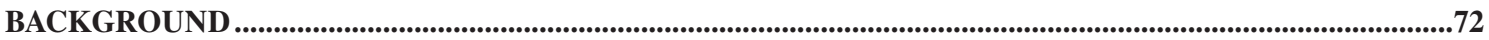

Early Screening—a Brief and Biased Philosophical History ..........................................................................72

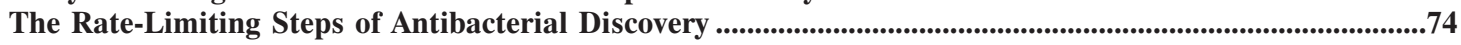

The Multitarget Hypothesis ......................................................................................................................................................74

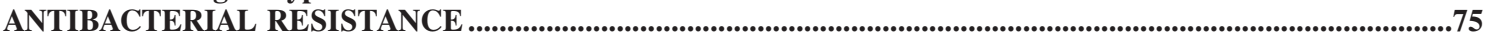

Endogenous versus Exogenous Resistance.....................................................................................................................75

Assessing Endogenous Resistance Potential ........................................................................................................76

Fitness of Resistant Mutants and Compensatory Mutations.................................................................................77

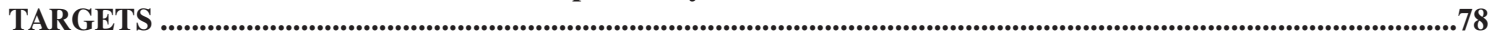

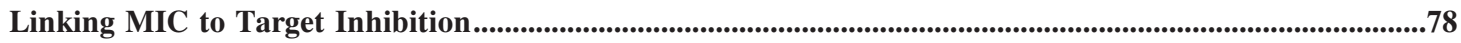

Support for Enzyme Inhibition as the Antibacterial Mechanism.......................................................................78

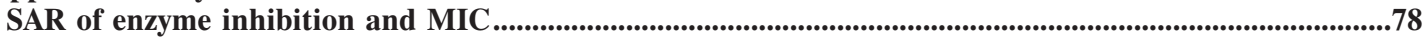

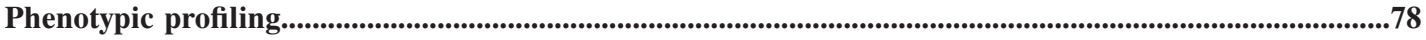

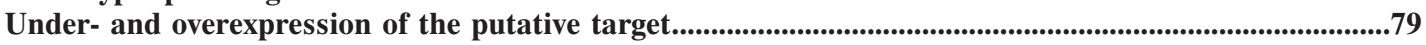

An array of arrays: expression, sensitization, resistance, and synergy ..............................................................79

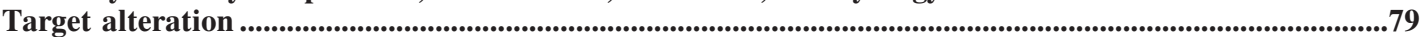

RECENT RECORD OF SINGLE-ENZYME-TARGETED AGENTS ...

The Opacity of the Discovery Process.....................................................................................................................80

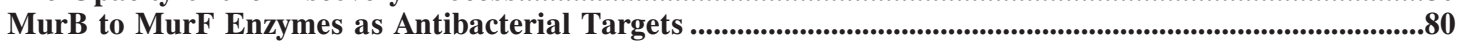

Targets of Inhibitors Discovered by Enzyme Screening or Design ......................................................................83

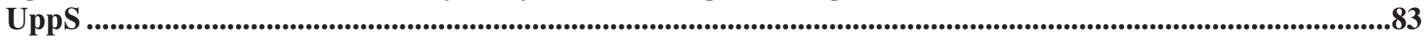

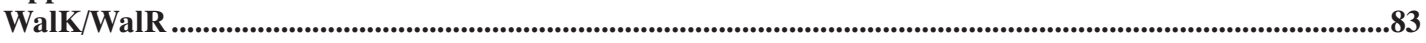

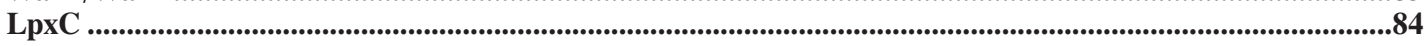

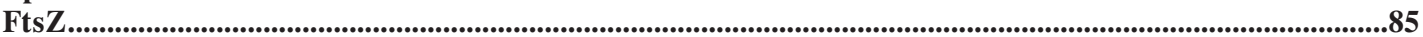

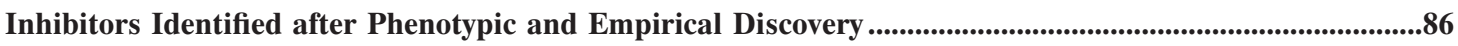

Single-Enzyme Targets of Novel Inhibitors in Clinical Trials .......................................................................................86

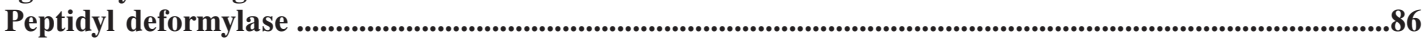

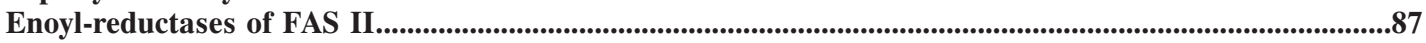

Leucyl tRNA synthetases of Gram-negative organisms....................................................................................88

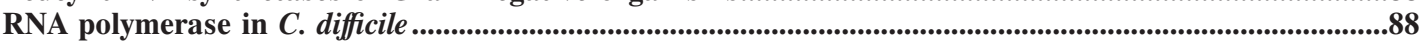

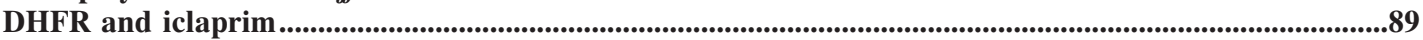

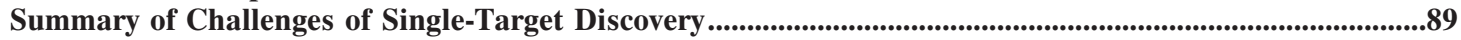

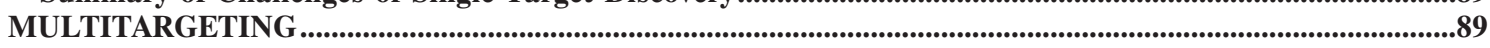

Single Pharmacophore, Multiple Targets...................................................................................................................90

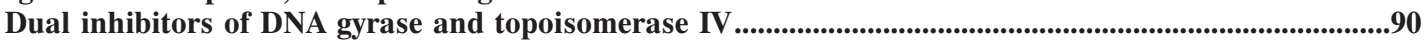

Dual inhibitors of Gram-positive DNA polymerases ................................................................................92

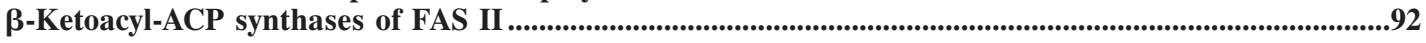

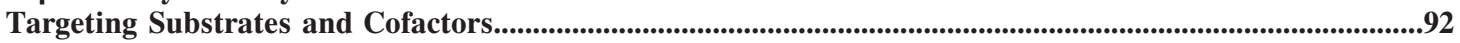

Lipid II and other specific cell wall substrates ...........................................................................................92

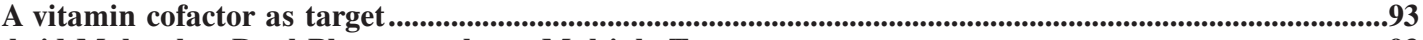

Hybrid Molecules: Dual Pharmacophore, Multiple Targets .................................................................................93

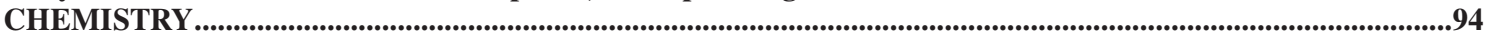

Spectrum Is Due to Permeability as Well as Target Distribution..............................................................................94

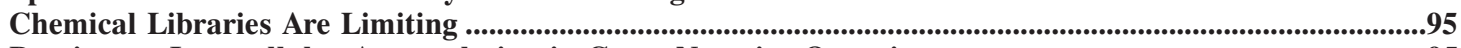

Barriers to Intracellular Accumulation in Gram-Negative Organisms ............................................................95

Cytoplasmic and outer membranes have orthogonal sieving properties ............................................................95

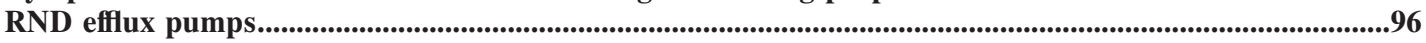

Formulation of Rules for Intracellular Accumulation..............................................................................................96

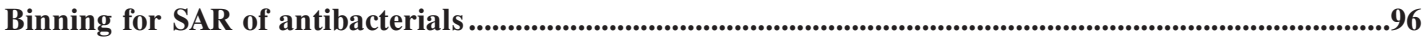

\footnotetext{
* Mailing address: LL Silver Consulting, LLC, 955 S. Springfield Ave., Unit C403, Springfield, NJ 07081. Phone: (973) 218-1466. E-mail: silverly@comcast.net.
} 


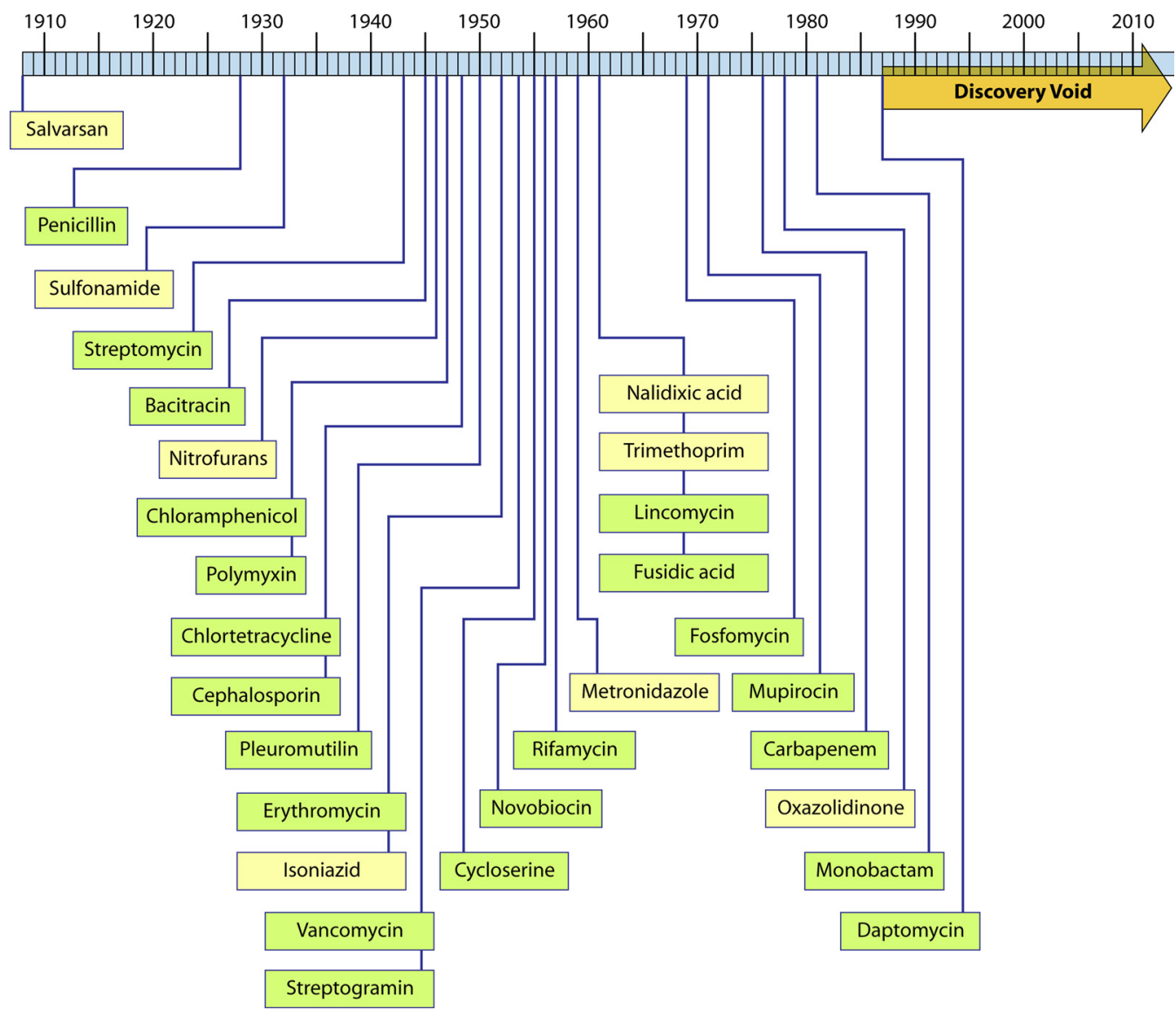

FIG. 1. Illustration of the "discovery void." Dates indicated are those of reported initial discovery or patent.

number of years, as the most common antibiotics (natural product-derived antibacterials) were discovered and rediscovered rapidly. The prevalence of production of "common" antibiotics among standard Actinomycetes has been estimated by Baltz (22). To efficiently discard such previously described compounds, methods of so-called "dereplication" were quickly developed to identify them $(1,104,352)$.

In an effort to make dereplication easier, starting by the early 1960s (126), screening methods were modified in order to limit the hits to subsets of all possible antibiotic compounds. For example, many screens were developed over the years to detect inhibitors of the pathway of peptidoglycan (cell wall) synthesis $(126,278,333)$. Each time a hit in such a screen was detected, it could be compared for biological and chemical similarity to the previously discovered cell wall synthesis inhibitors. Thus, pathway- or rudimentary target-based screening arose in part for dereplication purposes but also because certain pathways (cell wall and protein synthesis) appeared to be common targets for useful antibiotics. Furthermore, it was early recognized that cell wall inhibition was a very selective antibacterial target. The only clinically useful antibacterial classes discovered through directed screening thus far (monobactams, carbapenems, and fosfomycin) were discovered in these cell wall pathway screens.

Importantly, in 1977, at a time when the output of novel antibiotic classes had decreased, the low-hanging fruit having been found, Cohen proposed rational chemotherapy of infectious organisms through a search for inhibitors of specific enzymes in the target organism (77). This, along with the growing ability to clone genes and manipulate bacterial strains to enhance whole-cell phenotypic screens for inhibitors of specific targets (and eventually allow the production of purified proteins which could be used for in vitro screening and assays), turned the whole of antibacterial discovery toward more target-directed screens.

Much of early industrial antibacterial screening was carried out by cohesive groups that did natural product fermentation and both designed and ran the screens. The scientific direction and prioritization of resources were done within the group. But changes in the pharmaceutical industry led, in many cases, to a modularized system that is still more or less in effect. Drug discovery programs for different therapeutic areas (such as infectious diseases, cardiology, oncology, immunology, etc.) are generally organized such that biology and sometimes chemistry are committed to that area, but other functions (screening, animal testing, pharmacology, structural biology, etc.) may be shared. Since resources are always limiting, their allocation became a relatively high-level management decision (often at a remove from bench science), weighing the value to the company of a therapeutic area, the probability of success, the proximity to the "cutting edge" of current technology, and the ability of the scientists and their managers to push 
specific programs. For example, antibacterial discovery groups had to compete with other therapeutic areas for the opportunity (a so-called "slot") to screen natural products. The awarding of natural product screening slots came to be based on the perceived attractiveness of the target and its amenability to downstream biochemical and physical analysis. Those antibacterial screens designed to find primarily novelty (over inhibitors of a specific target) were often given low priority. It could be argued that finding novelty is the goal of natural product screening for antibacterials and that concentration on a small number of preselected "desirable" targets (for which inhibitors might or might not be present) is an inefficient use of the natural product resource. Screening strategies for novelty among natural products are noted in a later section.

Natural product screening (at least for novel antibacterials) waned with the low output of good leads, the advent of highthroughput liquid handling-based screening methods, for which crude microbial fermentation broths are a poor fit (since they require labor- and time-intensive culture isolation, fermentation, and extraction to produce a relatively limited number of samples), and the rise in the screening of chemical libraries, especially combinatorial chemicals. Antibacterial discovery largely became limited to screening these chemical libraries. This was not a fruitful source, as discussed below.

To summarize, after the Golden Age, antibacterial discovery became target oriented and largely abandoned natural product sources. Big Pharma evidently weighed the costs of maintaining the resources for natural product programs against the low probability of useful output and opted for the synthetic chemical route. Targets were pursued first as a means of dereplication in natural product screening and later to provide a rational basis for discovery and as a route to avoiding cross-resistance with other drugs, as discussed below.

\section{The Rate-Limiting Steps of Antibacterial Discovery}

The direction of novel antibacterial discovery research (as opposed to that of improving upon established classes) in the past 20 years has been to deploy an array of new technologies, based on genomics, bioinformatics, structural biology, and various high-throughput methods, in an effort to transform the giant leap of novel discovery into doable quantum steps. Indeed, the allure of the rational, engineering-oriented, stepwise application of techniques to make the discovery process a turnkey system is understandable. The concept has been to define broad-spectrum (or more species-specific) targets, screen for or design inhibitors, and then hope to address the subsequent obstacles of bacterial entry, non-mechanism-based toxicity, serum binding, pharmacokinetics, etc., in a piecemeal manner. But this approach has apparently not worked.

The purpose of this review is to underscore and illustrate some of those problems unique to the discovery and optimization of novel antibacterial agents that have adversely affected the output of the effort over the past 20 years. These are the rate-limiting steps of the antibacterial discovery process and can be divided into two main areas: (i) proper target selection, specifically the necessity of pursuing molecular targets that are not prone to rapid resistance development; and (ii) limitation of chemical diversity, especially that which is necessary to over-
TABLE 1. Systemic monotherapeutic antibacterials and their targets

\begin{tabular}{|c|c|c|}
\hline Class & Target & Function inhibited \\
\hline$\beta$-Lactams & PBPs & Peptidoglycan synthesis \\
\hline Glycopeptides & D-Ala-D-Ala of lipid II & Peptidoglycan synthesis \\
\hline Macrolides & rRNA of 50S ribosome subunit & Protein synthesis \\
\hline Lincosamides & rRNA of 50S ribosome subunit & Protein synthesis \\
\hline Chloramphenicol & rRNA of 50S ribosome subunit & Protein synthesis \\
\hline Oxazolidinones & rRNA of 50S ribosome subunit & Protein synthesis \\
\hline Tetracyclines & rRNA of 30 S ribosome subunit & Protein synthesis \\
\hline Aminoglycosides $^{a}$ & rRNA of $30 \mathrm{~S}$ ribosome subunit & $\begin{array}{l}\text { Protein synthesis/ } \\
\text { mistranslation }\end{array}$ \\
\hline Fluoroquinolones & $\begin{array}{l}\text { Topoisomerases (DNA gyrase, } \\
\text { topoisomerase IV) }\end{array}$ & DNA replication \\
\hline Daptomycin & Membranes & \\
\hline Metronidazole & DNA & \\
\hline
\end{tabular}

${ }^{a}$ Streptomycin, an aminoglycoside, is an exception in that it targets a ribosomal protein, and single-step resistance can occur by mutation in its gene, rps $L$.

come barriers to bacterial entry and proclivity to be effluxed, especially in Gram-negative organisms.

In regard to target selection, the emphasis here on the importance of choosing targets by their low propensity for rapid resistance selection may seem a narrow view of the problem. There are a number of other important considerations involved in choosing specific targets for rational antibacterial discovery projects. These include (i) essentiality to the organism of the function, enzyme, or structure so that inhibition of enzyme action or blockage of the function leads to inhibition of bacterial growth or, better, death; (ii) conservation of structure of the target enzyme across bacterial species sufficient to provide a useful antibacterial spectrum; (iii) a lack of structural homology with the same or similar functions in the mammalian host in order to avoid mechanism-based toxicity; and (iv) in common with other areas of human drug discovery, "druggability" of the chosen target, in that there should exist sites on the target enzyme or structure that small drug-like molecules can bind to and, in so doing, exert a biological effect. These are important considerations and, in practice, generally lead to the selection of single enzymes as targets to pursue. However, one of the theses of this review is that single enzymes may not make good antibacterial targets due to their potential for rapid resistance development. This possibility has largely been neglected in the course of recent antibacterial discovery, to its detriment, and thus it is spotlighted here.

Many challenges to candidate selection and subsequent development of antibacterials, including pharmacological properties, pharmacokinetic/pharmacodynamic (PK/PD) analysis, and toxicities (both mechanism and chemistry-based), are common to all drug discovery. They have been approached, addressed, and overcome by more-standardized medicinal chemistry magic for many generations of successful antibacterials and other human health drugs and are addressed only minimally in this review.

\section{The Multitarget Hypothesis}

The fact that successful systemic antibacterials have multiple molecular targets or targets encoded by multiple genes has been evident for the past 20 years $(50,73,204,337,339,340$, 347). This is illustrated in Table 1 , where the currently used systemic monotherapeutic agents and their targets are listed. 
TABLE 2. Mechanisms of antibacterial resistance

\begin{tabular}{|c|c|c|}
\hline Origin & Mechanism & Examples of affected drug classes \\
\hline \multirow[t]{5}{*}{ Exogenous } & Class-specific efflux & Tetracycline, macrolides \\
\hline & Class-specific degradation/modification & $\begin{array}{l}\beta \text {-Lactams, aminoglycosides, chloramphenicol, streptogramin } \\
\text { A, metronidazole (for anaerobes), fosfomycin }\end{array}$ \\
\hline & Target protection/modification & $\begin{array}{l}\text { Tetracycline, macrolides, lincosamides, oxazolidinones, } \\
\text { streptogramin B }\end{array}$ \\
\hline & Replacement with reduced-affinity target & $\beta$-Lactams, vancomycin, trimethoprim, mupirocin, sulfonamides \\
\hline & Sequestration of target & Fluoroquinolones, fusidic acid \\
\hline \multirow[t]{6}{*}{ Endogenous } & Single mutations reducing target affinity & $\begin{array}{l}\text { Rifamycin, streptomycin, trimethoprim (for Gram-positive } \\
\text { organisms), fusidic acid }\end{array}$ \\
\hline & $\begin{array}{l}\text { Multistep mutations reducing affinity or } \\
\text { remodeling of target }\end{array}$ & $\begin{array}{l}\text { Fluoroquinolones, oxazolidinones, daptomycin, vancomycin, } \\
\text { polymyxin, } \beta \text {-lactams (for transformable species) }\end{array}$ \\
\hline & General efflux mechanisms & Most classes for Pseudomonas; many classes for other species \\
\hline & Reduced uptake (porin or permease loss) & Carbapenems, fosfomycin \\
\hline & Loss of activation & Metronidazole (for H. pylori) \\
\hline & Upregulation of target & Fosfomycin \\
\hline
\end{tabular}

These antibacterials are not subject to high-level target-based resistance by single genetic changes in the host. The hypothesis is that these agents are successful monotherapeutics and not subject to such resistance because they are multitargeted $(339,340)$.

Only two of the commonly used antibacterial classes actually target multiple different enzymes in a given species. The betalactams target the penicillin binding proteins (PBPs) $(34,93$, 130,348 ), and the fluoroquinolones (FQs) target the catalytic subunit of DNA gyrase (GyrA) and topoisomerase IV (ParC) $(65,112,189)$. The multitarget hypothesis was offered before the second target of the FQs, topoisomerase IV, was recognized $(112,189)$. The FQs had appeared to be an exception to the rule (340), since resistance to the FQs was not extensive in the clinic by the early 1990s. This finding thus served to support the hypothesis.

The clinically used agents that target rRNA in their inhibition of protein synthesis provide another avenue of support for the hypothesis. These include macrolides, lincosamides, chloramphenicol, oxazolidinones, tetracyclines, aminoglycosides, and pleuromutilins (the last is not included in Table 1 because it is not yet used systemically). They are useful in monotherapy against organisms that contain multiple copies of rRNA genes. Against the slow-growing mycobacteria, however, which contain only a single rRNA cistron $(36,188)$, they are used in combination with other agents because single base changes in the rRNA gene lead to high-level resistance. With Helicobacter pylori, which contains 2 rRNA cistrons (55), clarithromycin resistance arises during therapy $(2,376)$, and heterozygous strains display a resistant phenotype (376). Of course, anti- $H$. pylori therapy generally involves 2 or more antibacterial agents, although not strictly due to resistance development. For enterococci, it has been shown that MICs of linezolid-resistant isolates are highly correlated with the percentage of rRNA cistrons mutated (237). In a way similar to the rRNA case, the FQs which have dual targets in standard pathogens have only a single target (DNA gyrase) in both Mycobacterium tuberculosis and $H$. pylori (160) and do yield to single-step resistance $(178,195)$.

It remains a hypothesis that the low potential for targetbased resistance is causally related to the success of multitarget agents in monotherapy. This is supported by the inverse, that most single targeted antibacterials in the clinic are indeed subject to single-step high-level resistance selection and are used as part of combination therapies, especially in therapy of M. tuberculosis or as topical agents (see Tables 3 and 4 of reference 337). Of course, all antibacterials with even moderate spectra have multiple homologous targets in that they must inhibit enzymes or bind to structures that are present and varied among the bacterial species of that spectrum.

If success as a monotherapeutic is indeed due to multitargeting (or targets encoded by multiple genes) and single-targeted agents, prone as they are to single-step mutation to target-based resistance $(347,388)$, are not optimal for monotherapy, then there are grave implications for antibacterial discovery. The impact of endogenous resistance (that occurring by antibiotic selection in the pathogen) on antibacterial drug discovery and development is covered below.

\section{ANTIBACTERIAL RESISTANCE}

\section{Endogenous versus Exogenous Resistance}

Antibacterial resistance may be categorized as arising endogenously in the pathogen, by mutation and selection, or exogenously, by transmission to human pathogens from environmental organisms (antibiotic producers, commensals, nonhuman pathogens, etc.) by horizontal gene transmission (HGT) (54, 78, 85, 82, 147, 240, 241, 340).

The collective genomic repertoire of possible mechanisms of resistance to antibacterial agents, via chemical modification or breakdown of antibiotics, target protection, efflux, or specific changes to the target, has been termed the antibiotic "resistome" (85). The types of exogenous and endogenous resistance mechanisms acting on marketed (nonmycobacterial) antibacterials are summarized in Table 2. Recent reviews have generally emphasized the role of the exogenous resistome and HGT in the spread of clinically important antibiotic resistance $(78,84,85,239,241,390)$. Indeed, most of the mechanisms which have played major roles in resistance to the standard monotherapeutic agents have arisen in this way, with the notable exception of the FQs. According to the multitarget hy- 
pothesis, these drugs are useful monotherapeutically precisely because of their low susceptibility to high-level, single-step endogenous resistance development, although chromosomally encoded resistance via efflux or reduced permeability or changes to multiple targets (as with FQs) may compromise these drugs in a stepwise fashion (as noted in Table 2). Woodford and Ellington (388) discuss the importance of mutation in the development of resistance and make the important distinction between those antibiotics to which resistance can arise rapidly in the laboratory (such as rifampin, streptomycin, and fusidic acid) and compromise their use in monotherapy and clinically useful monotherapeutic agents (such as FQs and linezolid) to which resistance may arise via stepwise mutation.

Studies of resistance genes from antibiotic-producing species that are theorized to be a reservoir for HGT raise the possibility that antibiotics derived from natural products are more likely to be susceptible to such a preexisting set of resistance mechanisms than are totally synthetic drugs (61). However, it has been shown that among antibiotic-producing genera, resistance determinants for the synthetic sulfonamides (82), oxazolidinones $(219,324)$, and FQs (85) are not rare. Thus, the strong implication is that resistance via horizontal transfer from environmental organisms will eventually compromise both known and still-undiscovered antibacterial agents, whether derived from natural products or synthetic.

What relevance does this have to the discovery and development of new antibacterial agents? Obviously, novel drugs intended for development must not be cross-resistant with existing therapies. For at least the last 20 years, the general answer to the challenge of avoiding cross-resistance has been to search for inhibitors of molecular targets that had not previously been "exploited," that is, they were not the targets of previously developed agents $(6,29,49,61,168,253)$. This presupposes that existing resistance mechanisms to the drug classes in use are target directed-which some are-but many are class specific (Table 2). Of course, inhibitors of these new targets would eventually fall to exogenous resistance from the resistome. How long would that take?

For natural products, the range of times between introduction and first report of transmissible resistance in pathogens has been very large: resistance arose immediately for $\beta$-lactams, as $\beta$-lactamases were seen in Staphylococcus aureus very soon after the broad introduction of penicillin (191), while vancomycin resistance in enterococci took 33 years to be recognized in the clinic (206). For the synthetic antibacterials, the first transmissible resistance in pathogens was recognized for sulfonamides, fluoroquinolones, and oxazolidinones in 23,11 , and 6 years, respectively $(194,219,242)$. Thus, the prospects for long-term avoidance of resistance to a novel synthetic agent are not rosy, but a few years might be expected to elapse before exogenous resistance mechanisms come into play. However, even this short period may be further abbreviated if endogenous resistance occurs more rapidly, perhaps even during therapy, as could be expected with a single enzyme target.

Thus, it may be misleading to apply lessons learned from the patterns of resistance development via HGT to expectations for inhibitors of new targets. It might be more reasonable to expect the patterns of resistance development to single-enzyme inhibitors that are seen with drugs used in therapy of $M$. tuberculosis or, for that matter, HIV, where the drugs are all single targeted or subject to high-level resistance via single mutations. It is clear for M. tuberculosis that resistance is not due to the exogenous resistome, since it lacks plasmids and does not participate in HGT, but to endogenous resistance arising through mutation of individual clones of $M$. tuberculosis (131, 262, 349). As a consequence of single targeting of drugs for these infections, successful therapy for M. tuberculosis and HIV has evolved to use combinations of these agents. Indeed, since the standard of care for M. tuberculosis and HIV is treatment with combinations, the resistance potential of new single-targeted agents for treatment of those pathogens is not as problematic as it might be for more-standard pathogens. In contrast to the case with standard pathogens, a number of interesting new anti- $M$. tuberculosis agents are in various stages of development $(229,374)$. Is combination therapy a feasible path for development of new single-targeted agents?

In summary, it seems that in the initial stages of antibacterial discovery, endogenous resistance, that which is selected for by the lead compound in the pathogen itself, is critical. Successful development of such compounds will depend on whether endogenous resistance compromises monotherapy. What level of resistance selection in vitro is compatible with advancement of a lead to clinical candidate status?

\section{Assessing Endogenous Resistance Potential}

A number of reviews have described useful methods for ascertaining resistance frequency (number of resistant organisms in a given population) or rates of resistance (number of mutational events leading to resistance per bacterium per generation) to a given antibacterial in the laboratory (240, 281, 314). O'Neill and Chopra (281) give practical information on preclinical evaluation of novel antibacterials, including important directions for evaluation of resistance potential in vitro. Martinez et al. (241) emphasize that such measurements should be made under a variety of growth conditions. Several authors recommend the use of hypermutator strains to determine the range of possible endogenous resistance mutations $(241,256,282)$. The determination of mutation rates by fluctuation tests $(227,281,314)$ avoids "jackpots," which can occur when single saturated cultures are plated and may distort determinations of mutation frequency. It also demonstrates, as originally intended by Luria and Delbruck (227), that mutation to resistance can occur before selection is applied. Mutation frequencies to significant levels of resistance (between $10^{-6}$ and $10^{-9}$ ) usually indicate a single target. The higher rate would generally be due to resistance via loss of a function, which can occur through deletion, insertion, or base changes at many sites in the gene encoding that function. The lower frequency $\left(10^{-9}\right)$ would indicate that resistance is due to a limited number of allowable base changes at a single site.

The resistance frequency (or rate) depends upon the concentration of the selecting inhibitor. If the inhibitor has a single target, it may require plating at a relatively high multiple of the MIC to detect target-based resistance, since at lower multiples, mutations that affect permeability and efflux functions occur at relatively high frequencies and may predominate. With some single-enzyme inhibitors, such as rifampin, single base changes can raise the MIC 32,000-fold (17). If the inhibitor has multiple targets with various sensitivities to inhibition (but within a 
narrow concentration range), as with the FQs, then the increment of MICs possible with changes to one of the targets can be small and will be related to the difference in intrinsic sensitivities of the targets. That is, if the most sensitive (primary) target is inhibited sufficiently at an external concentration of $0.01 \mu \mathrm{g} / \mathrm{ml}$ to prevent growth $(\mathrm{MIC}=0.01 \mu \mathrm{g} / \mathrm{ml})$ and the secondary target is inhibited at $0.04 \mu \mathrm{g} / \mathrm{ml}$, then even a 100 fold decrease in the sensitivity of the primary target would raise the MIC no higher than $0.04 \mu \mathrm{g} / \mathrm{ml}$. In fact, this illustrates the benefit of having multiple targets. Even though mutations in the most sensitive target (GyrA or ParC, depending on the species and drug being tested) occur at significant frequencies, high-level FQ resistance requires multiple mutational events $(98,171,354)$.

What does a specific frequency portend for the future potential of endogenous resistance development in the clinic? Generally, a frequency of $<10^{-10}$ is sought because organisms in an infection can reach $10^{9}$ cells $/ \mathrm{ml}(256,281)$ or $10^{10}$ cells in an infected individual (98). However, this may not be stringent enough. As noted above, the use of hypermutator strains can help to reveal the range of endogenous resistance. While these can give up to 1,000-fold higher resistance frequencies than normal (256), their use may be particularly relevant, since a significant percentage of antibiotic-resistant clinical isolates, especially those from chronic infections, have been shown to be hypermutable strains $(138,146,241,256,359)$. The pressure of selection for mutations will itself select for hypermutators (235).

Optimally, it should be determined (i) whether single mutational events that raise the MIC above clinically relevant drug levels can occur in a target organism and (ii) whether strains containing these mutations are sufficiently fit and virulent to survive and be infective in the absence of selective pressure. This is easier said than done.

\section{Fitness of Resistant Mutants and Compensatory Mutations}

If they preexist in a population, mutations conferring resistance will be selected for by treatment with a dose of inhibitor that kills off the parental strain but to which the mutant strain is resistant. Under conditions of drug treatment, then, such mutants compete well and are fit relative to their dead siblings. In the absence of drug, many forms of resistance can exact a fitness cost, such that mutants will be slowed in growth rate and will not compete well with the nonmutant, sensitive parental strain (9). However, further compensatory mutations can often occur that reduce the fitness cost of the original mutation, and these will tend to stabilize the resistance mutation in the population (8). It should be noted that hypermutators also will play a role in the appearance of these compensatory mutations (388). It is the complex balance of these events and the pressures of repeated selection with antibacterial agents that control the overall rate of evolution of resistance that occurs upon clinical introduction of a new agent (241). The occurrence of compensatory mutations has been studied for a number of drugs, both in vitro and in clinical isolates, by Andersson and coworkers (for example, see references 198, 230, 231, 268, 273, and 292). For new and novel drug candidates, how should the problem of fitness be addressed? In vitro methods, including hollow-fiber "pharmacodynamic infection" models, have been described $(9,99,144,241)$ and can be used profitably, but animal models for resistance selection and competitive fitness should also be standardized and applied (39, 220, 241). Since it is difficult to predict the impact resistance would have in the clinic when an inhibitor is already in hand, it should be apparent that predicting low resistance potential for a given target in the absence of an inhibitor is much more problematic. It is possible to predict, however, by using microbial genetics, that inhibition of a particular target might lead to a bypass event at a relatively high frequency [see "Peptidyl deformylase" below].

Although most single-enzyme-targeted agents are used in combination or topically and thus avoid rapid endogenous resistance development, there are a few exceptions, such as fosfomycin (272), which has been used successfully (outside the United States) against urinary tract infections (UTIs). Why is there a lack of clinically relevant endogenous fosfomycin resistance? Fosfomycin targets UDP- $N$-acetylglucosamine enolpyruvyl transferase (MurA), the first committed step of peptidoglycan synthesis, forming a covalent adduct with an active site cysteine (181). Despite its covalent and irreversible action, its activity appears to be highly selective, and it has a very low toxicity $\left(50 \%\right.$ lethal dose $\left[\mathrm{LD}_{50}\right]$ in mice of $>20 \mathrm{~g} / \mathrm{kg}$ of body weight when dosed orally [126]). M. tuberculosis is naturally resistant to fosfomycin due to the existence of an aspartate instead of cysteine at that site, and the aspartatecontaining enzyme is highly active in Escherichia coli (190). Thus, it appears that the cysteine is not required for enzyme activity, and theoretically, a mutation consistent with cell growth could occur at that site, leading to fosfomycin resistance. However, there have been no reports of in vitro selection of spontaneous murA mutants resistant to fosfomycin (although one was selected after mutagenesis and counterselection against uptake mutants [393]). Rather, selection with fosfomycin in the laboratory results in a relatively high frequency of resistance due to loss of the $\alpha$-glycerophosphate $(g l p T)$ or hexose-P ( $u h p)$ active uptake system (272), and the high rate of uptake mutants (as great as $10^{-7}$ per generation) may obscure selection of murA mutants. These uptake mutants have been reported to be nonvirulent and slow growing $(272,389)$ and, hence, likely to be unstable in an infecting population. Furthermore, fosfomycin treatment leads to high urinary levels of drug ( $>1 \mathrm{mg} / \mathrm{ml}$ for $12 \mathrm{~h}$ after oral dosing [326]), which would likely kill off preexisting mutants (of the target or uptake type) resistant to lower concentrations; additionally, the total organismal load in uncomplicated UTI is probably $<10^{8}$ (based on calculations for $E$. coli in reference 272). In the clinic, fosfomycin resistance generally is due to covalent formation of a fosfomycin-glutathione adduct by FosA, FosB, and FosX enzymes which have spread by HGT $(52,113,252)$.

The fosfomycin case raises the possibility that endogenous resistance to single-enzyme targets may be avoided if drug levels at the infection site can be kept high without toxicity and/or the mutants are unfit or of low virulence. Clearly, fosfomycin has been successful (although for a limited indication), but is the fosfomycin/MurA scenario more broadly applicable? Should single-enzyme targets be avoided altogether, or has in vitro analysis of resistance frequencies had an unnecessary chilling effect on discovery programs within industry? Has the awareness of the potential for resistance to single-target agents led to the early demise of programs that would otherwise have 
proceeded-to optimization or even to the clinic? This is a chastening thought.

\section{TARGETS}

The effort spent in cataloguing likely targets through genomics, functional genomics, and bioinformatics appears to have been unsuccessful in providing a starting place for the desired stepwise process to discovery of a novel drug.

As noted above, potential antibacterial targets would traditionally be defined as essential, distinct from related mammalian structures/enzymes, present in a useful spectrum of bacteria, such that an inhibitor might be reasonably used for therapy of a clinical indication (such as community-acquired pneumonia $[\mathrm{CAP}]$ ), and possessing a reasonable potential for druggability. At least for protein targets, most of these parameters (aside from essentiality) can be ascertained by in silico methods of bioinformatics and structural analysis. Even the potential for multiple targets sharing active site sequence homologies or protein motifs may be addressed by ever more sophisticated analytical tools, as noted in Multitargeting.

The focus on targets for discovery led to the deployment of intensive campaigns for target evaluation, to the development of high-throughput screening (HTS) platforms, and to programs of virtual ligand screening and rational structure-based drug design (SBDD). While most of the programs discussed and tabulated below come from screening efforts, SBDD should play more of a role in the future. Virtual ligand screening and a number of its successes in human health drug discovery are reviewed by Villoutreix et al. (377). A highly relevant recent review by Simmons et al. focuses on rational discovery of antibacterials by SBDD (341). Antibacterial SBDD is based on the extensive and growing number of sequenced bacterial genomes and solved crystallographic and nuclear magnetic resonance (NMR) structures of bacterial proteins and their bound ligands. Through a variety of algorithms, it makes in silico predictions for docking of new ligands (compounds and fragments, both real and theoretical), which can then be prioritized and tested for enzyme inhibition, structural interactions, and other biological readouts (such as whole-cell activity, solubility, or bioavailability). The process is iterative and heuristic. Two potent inhibitors of HIV protease, nelfinivir (182) and amprenavir (369), were developed through such iterative SBDD.

The number of potential target enzymes (selected as essential in bacteria but not humans, with a broad or useful spectrum) has been estimated to be $\sim 160$ by Payne et al. (293). Lange and coauthors (204) list 16 enzyme classes that are targets of commercialized antibacterials, in addition to the nonenzyme targets rRNA, lipid II, membranes, and DNA. Thus, there are a significant number of "new" targets that have been nominated for screening and/or inhibitor design. It should be noted, however, that while these "new" targets may not have been screened explicitly for inhibition previously (although most were, in the pregenomic era), empirical screens for whole-cell growth inhibition should have implicitly screened for them.

How did screening and design with the new targets turn out? An investigation of this question will benefit from discussion of the process of analyzing hits that arise from targeted screens and design programs, with an emphasis on compounds identified by in vitro biochemical screens and assays of enzyme inhibition or binding.

\section{Linking MIC to Target Inhibition}

While it is not necessary that an antibacterial discovered during targeted screening hit solely the desired target, or even that target at all, the raison d'être of target-directed screening is that specific bacterium-selective and hence nontoxic inhibitors will be discovered in this manner. While it should be obvious that an inhibitor discovered in a general empirical screen for growth inhibition must be shown to be selective and not kill through nonspecific (and likely cytotoxic) activity (such as detergency, alkylation, energy poisoning, etc.), this is equally important for a compound identified via in vitro enzyme inhibition. This linkage has not been made in a number of cases (as shown below), and eventual determination that the antibacterial activity was not causally linked to enzyme inhibition might have contributed to termination of the program.

\section{Support for Enzyme Inhibition as the Antibacterial Mechanism}

SAR of enzyme inhibition and MIC. Hits from screens for enzyme inhibition are generally tested early on for antibacterial activity. If the hits are chemically tractable, exploratory medicinal chemistry may be instituted to improve enzymeinhibitory potency and solubility and, if no or poor whole-cell activity is present, to improve MICs. Throughout this optimization process, it is important to ascertain whether antibacterial activity tracks with enzyme-inhibitory potency. Such tracking may not be seen for perfectly legitimate reasons, as the parameters for net bacterial accumulation are not likely to track with enzyme inhibition. Regardless of the proportionality of MIC to inhibitor potency at the enzyme level, antibacterial activity should be shown to be dependent upon enzyme inhibition throughout the optimization process. Often, in discovery programs, data will be generated that show a general or even good structure-activity relationship (SAR) between enzyme inhibition and the MIC. This is supportive evidence (at best), but it does not show causality. A demonstration of causality is especially critical with a target for which there have not been any antibacterial inhibitors described, where the process of linking whole-cell activity (MIC) to inhibition of the enzyme is critical for target validation. This can be done in a number of ways, as noted below and reviewed by O'Neill and Chopra (281).

Phenotypic profiling. In order to prove that antibacterial activity is due to specific target inhibition, several avenues are possible. With targeted screening, there is already a starting hypothesis for the mechanism of action and molecular target. Thus, initial work may be directed toward demonstration of phenotypes that should be associated with inhibition of that target, such as morphological changes (e.g., filamentation for inhibitors of FtsZ [81, 277]), stress responses (stringent response for inhibitors of tRNA synthetases [38]), and specific promoter induction (gyrase inhibition leads to homeostatic upregulation of gyrase promoters as well as SOS promoters [7]). With these studies, it is necessary to use a wide variety of 
negative controls to show that the tested phenotypes are not caused by other classes of inhibitors. An important method of ascertaining the pathway of inhibition is measurement of effects on macromolecular synthesis (MMS). This is done most straightforwardly by use of radiolabeled tracers of DNA, RNA, protein, cell wall, and fatty acid/lipid synthesis, where the doseresponse relationship for the test compound (and control inhibitors) is measured at a fixed time of incubation $(4,381)$. For specific inhibitors of one of the pathways of macromolecular synthesis, incorporation of precursors of the end product of that pathway will be inhibited preferentially. If all pathways are inhibited within a narrow concentration range, then a nonspecific mechanism of inhibition, such as membrane lysis or energy poisoning, is likely.

Under- and overexpression of the putative target. Frequently used genetic methods implicating inhibition of a particular enzyme as the antibacterial mechanism of action of a compound are underexpression of the expected target protein, in order to sensitize the organism to an inhibitor, and overexpression to yield resistance. Hypersensitization by target underexpression has been demonstrated by various methods, including use of tightly downregulatable promoters directing the synthesis of reduced amounts of the target protein (via reduced transcription) (95) and upregulated production of antisense RNA, which leads to reduced protein expression $(118,398)$. But there are caveats.

If the MIC of a given inhibitor is reduced when its putative target is downregulated, then the enzyme in question is likely to be essential, and it may indeed be responsible for the antibacterial activity of the compound. However, reduction of one enzyme can sensitize another enzyme (perhaps the true target) to inhibition (for example, if they are both members of the same pathway) (96). Furthermore, even if the underproduced enzyme is a target of the inhibitor, that does not preclude the existence of other, less-sensitive targets, nor does it even establish that the underproduced enzyme is responsible for setting the MIC when it is produced at its normal level. For example, underexpression of FabI sensitized $S$. aureus to a thiopyridine inhibitor of FabI, but overexpression did not raise the wild-type MIC (214). Furthermore, MMS analysis showed preferential inhibition of RNA and DNA synthesis over that of fatty acids. Thus, underexpression alone is inadequate to prove that the underexpressed enzyme is the MIC-determining target of inhibition.

Interestingly, some targets, when underproduced, may actually reduce sensitivity. This is seen with FQs, where the inhibited enzyme-DNA complex forms a "poison" such that lowering enzyme levels reduces the number of complexes (172).

Overexpression of a target may be accomplished by cloning of the expected target behind a regulatable promoter or by use of an overexpression library of random potential targets (which are then screened for resistance to the inhibitor) (211). A rise in the MIC of an inhibitor of an overproduced putative target indicates that the overproduced enzyme can indeed bind the inhibitor and lower its effective intracellular concentration, but it does not ensure that the candidate enzyme is the cause of growth inhibition, only that the inhibitor can bind to that enzyme: another MIC-determining target may be present. For example, curcumin, a spice component with a long history of dietary and medical use in Asia, was shown to inhibit FabI (enoyl reductase) of $E$. coli in vitro, and its MIC against $E$. coli was raised $>7$-fold by overexpression of FabI. However, other investigators showed that curcumin bound to FtsZ and inhibited Z-ring assembly in Bacillus subtilis (307). Curcumin has also been shown to inhibit the human enzymes glyoxylase I (319) and monoamine oxidase B (308), as well as HIV integrase (246). This type of pattern indicates that curcumin is a promiscuous inhibitor (and probable binder) and that caution should be exercised in target attribution by overexpression.

Thus, these methods alone are not definitive in demonstrating that a given enzyme is the antibacterial target of the inhibitor. Nevertheless, these methods will generally implicate a certain pathway or function as playing a role in the mechanism of action.

An array of arrays: expression, sensitization, resistance, and synergy. Recently, a variety of methods based on the use of arrays (transcriptional [121], translational [23], hypersensitization [96], overexpression [394], stress response [24], and synergy/antagonism [397] arrays) have been described that may be useful in identifying the antibacterial mechanism of action of an inhibitor. These methods have also been used for evaluation of leads from enzyme inhibitor programs or with activities discovered through phenotypic or empirical whole-cell screening. In each of these methods, patterns of the effects of known antibacterial activities on the components of the array are established, and unknowns are then compared to these patterns to identify inhibitors with previously described mechanisms of action. With a hypersensitization array (96), for example, a set of strains, each underproducing a single target, is exposed to the unknown inhibitor, and those strains which are hypersensitive to the inhibitor are noted. In a few cases, only a single strain will be hypersensitive, indicating the probability that the underproduced enzyme is the target. However, most often several strains will be sensitized to various extents, which may indicate inhibition of a step in a particular pathway. In each type of array, complex patterns are often seen that are difficult to interpret, necessitating further dissection by phenotypic and other genetic means.

Target alteration. The strongest demonstration that a particular cellular molecule is the proximal target of an inhibitor is to change that putative target in such a way as to prevent interaction with the inhibitor and to show that this blocks further downstream sequelae. With single-enzyme-targeted agents, this may be accomplished by direct selection and mapping and/or sequencing of mutations which increase the MIC significantly, as discussed above. It may also be demonstrated by replacing the gene for the putatively targeted enzyme with one known to encode an insensitive enzyme, as shown with LpxC inhibitors (26). If the target enzyme is known to be present or essential in only specific species, then a lack of activity of an inhibitor against other species is supportive evidence of the specificity of action, as seen with ClpXP (70), FabI (152), and LpxC (283). With a strong target hypothesis (as when the agent is selected as an enzyme inhibitor), interpretation of resistance selection results is relatively straightforward. The best evidence, as noted above, is the isolation of the mutant target enzyme and demonstration that the resistance mutation leads to reduced inhibition of (or binding to) the altered target in vitro.

It is an irony of the antibacterial discovery process that 
finding resistance to a lead due to a single base change in a target can validate the mechanism of antibacterial action of the compound but may well signal that the lead is unfit for development, or at least for monotherapy.

\section{RECENT RECORD OF SINGLE-ENZYME- TARGETED AGENTS}

\section{The Opacity of the Discovery Process}

What has been the demonstrable record of antibacterial discovery of novel agents in the past decade or so? Since the clinical pipeline of novel agents has been so small, the overall record is clearly not good. But what avenues have been pursued, and why have they failed? In general, the reasons for failure, or even the fact of failure, have not been revealed in the literature. While this could be attributed to the general opacity of the industrial drug discovery process due to commercial concerns of intellectual property and restriction of information that might move stock prices, recounting of failed initiatives is infrequent in the academic literature as well. The patent literature may reveal the industrial seriousness with which projects are regarded. In fact, while reasons for failure may be veiled, it should be noted that success is also often kept from view. In biotech and academe, early advances are often published: the former to secure investor financing, the latter for intellectual pursuit but also to validate grant support. In Big Pharma, however, it is often the case that results of active programs are not publicized or published until they approach the clinic. Thus, publications may recount many dead ends (without advertising them as such or explaining why they did not go forward), as there is little publication on actual leads until they are dropped or until they enter the clinic.

We must often rely on retrospectives of internal programs, such as that of Payne and colleagues, who summarized lessons learned from 70 targeted screening campaigns at GlaxoSmithKline (GSK) (293), or on external subjective analyses such as this and other reviews $(111,204,209,280,302,335)$. In the following sections, which review novel discovery efforts, it is generally unknown if or why the projects were dropped. Was it due to high resistance frequency, insufficient potency, an inability to overcome a high protein binding level, a lack of efficacy in animal models due to instability, metabolism, or otherwise poor pharmacokinetics, a nonspecific mechanism of action, undisclosed toxicities, or a poor spectrum making development clinically and/or commercially infeasible, or did lead optimization stop early with the recognition of poor lead structures? It would certainly be instructive to know more.

A possibly instructive survey involves the output of targeted discovery programs or programs that produced inhibitors with purportedly identified targets. This survey should serve to exemplify some of the problems of discovery and development and, furthermore, illustrate that inhibitors of antibacterial targets are discoverable but that few have been optimized sufficiently to be chosen for development. Programs attempting to exploit $\sim 35$ targets are noted in the text and in Table 3, among which only 3 (MurA, RNA polymerase, and DNA gyrase) are targeted by drugs already used in human therapy.

\section{MurB to MurF Enzymes as Antibacterial Targets}

Many attempts have been made to find inhibitors of cytoplasmic enzymes of the peptidoglycan synthesis pathway, including MurB (UDP- $N$-acetylenolpyruvylglucosamine reductase) and the UDP- $N$-acetylmuramyl-amino acid ligases MurC, -D, -E, and -F, which sequentially add L-Ala, D-Glu, mesodiaminopimelic acid ( $m$-DAP) (in most rods) or L-Lys (in most cocci), and D-Ala-D-Ala, respectively, to UDP-muramic acid. These have been considered good antibacterial targets because they are part of the synthetic pathway of the essential macromolecule peptidoglycan and were themselves shown to be essential by conditional mutations (223-226). It would have been expected that inhibitors of these enzymes would be found in the many phenotypic screens for inhibitors of the cell wall pathway $(126,278,333,336)$, but they were not. Merck and Versicor (later Vicuron, and then Pfizer) reported using a "one-pot" in vitro screen for inhibitors of MurA to MurF, but no inhibitors arising from them have been reported $(67,387)$. In fact, while some inhibitors of the enzymes MurB through MurF have antibacterial activity, in no case has that activity been shown to be due to inhibition of the Mur enzymes in vitro.

Many of the reported inhibitors of MurB to MurF have been described in earlier reviews $(105,196,334,336)$. Phosphinate transition-state analogs of the MurC to -F enzymes were synthesized by various groups in the 1990s, and some of these showed potent enzyme inhibition (at low nanomolar levels for some, illustrating druggability of the targets) but no antibacterial activity, presumably due to a lack of cell entry $(127,254$, $310,362,403)$. A number of inhibitors of MurB, -C, -D, and -F, found via screens for enzyme inhibition or binding, had micromolar (in some cases, low micromolar) $50 \%$ inhibitory concentrations $\left(\mathrm{IC}_{50} \mathrm{~s}\right)$ and no (or weak in one case [370]) antibacterial activity $(11,30,103,141,364,370)$.

The thiazolidinone core of the MurB inhibitors reported by workers at Bristol-Myers-Squibb was postulated to be a diphosphate mimic (11). These inhibitors were not antibacterial, but replacement of the thiazolidinone with an imidazolinone led to gain of antibacterial activity (48). There was a correlation between MIC and enzyme-inhibitory activity in a small series, but no further proof of causality was demonstrated. This is one of many cases in the literature where the project was left (as far as reported) at the preproof stage.

A number of synthetic projects undertaken by the Wyeth group $(12,119,201,212,234,395)$ were directed toward finding inhibitors of multiple enzymatic steps in the Mur pathway, with the idea that hitting multiple targets would lessen ultimate resistance selection. For many of these, the lead compound was discovered in a "one-pot" MurA-to-MurF screen (234), probably similar to those of Merck and Versicor. Hits from that screen were assayed against the individual enzymes, and leads were chosen for expansion. Where tested, these inhibitors were reported to be subject to abrogation of antibacterial activity by $4 \%$ bovine serum albumin (BSA). These campaigns all yielded sets of compounds with various spectra of target inhibition, from inhibiting a single target (among MurA to MurF) to inhibiting sets of one, two, three, or four enzymes. Some were shown to inhibit synthesis of soluble peptidoglycan in whole cells, but no other MMS inhibition was measured $(119,395)$. The lack of this negative control lowers the value of 


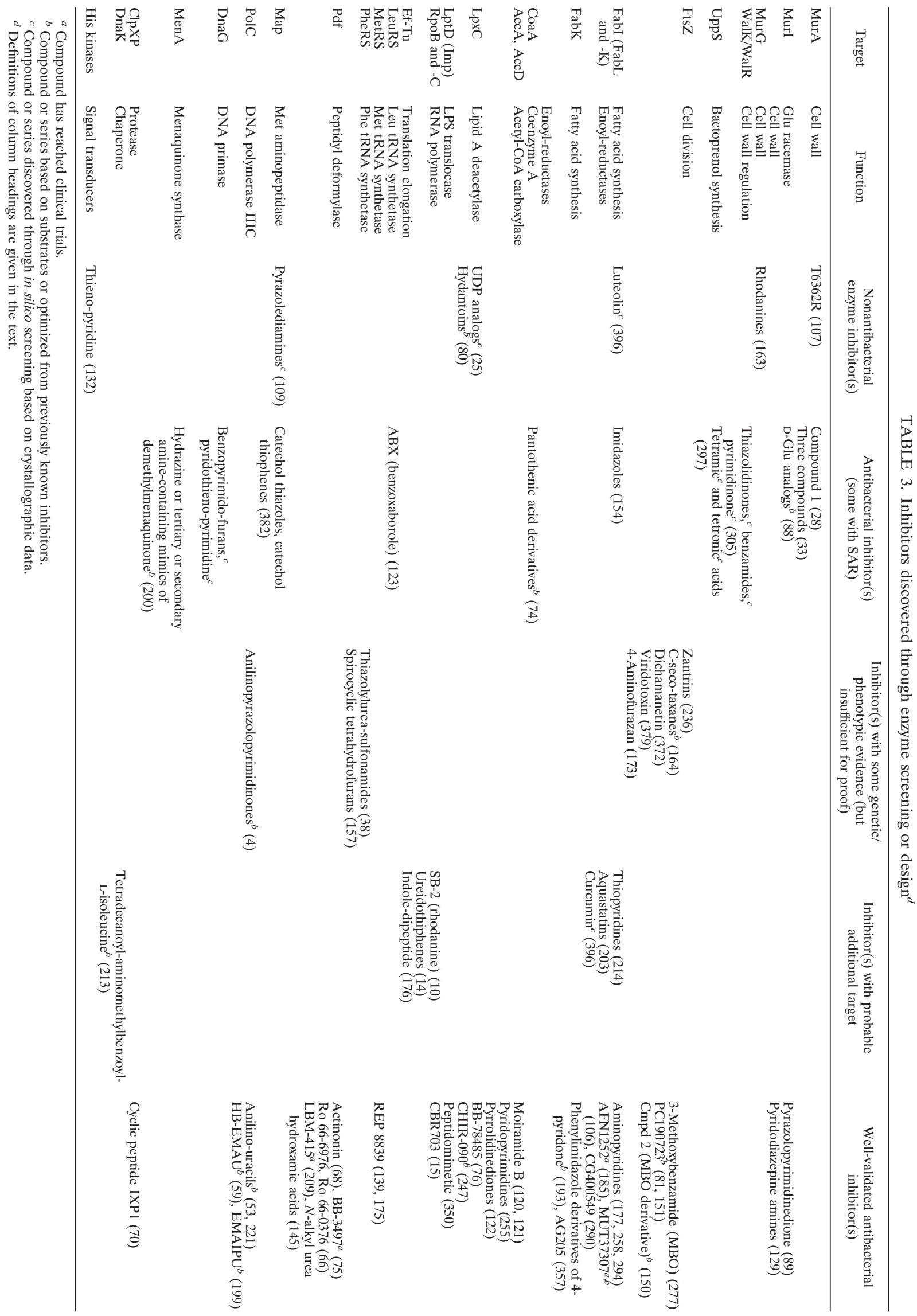


A<smiles>CCCCCCC(=O)C1C(=O)C(c2ccc(Cl)cc2)C(c2ccc(Cl)cc2)C1=O</smiles>

MurB
B<smiles>CC(C)(C)C1N=C(NC(=O)Nc2ccc(Cl)c(Cl)c2)SC1C#N</smiles>

C<smiles>CC1/C(=C/c2cccc3ccccc23)OC(=O)C1c1cc(Cl)cc(Cl)c1</smiles>

MurB,C

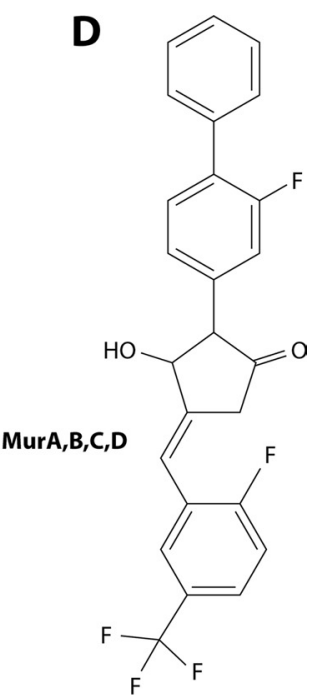<smiles>O=C1NC(=S)S/C1=C\c1cc(O)c(O)cc1O</smiles>

$\mathbf{F}$<smiles>COc1ccc2nc(OC)c(C(c3ccccc3)C(c3ccccc3)C(O)CN(C)C)cc2c1</smiles><smiles>N#CC1=C(NC(=O)C2C=C(S(=O)(=O)N3CCOCC3)C(Cl)=CC2Cl)CC2CC(c3ccc(O)cc3)CCC12</smiles>

FIG. 2. Antibacterial inhibitors of the cytoplasmic Mur pathway. Inhibited enzymes are indicated. Compounds are described in the text.

the finding. Examples of these compounds and the enzymes they preferentially inhibit are shown in Fig. 2A to D.

The active sites of the Mur ligases (MurC to MurF) have been shown to have homology (110), so inhibitors of multiple Mur ligases are not unexpected. It is not impossible that a single molecule (especially a diphosphate mimic) could inhibit a range of enzymes, including MurA or -B plus some of the Mur ligases, since all of these enzymes have a UDP-sugar as a substrate. With a goal similar to that of Wyeth, a group at the University of Ljubljana discovered rhodanine derivatives that were balanced inhibitors of MurD, -E, and -F, one of which had extremely weak antibacterial activity (363) (Fig. 2E). Recent analyses by Baell and Holloway showed a number of promiscuous, panassay-interfering (PAIN) compound classes (18), among which rhodanines were prime culprits. While none of the Wyeth compounds appear to match Baell and Holloway's list of PAIN compounds, it seems reasonable to require further evidence that the inhibition seen in assays of a set of enzymes is selective and not a reflection of promiscuity of the compound class.

The best pieces of evidence for MurB to -F inhibitors having any target-related activity in whole cells are the MurF inhibitors of Baum et al. $(31,32)$. The 4-PP compound (32) and the diarylquinoline DQ1 (Fig. 2F) (31) were shown to moderately inhibit E. coli MurF ( $\mathrm{IC}_{50}, 24$ to $\left.29 \mu \mathrm{M}\right)$ and to cause an intracellular build-up of the pool of UDP-muramyl-L-Ala-DGlu- $m$-DAP, the MurF substrate, and a decrease in the UDPmuramyl-pentapeptide product, as would be expected for inhibitors of MurF. Treatment with DQ1 eventually led to cell lysis. Overproduction of MurF led to normalization of pools but did not affect the MIC of DQ1. Thus, these inhibitors can enter the cell (permeable E. coli) and exert an inhibitory effect on MurF, but the antibacterial effect was not shown to be due exclusively or at all to MurF inhibition. This is in contrast to 
the potent benzothiophenyl-(morpholine-4-sulfonyl)-benzamide inhibitor (Fig. 2G) of Streptococcus pneumoniae MurF $\left(\mathrm{IC}_{50}=22 \mathrm{nM}\right)$ described by Stamper et al. (351), which had no activity on permeabilized $E$. coli or $S$. aureus. Unfortunately, no MIC testing on $S$. pneumoniae was reported. Was the lack of activity due to a lack of cell entry or to some other factor?

The fact that the MurB to -F enzymes lack validation (as useful antibacterial targets) with inhibitors, even though they have been shown genetically to be essential, is curious and has been commented on in the literature $(141,336,351,368)$. One speculative possibility, against which there is no clear evidence, is that the action of the pathway is concerted, perhaps performing as a multienzyme complex with channeling of intermediates, the active site(s) being inaccessible to inhibitors. Other possibilities include the lack of a rate-limiting step within that part of the pathway or upregulation of the pathway by inhibition of one of the steps, either of which might lead to the necessity for very strong inhibition of the cellular enzyme, perhaps by $99 \%$ or more. Presumably, irreversible and/or covalent inhibitors would overcome these obstacles. While generally avoided in human drug discovery programs, covalent inhibitors (e.g., the $\beta$-lactams) have clearly been useful in the antibiotic field. Interestingly, in this regard, a treatise on leadlikeness and unlikeness (312) notes that such irreversible and covalent inhibitors would be considered false-positive and nonleadlike compounds in biochemical assays, in contrast to those found in biological assays (such as the $\beta$-lactams).

\section{Targets of Inhibitors Discovered by Enzyme Screening or Design}

Table 3 intends to display the stages of compound validation reached for leads from programs based on discovery and optimization of single-enzyme inhibitors as antibacterials. The table covers programs reported during the past 10 years and is organized by the enzyme targeted. The compounds (or series of compounds) are categorized as in vitro enzyme inhibitors (i) that have no reported antibacterial activity; (ii) where antibacterial activity is seen, but for which no further correlation than SAR has been shown; (iii) for which some phenotypic and/or genetic evidence has been accumulated to link inhibitor and target but which have not eliminated other target possibilities; (iv) that are likely to affect the putative target intracellularly, but for which there is a high probability that another target (or nonspecific activity) exists; and (v) whose enzyme inhibition is well validated to be the sole antibacterial mechanism by combinations of critical genetic, biochemical, and phenotypic means. The classes of validated inhibitors that have reached clinical trials are noted in the table and are discussed in a later section.

Forty of these programs and leads arose from enzyme-targeted high-throughput screens. Fifteen compounds or series (marked with a dagger in Table 3 ) resulted from synthesis of inhibitors based on known substrates (without other structural input) or optimization of previously discovered leads, most of those from empirical screening. Eleven compounds or series (marked with a double dagger in Table 3) were based on structural studies of six targets, using in silico docking or similar methods for virtual screening followed by actual assays of selected compounds (SBDD). This list is certainly incomplete, despite serious effort. Any selection bias was toward compounds that had antibacterial activity with some degree of validation that the MIC was due to inhibition of the targeted enzyme in vitro.

UppS. Among the earliest-stage target/inhibitor programs of interest are the tetronic acid inhibitors of UppS, the last enzyme in the bactoprenol (undecaprenol) pathway, which catalyzes double-bond formation during condensation of 8 isopentenyl-PP and 1 farnesyl-PP subunit to form bactoprenol-PP. A tetramic acid enzyme inhibitor was discovered by HTS and virtually docked in the enzyme active site to generate a pharmacophore model. Tetramic, tetronic, and carboxamide analogs (Table 3 ) and derivatives of the lead were synthesized and tested for inhibition of UppS, human farnesyl-PP (FPP) synthase (FppS), Enterococcus faecalis, S. aureus, and S. pneumoniae. The best antibacterial activity, the least FPP inhibition, and a reasonable correlation of enzyme inhibition and $S$. pneumoniae MIC were seen with the tetramic acids, as exemplified in Fig. 3A. More potent enzyme inhibitors appeared to have less antibacterial activity, most likely due to a lack of penetration. The mechanism of enzyme inhibition was explored using a tetramic acid probe and showed that it binds to an allosteric site near the FPP binding site (but does not bind to FPP-bound enzyme), changing enzyme conformation and preventing FPP binding (207). This illustrates that such docking studies with leads followed by in silico optimization can yield improved compounds and validate the in vitro inhibitortarget interaction. This work is promising and appears to be ongoing. While it is likely that the antibacterial activity seen is due to enzyme inhibition, substantiation of specificity is required, notably because many tetramic and tetronic acids are metal chelators and/or have cytotoxic properties (16).

WalK/WalR. WalK/WalR (YycG/YycF) is a histidine kinase/ response regulator two-component system essential in low-GC Gram-positive organisms. The system was reviewed recently (100). Both components are essential in S. aureus, B. subtilis, and E. faecalis; only WalR is essential in S. pneumoniae. WalK appears to be deletable in Streptococcus pyogenes (where it is called VicK) (216), and there are conflicting reports on WalK/ WalR essentiality in Streptococcus mutans. The system appears to be a regulator of peptidoglycan synthesis. Through structure-based virtual screening targeting the autophosphorylation activity of WalK, a set of 76 compounds were chosen and tested for antibacterial activity against Staphylococcus epidermidis (305). Seven compounds had antibacterial activity, and six of these bound to WalK. The compounds were from 4 structural classes and showed antibacterial activity against strains of $S$. epidermidis, $S$. aureus, $S$. pyogenes, and $S$. mutans, in roughly the same rank order. Enzyme-inhibitory activity for the 6 enzyme binding compounds was generally correlated with the MIC against $S$. epidermidis. The compounds had low cytotoxicity and showed low hemolytic activity. The finding of significant antibacterial activity with this set of compounds is quite surprising - since with many nonvirtual screening efforts, enzyme inhibition and antibacterial activity are seldom correlated (see Chemistry below). Even with the good correlation of enzyme inhibition and antibacterial activity (across 3 structural classes), more data are required to identify WalK as the antibacterial target. As noted above, it seems that WalK is nones- 


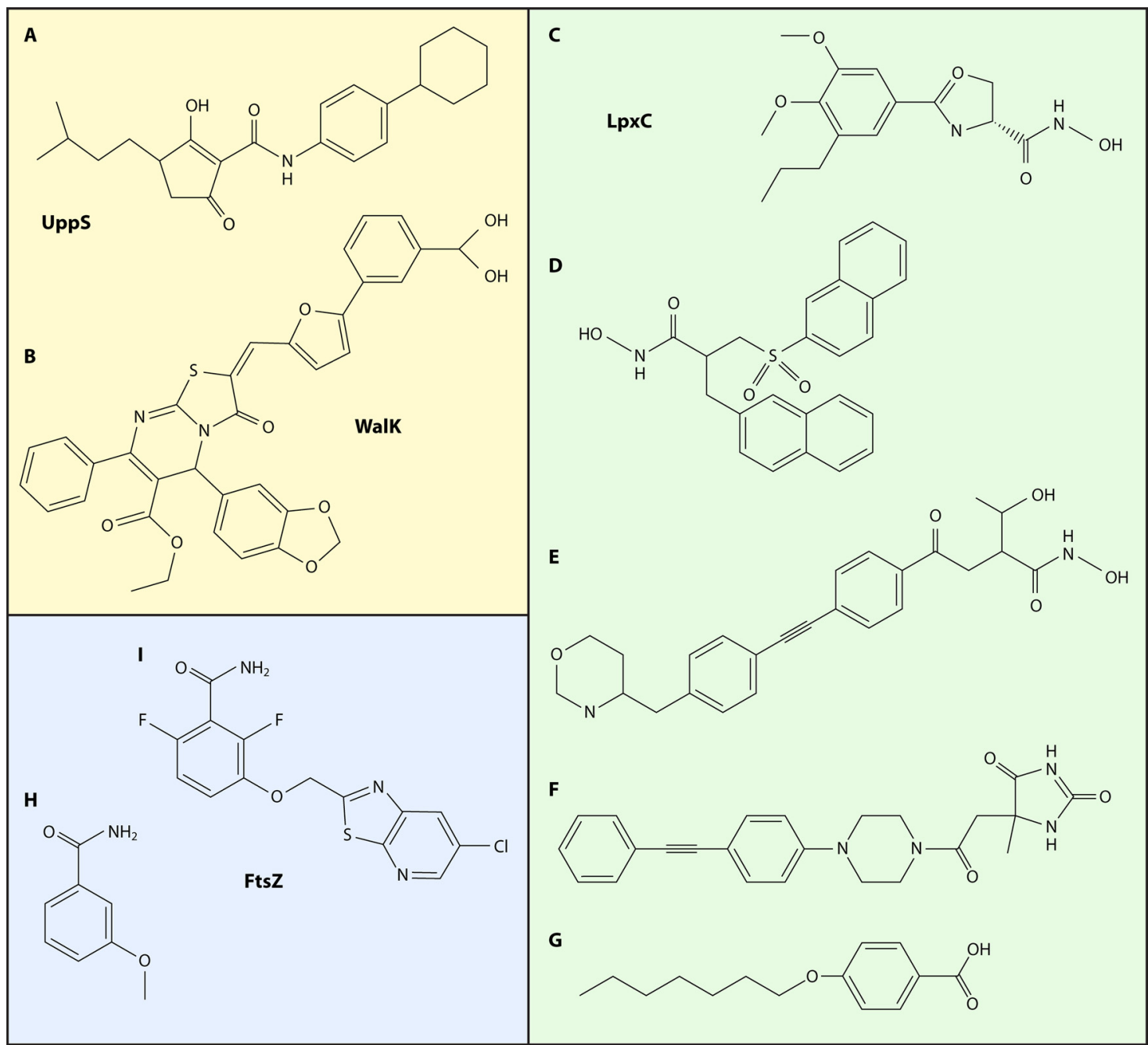

FIG. 3. Single-target inhibitors. Inhibited enzymes are indicated. Compounds are described in the text.

sential in $S$. pyogenes, so the activity against $S$. pyogenes, especially of the compound with the broadest spectrum (the thiazolidinone shown in Fig. 3B), may indicate that there are other targets being inhibited.

Many other programs that have produced inhibitors whose mechanism of antibacterial action has not yet been validated (shown to be due to inhibition of the targeted enzyme in vitro) are listed in columns 3 through 6 of Table 3. Rather than a continued dissection of these programs, a discussion of 2 targets, $\mathrm{LpxC}$ and FtsZ, with validated inhibitors follows.

LpxC. LpxC is the second enzyme and the first committed step of the essential lipid A synthetic pathway, which is present only in Gram-negative organisms. A hydroxamic acid inhibitor of $\mathrm{LpxC}$ (L-573,655 in Table 3) was first discovered at Merck by phenotypic screening for inhibitors of lipopolysaccharide (LPS) synthesis and later determined to be a specific inhibitor of LpxC. A program based on L-573,655 found more potent enzyme inhibitors of the $E$. coli enzyme with improved antibacterial activity against $E$. coli but no activity against Pseudomonas aeruginosa, with the best being L-161,240 (Fig. 3C), which was efficacious in vivo against $E$. coli septicemia (283). Resistance to L-573,655 and L-161,240 was seen at a frequency of $10^{-9}$; two of four mutants sequenced contained mutations in IpxC (283; N. Rafanan, S. Lopez, C. Hackbarth, M. Maniar, P. Margolis, W. Wang, Z. Yuan, R. Jain, J. Jacobs, and J. Trias, presented at the 40th Interscience Conference on Antimicrobial Agents and Chemotherapy). Programs at Versicor, British Biotech (later Oscient), and Chiron (later Novartis) followed that at Merck, all yielding compounds with hydroxamate groups necessary for coordination with zinc in the active site (76, 136, 174, 247). Activity was restricted to Gram-negative organisms, as expected for lipid A inhibitors. BB-78485 (Table 3; Fig. 3D) selected for resistance at two sites, lpxC and $f a b Z$ (76). FabZ is required for synthesis of the fatty acids which are attached to lipid A and which are substrates of LpxA, the first step of the pathway. Presumably, overproduction of FabZ overcomes inhibition downstream in the pathway (260). The Chiron inhibitor CHIR-090 (Table 3; Fig. 3E) was optimized for activity against $P$. aeruginosa and is a potent enzyme inhibitor and broad-spectrum Gram-negative antibacterial (247). A patent application (M. A. Siddiqui, U. F. Mansoor, P. A. 
TABLE 4. Selected single-enzyme inhibitors discovered by empirical or phenotypic screening ${ }^{a}$

\begin{tabular}{|c|c|c|}
\hline \multirow{2}{*}{ Target category and target } & \multicolumn{2}{|c|}{ Inhibitor(s) ${ }^{b}$ discovered by: } \\
\hline & Empiric screening & Phenotypic screening \\
\hline \multicolumn{3}{|l|}{ DNA replication and substrates } \\
\hline GyrA & Nalidixic acid $(137)$ & Pyrazole derivatives (360) \\
\hline GyrB (276) & Novobiocin, coumermycin, clorobiocin, cyclothialidine & \\
\hline $\mathrm{Ndk}$ & Desdanine $(318,330)$ & \\
\hline \multicolumn{3}{|l|}{ Cell wall synthesis and cell division } \\
\hline MurA & & Fosfomycin $(155,181)$ \\
\hline IspC & & Fosmidomycin $(202,279)$ \\
\hline WalK/WalR & & Aranorosinol B (383) \\
\hline SAV1754 (flippase? MurJ?) & Compound D (263) & $D M P I, C D F I(166)$ \\
\hline FtsZ & Sanguinarine (37), curcumin (307) & \\
\hline \multicolumn{3}{|c|}{ Transcription, translation, and chaperones } \\
\hline RNA polymerases $(72)$ & Rifamycins, streptolydigin, lipiarmycin, sorangicin & \\
\hline \multicolumn{3}{|l|}{ tRNA synthetases (RS) (73) } \\
\hline IleRS & Mupirocin & \\
\hline TrpRS & Indolmycin & \\
\hline PheRS & Ochratoxin & \\
\hline ThrRS & Borrelidin & \\
\hline LeuRS & Granaticin & \\
\hline ProRS & Cispenticin & \\
\hline Ef-G (73) & Fusidic acid & \\
\hline Ef-Tu (291) & Kirromycin, enacyloxin, pulvomycin & GE2270 (327) \\
\hline Pdf & Actinonin (68) & \\
\hline \multicolumn{3}{|l|}{ Lipid and membrane synthesis } \\
\hline FabF & & Platensimycin $(381)$ \\
\hline LpxC & & $L 573,655 ; L-161,240(283)$ \\
\hline $\mathrm{AccC}$ & Pyridopyrimidine (255) & \\
\hline
\end{tabular}

Reddy, and V. S. Madison, U.S. patent application 2007/ 0167426 A1) from Schering-Plough (now Merck) covers a large number of hydroxamates with some similarity to the Chiron compound. Since the absorption of the originating companies, the fate of these specific inhibitors is not known, but it is clear that several companies have continued to work on this target. For example, the Achaogen website lists an LpxC preclinical program.

Other approaches to discovery of LpxC inhibitors are the substitution of hydantoin for hydroxamate as the zinc binding group (Table 3; Fig. 3F), as described previously (80; U. F. Mansoor, P. A. Reddy, and M. A. Siddiqui, WIPO patent application 2008/027466 A1, 5 March 2008), and the exploration of the use of a lipophilic tail on a simple benzoic acid (Fig. 3G), a structure which lacks a metal binding group but has significant $(2.3 \mu \mathrm{M})$ activity (331). Another avenue is exploration of uridine-based compounds as potential UDP analogs of the substrate (25). No antibacterial activity has yet been shown for these. Schering scientists recently described a novel LpxC screening strategy and noted that a large group of active compounds were selected ( $\sim 286$ with $\mathrm{IC}_{50}$ s of $\left.<5 \mu \mathrm{M}\right)$ from over 700,000 compounds screened (205), but no structures were shown. Six compounds were tested for antibacterial activity, and 5 of 6 were shown to be more active on an $\operatorname{lpx} C$ mutant strain (which expresses a reduced amount of $\mathrm{LpxC}$ activity) than on its isogenic wildtype parent. As noted by the authors, this is to be expected for inhibitors of LpxC but would also be seen for compounds otherwise excluded from $E$. coli by the outer membrane (OM) (400).

Clearly, the target is of interest for its importance in Gramnegative organisms, especially $P$. aeruginosa, which are increasingly problematic in the clinic due to growing resistance. Work on the LpxC inhibitors appears to be continuing, and there are a number of drug-like leads. Will FabZ upregulation be able to suppress potent inhibition of LpxC? Once again, the question of in vitro resistance selection of single-target inhibitors arises. An LpxC inhibitor might be a good candidate for combination therapy with a current or future drug.

FtsZ. FtsZ, a protein required for cell division in most, if not all, bacteria, has been a popular target (217), with a number of reported inhibitors (Tables 3 and 4). Haydon and colleagues at Prolysis/Biota recounted the path of optimization of inhibitors (150) based on 3-methoxybenzamide (3-MBO) (Fig. 3H), a known inhibitor of ADP-ribosylase, whose antibacterial activity was reversed by mutations in fts $Z$ (277). This account describes an excellent antibacterial discovery program, with a variety of parameters tracked throughout in order to progress to a drug-like molecule (Fig. 3I) with excellent pharmacokinetic and acceptable pharmacological properties, including oral bioavailability and low cytotoxicity. The best compound, whose human plasma protein binding was reduced to $\sim 90 \%$ from the $99.9 \%$ value of a related compound, was efficacious in a mouse model of $S$. aureus septicemia. The compound is not 
sufficiently active for clinical candidacy, but the lead has validated fts $Z$ as an effective antibacterial target in vivo and is suitable for further optimization. And what of resistance? Notably, resistance selection was carried out on selected compounds at each step of optimization in order to monitor ontarget activity. In all cases, a mutant mapping in fts $Z$ was identified (though no resistance frequency was indicated). Will the program go forward despite in vitro resistance selection?

\section{Inhibitors Identified after Phenotypic and Empirical Discovery}

The discussion thus far has dealt with inhibitors discovered via screening for in vitro inhibition of isolated enzymes. Both phenotypic screening and empirical screening have played large parts in antibacterial discovery efforts, and lately, both have been revived, with the general failure of enzyme screening and the advent of relatively powerful methods of target identification (the array of arrays mentioned above). A number of single-enzyme inhibitors found through phenotypic and empirical screens throughout the years are noted in Table 4. Most of the listed natural product inhibitors are antibacterial due to specific enzyme inhibition (except in the case of the plantderived compounds inhibiting FtsZ, which may have other mechanisms). In contrast, as illustrated in Table 3 and discussed in Chemistry, very few enzyme inhibitors found in chemical collections have demonstrated antibacterial activity due to selective and specific inhibition of the putative enzyme target. Some exceptions, where chemical collections did yield compounds with antibacterial activity due to specific enzyme inhibition, are actinonin, a natural product that was present in chemical collections and discovered as a specific inhibitor of peptidyl deformylase (Pdf) (68), and a pyridopyrimidine compound found by empirical screening of a library of kinase inhibitors, which was found to be a specific inhibitor of the biotin carboxylase subunit of acetyl-coenzyme A (acetyl-CoA) carboxylase, AccC (255).

Phenotypic screening could be used profitably with chemical libraries, as it has the benefit of finding hits with wholecell activity due to a relatively specific mechanism. This has been seen with the compounds DMPI (3-\{1-[(2,3-dimethylphenyl)methyl]piperidin-4-yl $\}$-1-methyl-2-pyridin-4-yl- $1 H$ indole) and CDFII \{2-(2-chlorophenyl)-3-[1-(2,3-dimethylbenzyl)piperidin-4-yl]-5-fluoro- $1 H$-indole $\}$, detected in a screen for synergists of a carbapenem against methicillinresistant $S$. aureus (MRSA) (166). Their mechanism of action was discovered, in part, through use of an antisense hypersensitization array which implicated $S$. aureus open reading frame (ORF) SAV1754 as a possible target (96). SAV1754 shares homology with murJ of E. coli, which has been implicated as a lipid II flippase in cell wall synthesis (316). The compounds did indeed inhibit cell wall synthesis, and resistant mutants mapped in the indicated ORF.

\section{Single-Enzyme Targets of Novel Inhibitors in Clinical Trials}

Inhibitors of four single-enzyme targets became clinical candidates in the period from 2000 to the present. All of these targets were known to have essential bacterial functions by microbial genetic analysis before the "genomics" era. The sta- tus of these programs and of the development of specific compounds is not clear in some cases.

Peptidyl deformylase. The history of Pdf as an antibacterial target has been reviewed recently $(143,209,401)$. A unique feature of bacterial translation is that peptide chains are initiated with formylated methionine (fMet), which is synthesized by a transformylase (Fmt) acting on initiator fMet-tRNA charged with unformylated methionine. The enzyme which removes the N-terminal methionine from a number of bacterial proteins, methionyl-aminopeptidase (Map), is essential (62). Since deformylation of the fMet must be carried out by peptidyl deformylase (Pdf), before demethylation by Map, deformylation too is an essential function. The stabilization, purification, and characterization of Pdf, both biochemically and genetically, led to its proposal as an antibacterial target (245). This was followed by a rush to find inhibitors of the enzyme by most antibacterial drug discovery groups. Enzymologists, biochemists, structural biologists, and medicinal chemists were very optimistic about this target, but (by informal survey) microbial geneticists were not, since the original genetic characterization of the essentiality of Pdf also showed that cells lacking Fmt could survive the loss of Pdf. In that case, a nonformylated pathway (similar to that used by eukaryotes) was used for translation initiation. Such $p d f$-fmt deletions of $E$. coli grew very slowly (245), but faster-growing variants overgrew the cultures. Thus, it appeared that the requirement for Pdf could be bypassed, and even with reduced fitness, compensatory events appeared to improve that fitness. The genetic prediction is that inhibitors of Pdf would lead to a similar situation.

When such inhibitors were discovered $(13,66,68,145,261$, 401 ), including the previously mentioned natural product antibacterial, actinonin (Fig. 4A) (68), resistance to inhibitors arose as expected, at a high frequency $\left(10^{-7}\right.$ in permeable $E$. coli [13]), due to mutations in the fmt gene. Fmt loss-of-function mutations were found in other species, including $S$. aureus, Haemophilus influenzae, and $P$. aeruginosa. In $S$. pneumoniae, mutations of the target $p d f$ gene were found at a low frequency, as would be expected for specific target-based "gain-of-function" resistance (209). In a detailed study of actinonin resistance in Salmonella enterica serovar Typhimurium LT2, 31 loss-of-function mutations were mapped to either the fimt or folD gene. (FolD is required for synthesis of 10-formyl-tetrahydrofolate, the formyl donor used by Fmt.) Compensatory mutations for a number of these mutants, all of which grew slowly, were selected by serial passage in rich medium until faster-growing cells dominated the populations. Intragenic suppressors of the original folD and fmt resistance mutations were identified which led to actinonin susceptibility. Interestingly, compensatory mutations leading to amplification (5- to 40 -fold) of the genes encoding initiator fMet-tRNAs led to higher growth rates and retained actinonin resistance (273).

Pdf inhibitors BB83698 (Oscient) (309) (Fig. 4B) and LBM415 (Novartis) (209) (Fig. 4C) were optimized to meet criteria for clinical development (143). The phase I singleascending-dose trial of BB83698 proceeded without problems and appeared successful (75). However, both development programs were stopped in 2004. Reasons for this are not clear, but concerns about resistance development were likely important, as was the finding of a human mitochondrial homolog of 
A<smiles>CC(CC(=O)NO)C(=O)NC(C)C(=O)C1=C(CO)CCC1</smiles><smiles>CC(=O)N(C)CC(C(=O)N1CCCC1C(=O)Nc1ccc(F)c[n+]1[O-])C(C)(C)C</smiles>

$\mathbf{F}$<smiles>Cc1c(CN(C)C(=O)/C=C/c2cnc3c(c2)CCC(=O)N3)oc2ccccc12</smiles><smiles>[B]c1ccc(CN2CCN(C(=O)C(C)NC(=O)C(CC(O)C=O)CC3CCCC3)CC2)cc1OCO</smiles><smiles>Oc1cc(Cl)ccc1Oc1ccc(Cl)cc1Cl</smiles>

E<smiles>CN(Cc1cc2ccccc2n1C)C(=O)/C=C/c1ccc(N)cc1</smiles>

G<smiles>Cc1c(N)cccc1Cn1ccc(OCCc2cccs2)cc1=O</smiles>

H<smiles>CCc1cc(O)c(Oc2cccnc2F)cc1F</smiles>

I<smiles>NCC1OB(O)c2cccc(F)c21</smiles>

J<smiles>COc1cc(Cc2cnc(N)nc2N)c2c(c1OC)OC(C1CC1)C=C2</smiles>

$\mathbf{K}$<smiles>COc1cc(Cc2cnc(N)nc2N)cc(OC)c1OC</smiles>

FIG. 4. Single-target inhibitors that have reached the clinic (and their relations). (A) Actinonin; (B) BB83698; (C) LBM415; (D) triclosan; (E) GSK FabI inhibitor; (F) AFN-1252; (G) CG400549; (H) MUT37307; (I) iclaprim; (J) trimethoprim.

Pdf that is inhibited by inhibitors of the bacterial enzyme (208, 209). Furthermore, both of the development candidates and most other reported inhibitors had hydroxamic acid moieties as the metal chelating warhead. Hydroxamates are generally avoided by medicinal chemists for their possible promiscuity, toxicity, and instability/metabolism $(117,148,312)$; however, hydroxamates have reached the market, including a histone deacetylase inhibitor licensed for therapy of certain cancers, i.e., vorinostat (233). Recently, efforts at optimizing Pdf inhibitors for therapy of M. tuberculosis, where single-target inhibitors are the norm, have been reported $(298,329)$.

Enoyl-reductases of FAS II. The enoyl-reductases of bacterial fatty acid synthetase II (FAS II) and their inhibitors have been reviewed recently $(222,243)$. Triclosan (Fig. 4D) was initially thought to be a nonspecific antiseptic but was later found to target the enoyl-reductase FabI (250). With the advent of genomically driven drug discovery programs, the broadly distributed FabI enzyme was targeted in a number of programs. In the same time frame, it was discovered that cer- tain pathogens either lacked FabI or contained FabI in addition to another nonhomologous enoyl-reductase (243). For example, S. pneumoniae uses FabK instead of FabI (152), while E. faecalis and Enterococcus faecium have both FabI and FabK (152). P. aeruginosa and Vibrio cholerae contain FabV in addition to FabI $(244,405)$. FabL and FabI are present in B. subtilis (153). It is interesting that FabK, FabL, and FabV encode triclosan-resistant enzymes, which Heath and Rock (152) noted would have implications for drug discovery. For broadspectrum Gram-positive activity, such an inhibitor would have to target both FabI and FabK with similar potencies (295). Indeed, the FabI program at GSK, which was initially directed toward respiratory pathogens (293), discovered potent aminopyridine inhibitors of the $S$. aureus enzyme, but their lack of useful activity against $S$. pneumoniae, explained by poor activity against FabK, led the company to outlicense the program to Affinium (294). Most of the GSK inhibitors (Fig. 4E) were shown to target FabI by overexpression of the enzyme in $S$. aureus leading to raised MICs and by specific inhibition of lipid 
synthesis over other MMS in S. aureus (258, 294). In later work, antisense depression of expression of FabI in $S$. aureus was shown to sensitize cells specifically to the GSK FabI inhibitors (177). The accretion of SAR, biochemical, and genetic evidence along with the lack of activity against $S$. pneumoniae supports the specific antibacterial mechanism of FabI inhibition, although resistant mutants were not sought. Interestingly, the most potent inhibitor of the GSK aminopyridine series (294) had activity against $S$. pneumoniae in addition to $S$. aureus, was found to inhibit FabK as well as FabI, and had relatively nonspecific MMS results, and its $S$. aureus MIC was not raised by FabI overexpression. This illustrates the need to characterize the mechanism of whole-cell activity across a series of inhibitors, especially when activity is increased or altered significantly.

The Affinium clinical candidate AFN-1252 (Fig. 4F), which is closely related to its GSK progenitors, is staphylococcus specific in spectrum and has no demonstrable S. pneumoniae or $S$. pyogenes activity (184). No data on resistance selection by the GSK or Affinium FabI inhibitors are available. A different FabI inhibitor, CG400549 (Fig. 4G), which is based on triclosan and whose MIC has been shown to be raised by FabI overexpression, has been shown to select for resistance in a single step at low frequencies (290). The resistance mutations occurred at a single site in $\mathrm{fabI}$ in 10 of 13 mutants tested. The Mutabilis FabI inhibitor, MUT37307 (Fig. 4H), an aryloxyphenol inhibitor based on triclosan, is highly active against staphylococci and has activity only against organisms containing solely FabI (92). Resistance was found at $10^{-8}$ at 4 times the MIC (106).

AFN-1252 has been in phase I clinical trials, and Mutabilis announced it would have a FabI inhibitor candidate (most likely MUT37307) in the clinic in 2009 (125), but no results have been announced. While company websites indicate that the programs are ongoing, the following findings may influence further development of these and other FAS II inhibitors. Recently, data were reported that may undermine the validity of FAS II enzymes as Gram-positive drug targets (46). This controversial work showed that Streptococcus agalactiae and $S$. aureus appear to be able to take up sufficient unsaturated fatty acids from human serum to obviate the essentiality of FAS II enzymes in vivo. The authors caution that the uptake of fatty acids may require time for adaptation of the infecting organisms to growth (and fatty acid uptake) in serum; hence, animal models of efficacy of FAS II inhibitors may overestimate the therapeutic effect unless they are carefully designed to allow sufficient adaptation time and organismal load. A counterargument to that paper (20) and a reply by the original authors (47) appeared even more recently. Further elucidation is needed, but the preliminary report of a fabI deletion mutant of $S$. aureus that can be maintained on an exogenous source of fatty acids (47) seems to militate against development of FabI inhibitors for $S$. aureus (or other Gram-positive?) infections. In vivo models were used to show the efficacy of the FabI inhibitors described above. AFN-1252 is active in a murine subcutaneous abscess model (384), the similar GSK inhibitors are active in a rat groin abscess model (294), and MUT37307 is active in methicillin-susceptible $S$. aureus (MSSA) and MRSA septicemia and thigh abscess in a murine model (106). While not all infections involve growth in the presence of serum and long-chain fatty acids may not be sufficient for supplementation at some infection sites, it should be noted that the free linoleic and oleic acid concentrations in staphylococcal abscesses are $1.2 \mathrm{mg} / \mathrm{ml}(4.2 \mathrm{mM})$ and $0.9 \mathrm{mg} / \mathrm{ml}(3.2 \mathrm{mM})$, respectively (calculated from data in reference 332 ), similar to those in whole serum (46).

Thus, the FabI inhibitors illustrate a number of problems that target-directed antibacterial discovery programs have encountered: the occurrence of nonhomologous enzymes with similar (complementing) activities in important pathogens can narrow the ultimate spectrum, analysis of fitness of a target by genomic and in vitro methods may miss the inappropriateness of the target in the infected host, and resistance occurs readily in vitro.

Leucyl tRNA synthetases of Gram-negative organisms. Anacor Pharmaceuticals has been exploring boron-based chemistry for systemic antibacterials in a program partnered with GSK. First announced at a recent meeting, Anacor disclosed a prototype benzoxaborole, ABX (Fig. 4I), that is reported to be a specific inhibitor of the editing domain of leucyl tRNA synthetase (LeuRS) with excellent activity against Gram-negative organisms (123). ABX was shown to be active in vitro against multidrug-resistant (MDR) Gram-negative strains of Enterobacteriaceae (except for Proteeae), P. aeruginosa, and Stenotrophomonas maltophilia, with an $\mathrm{MIC}_{90}$ of $1 \mu \mathrm{g} / \mathrm{ml}$, and against Burkholderia cepacia $\left(\mathrm{MIC}_{90}\right.$ of $\left.4 \mu \mathrm{g} / \mathrm{ml}\right)$, but it had little activity $\left(\mathrm{MIC}_{50}\right.$ of $\left.>128 \mu \mathrm{g} / \mathrm{ml}\right)$ against Acinetobacter spp. In a neutropenic mouse thigh abscess model, ABX gave 3.5-log killing of $P$. aeruginosa with a dose of $30 \mathrm{mg} / \mathrm{kg}$ subcutaneously or $100 \mathrm{mg} / \mathrm{kg}$ dosed orally. No data on resistance selection or details of validation of leuRS as the antibacterial target of the compounds have been reported. Soon after the first disclosure of the program, a November 2009 news release reported that a clinical candidate, AN3365, had entered phase I trials. Presumably, it is related to $\mathrm{ABX}$, but its structure and activity have not yet been disclosed; it is likely to be covered in the same patent application as ABX (S. J. Baker, V. S. Hernandez, R. Sharma, J. A. Nieman, T. Akama, Y.-K. Zhang, J. J. Plattner, M. R. K. Alley, R. Singh, and F. Rock, U.S. patent application 2009/ 0227541). The fact that this compound series entered the clinic so soon after its first disclosure is exciting.

RNA polymerase in $\boldsymbol{C}$. difficile. Although it is neither a novel target nor a newly discovered agent, nevertheless fidaxomicin is a single-target inhibitor in the late stage of clinical development ( 2 phase III trials have been completed at this time). Fidaxomicin is the generic name of an Actinoplanes product, variously known as lipiarmycin (Table 4), tiacumicin B, and difimicin, discovered in 1975 (289). It is a specific inhibitor of transcription by RNA polymerase $(328,344)$, and in B. subtilis, it selects for resistant mutants mapping in $r p o C$ (at a frequency of $2 \times 10^{-6}$ in one report [344] and $<10^{-7}$ in another [although 2 such mutants were indeed selected and mapped] [142]). Such mutants have MICs that are raised $\geq 16$-fold. In the latter report (142), mutations leading to reduced permeability (or efflux?), as indicated by effects on MICs of other antibiotics, were also found. Fidaxomicin is highly active on Clostridium difficile but not on enteric Gram-negative organisms, including anaerobes. The frequency of resistance selection in $C$. difficile was reported to be $<2 \times 10^{-8}$ at 4 or 8 times the MIC (356). Fidaxomicin has a selective Gram-positive 
spectrum (somewhat narrower than that of vancomycin [114]) that should lead to minimal disruption of gut flora, which is desirable for treatment of $C$. difficile. It has thus been under development for $C$. difficile-associated diarrheal disease (CDAD) by Optimer Pharmaceuticals. No resistant isolates have been seen in clinical trials (134). It should be noted that levels of drug are very high in the gut, as the compound is not absorbed, reaching average levels of $10^{4}$ times the MIC (325), which would be expected to suppress selection of resistant mutants. It appears to be effective in phase III trials, with relapse rates significantly lower than that of vancomycin (133).

DHFR and iclaprim. Although iclaprim (Fig. 4J) is not a member of a novel class of agents, but rather an optimized trimethoprim (Fig. 4K), it is an example of a single-target inhibitor specifically designed to overcome target-based resistance to its progenitor. The derivatization project was begun by Roche and spun off to Arpida, who continued research and development. The added rings of iclaprim allow interaction of the compound with two binding sites different from the site altered in the dihydrofolate reductase (DHFR) target enzyme with resistance to trimethoprim (point mutation yielding a Phe98-to-Tyr98 change in the $S$. aureus enzyme). This change in DHFR is a main form of trimethoprim resistance in Grampositive organisms. Thus, while trimethoprim has a low affinity for the resistant form of DHFR, iclaprim retains high affinity for the enzyme because of its additional binding sites (although it too loses affinity for the altered site) (149). Indeed, it has been reported that iclaprim is active against trimethoprimresistant Gram-positive strains and that iclaprim does not select for resistance in a single step from wild-type or trimethoprim-resistant starting strains (frequencies of $<10^{-10}$, spontaneously in $S$. aureus or with UV treatment in $E$. coli). It also appears to be very slow to yield resistance upon serial passage (little change in MIC after 15 passages) (149). While iclaprim is active against wild-type $E$. coli and does not yield to endogenous resistance upon selection, $\mathrm{MIC}_{90} \mathrm{~s}$ for $E$. coli and other Enterobacteriaceae are quite high $(>8)(179,386)$. This is likely due to the fact that trimethoprim resistance in the enterics can be conferred by plasmids carrying many types of resistant DHFR enzymes, as opposed to Gram-positive organisms, where resistance is generally due to endogenous mutation (170). The activity of iclaprim against strains of Enterobacteriaceae with defined trimethoprim resistance mechanisms has not been reported.

Clinical development of iclaprim was begun for treatment of complicated skin and skin structure infections (cSSSI) as well as hospital-acquired pneumonia (HAP), ventilator-acquired pneumonia (VAP), and CAP. Unfortunately, iclaprim was not approved for use in SSSI in either the United States or the European Union because of a failure to meet noninferiority standards. In late 2009, Arpida, financially unable to support further trials, sold the rights for iclaprim to Acino Pharma, which plans to continue development on a limited scale for parenteral treatment of selected pneumonias.

This type of approach, the specific design of single-enzyme inhibitors to overcome target-based resistance by iterative synthesis, resistance selection, crystallography, and redesign, might provide a light at the end of the single-target dilemma if it can be applied to novel compounds (before reaching the clinic) on the basis of resistance patterns seen in vitro or in animal models

The concept of adding chemical moieties providing extra intramolecular binding sites in order to overcome preexisting exogenous target-based resistance has indeed been applied in the development of other compounds (even those having complex targets), such as the ketolides, telavancin, glycylcyclines, cephalosporins active against MRSA (such as ceftaroline), and newer oxazolidinones. This approach has been discussed in some detail in several reviews $(5,64,97,337)$.

\section{Summary of Challenges of Single-Target Discovery}

To summarize, single-target screening and design, which have been the major efforts in antibacterial discovery for at least 15 years (the start of the genomic era), have had little success thus far. Although inhibitors for many targets have been discovered in this period, only a few new single-target agents have reached the clinic, with at least 2 candidates currently viable. It is likely that most of the programs presented in Table 3 have ended, for unknown reasons. Indeed, in the industry, clinical candidates often appear "fully formed" in the literature or at meetings (although often presaged in the patent literature), as was the case with linezolid (45) and the new benzoxaborole Leu-tRNA synthetase inhibitors (123). A variety of problems that may have contributed to cessation of programs are in evidence. Since for many published compounds enzyme inhibition was not proven to determine the MIC, later (unpublished) work might have shown otherwise, for example, that the inhibitors were promiscuous or nonspecifically lytic or toxic. The nature of the chemical library may have been "at fault," as discussed below. Perhaps the inhibitors were nonselective, hitting mammalian targets and yielding mechanism-based toxicity. It is likely that other factors played a part in preventing program progression as well, such as intractable low potency or solubility, a narrow spectrum, or high protein binding levels. It remains probable, however, that many of the programs that led to validated inhibitors were terminated because, where investigated, these inhibitors all were subject to selection of resistance due to a single mutational event.

What is the future of antibacterial discovery based on singletarget agents? Screening and, no doubt, increased SBDD efforts will continue, but these should be carried out with due attention paid to whole-cell activity and bacterial entry (discussed below) and the potential for resistance development. Once inhibitors are designed and/or optimized and whole-cell activity due to inhibition of the putative enzyme target demonstrated, then SBDD can be used to analyze resistant enzymes and to iteratively redesign them to overcome that resistance.

\section{MULTITARGETING}

If it is true that the best targets are "multitargets" due to their theoretically low potential for resistance development, then what are the prospects for the discovery and development of novel agents with such benefits? The majority of monotherapeutic antibacterial classes are targeted to the ribosome, with the source of their low endogenous resistance potential being 
the multiplicity of rRNA cistrons in a given pathogen. Undoubtedly there are other types of chemicals that could selectively bind to and interfere with the activities of protein synthesis. Two companies were founded with the idea of exploiting then new structural information about the ribosome. RiboTargets, in England, targeted the 30S subunit, and Rib-X, in Connecticut, targeted the 50S subunit. Rib-X is still in business, and while it has disclosed a number of programs, no completely novel drug candidates have emerged. Still, rRNA is an attractive target, perhaps one of the best for natural products, and should remain in play. A popular area of multitargeted drug discovery, as noted above, has been that of the Mur ligases (MurC to MurF) of the peptidoglycan synthesis pathway, since their active sites are similar (110). But, thus far, neither singly nor multiply targeted agents have been shown to be antibacterial due solely to the inhibition of peptidoglycan synthesis. Several avenues toward discovery of multitargeted inhibitors that have demonstrated antibacterial activity are discussed in the sections below.

There are few obvious multitargets. Can more be identified? One avenue may take advantage of methods for identifying so-called polypharmacology. It has been recognized that the basis for toxicity of many human health drugs is their interaction with multiple targets, which has been termed polypharmacology. Polypharmacology may have positive effects as well, such as overcoming resistance to single targets in cancer chemotherapy or increasing potency (101). A variety of in silico methods have been developed for predicting the possible targets of newly discovered small molecules and for identifying those proteins that might share active sites and thus have the potential for being inhibited by a single small molecule. In general, these methods rely on analysis of protein sequences, structures of proteins and bound ligands, and the interaction patterns of ligands (as similar ligands are likely to bind to similar targets). Key to this is a focus on the structure of the site of ligand-target interaction, independent of homologies between entire proteins (101). This area was reviewed recently by Bajorath (19), and a number of such programs have been described (for example, see references 101, 187, and 355). Antibacterial discovery should be able to take advantage of some of these methods in order to predict which essential bacterial proteins might be expected to interact with similar ligands.

\section{Single Pharmacophore, Multiple Targets}

Dual inhibitors of DNA gyrase and topoisomerase IV. Because of the attractive possibility of dual targeting, as demonstrated by the FQs, an area of active research has been the pursuit of inhibitors of the topoisomerases DNA gyrase and topoisomerase IV. This area has been reviewed recently (42, 276). Interestingly, these topoisomerases themselves were identified relatively long after specific inhibitors targeting them were discovered empirically. Nalidixic acid and novobiocin were tested in humans (nalidixic in 1963, novobiocin in 1956 [192, 343]) well before the discovery of DNA gyrase in 1976 and the identification of topoisomerase IV as a target of the FQs in 1994 (112, 128). As discussed earlier, the understanding of the dual targeting nature of the FQs explained the relatively low resistance potential of the class over their first 10 years of use in the clinic.

Novel inhibitors of the catalytic A subunits (GyrA and ParC) of these topoisomerases have been reported. Members of Achillion's heteroaryl isothiazolone (HITZ) series (69) have a broad Gram-positive spectrum, with activity against $H$. influenzae, Moraxella catarrhalis, and Neisseria spp. (304), very low resistance potential, activity against FQ-resistant strains (69), and in vivo efficacy in $S$. aureus septicemia and thigh abscess models in the mouse (304). Achillion's apparent current lead compound, ACH-702 (Fig. 5A), has potent activity against MRSA and M. tuberculosis.

Tanitame and coworkers at Sumitomo have reported on arylvinylpyrazoles, some of which have balanced in vitro inhibition of DNA gyrase and topoisomerase IV and good Grampositive activity and are not cross resistant with FQs (361). One of these, compound 7c, is shown in Fig. 5B. Some compounds are active against wild-type $E$. coli. No resistance studies have been shown. The lead series, interestingly, was derived from a hit detected in a whole-cell phenotypic screen for specific inhibition of chromosome partitioning (360).

Pfizer's quinazolinediones PD 0305970 (Fig. 5C) and PD 0326448 bear a resemblance to FQs and, like them, have rapid bactericidal activity. Resistance to the so-called "diones" arises in $S$. aureus and at low but significant levels in S. pneumoniae and, surprisingly, maps in the QRDR region of the GyrB and ParE ATPase subunits of the topoisomerases (as opposed to the catalytic subunits, which are the primary and secondary targets of the FQs) (165). Recent work from Fisher's laboratory, using selection of stepwise mutations, confirmed that the primary target of diones is GyrB, with secondary mutations in ParE. Furthermore, it was shown that dione inhibition leads to double-stranded DNA breakage (288). Thus, it appears that while mutations arise in the ATPase subunit, it is the catalytic activity of the topoisomerases that is inhibited. As might be expected from the site of resistance mutations, diones are not cross resistant with FQs. In fact, while FQ resistance does not alter susceptibility to diones, resistance to the diones may cause hypersusceptibility to FQs (288). No characterization of toxicity (including selectivity for bacterial over mammalian topoisomerases) of the diones has been reported. The clinical status of these catalytic inhibitors is unknown.

NXL101 is a quinoline antibacterial directed against GyrA and ParC with a target preference opposite that of most quinolones (Fig. 5D). In E. coli, ParC is preferred, while in $S$. aureus, the most sensitive target is GyrA (40). The useful spectrum of NXL101 is Gram positive, with particular utility against MRSA, and it is not cross resistant with FQs. NXL101 can inhibit both DNA gyrase and topoisomerase IV in vitro, but single base changes in $S$. aureus gyrA, although occurring rarely, give rise to high-level resistance. Thus, NXL101 might be expected to behave as a single-target inhibitor vis à vis resistance development in the clinic. Interestingly, NXL101 resistance mutations in gyr $A$ are incompatible with FQ resistance mutations in the same gene, raising the possibility that combination therapy with an FQ might combat resistance. NXL101 entered phase I trials, but development was curtailed because of findings of "QT prolongation" (prolongation of the interval between the end of the $\mathrm{Q}$ wave and the start of the $\mathrm{T}$ 
A<smiles>COc1c(N2CCC(C(C)(C)N)C2)c(F)cc2c(=O)c3c(n(C4CC4)c12)SNC3O</smiles>

C<smiles>Cc1c(N2CCC(C(C)N)C2)c(F)cc2c1N(C1CC1)C(=O)[C@@H](N)C2=O</smiles>

B<smiles>Cn1cc(/C=C/c2cc(C3CCNCC3)nn2-c2cccc(Cl)c2)c2cc(Cl)ccc21</smiles>

D

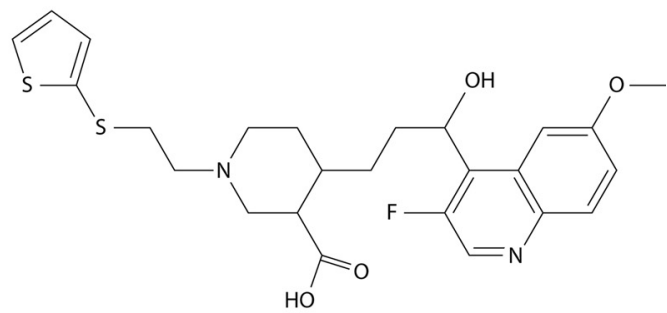

E<smiles>COc1ccc2cccc(-n3cc4c(n3)CCC(NCc3ccc5c(c3)NC(=O)CS5)C4)c2n1</smiles>

F<smiles>O=C(NCF)Nc1nc2cc(-c3cccnc3)cc(-c3ncccc3F)c2[nH]1</smiles><smiles>Nc1cc2ncn(CCCCN3CCOCC3)c2c(=O)[nH]1</smiles>

H<smiles>C=C/C(C)=C/C1(C)SC(=O)C(C)=C1O</smiles>

J<smiles>CC(=O)Oc1ccccc1C(=O)CC(=O)Nc1ncc([N+](=O)[O-])s1</smiles>

FIG. 5. Multitargeted compounds. Compounds are described in the text. (A to F) Dual inhibitors of DNA gyrase and topoisomerase II. (G) Inhibitor of DNA Pol IIIC and -E of Gram-positive organisms. (H and I) Inhibitors of $\beta$-keto-acyl-ATP synthases of FAS II. (J) Nitazoxanide, an inhibitor that inactivates a cofactor, thiamine triphosphate, of the enzyme pyruvate:ferredoxin oxidoreductases.

wave on an electrocardiogram [EKG], which signals a risk of arrhythmias) (317). Here is another case where a single-target inhibitor has stalled in phase I-before the question of resistance development could be addressed in the clinic.

Johnson \& Johnson has reported on tetrahydroindazole analogs $(135,385)$, some of which have good activity against $S$. aureus, S. pneumoniae, and E. coli (Fig. 5E shows compound I from reference 135). Resistance mutations in S. pneumoniae selected with these compounds are reported (without data) to reside in parC (135) and are not cross resistant with FQs (385). Interestingly, the tetrahydroindazoles do not lead to the formation of a DNA-DNA gyrase cleavage complex, as do FQs, but compete with ciprofloxacin for the formation of such com- plexes (385). Thus, they may well have some interaction with GyrA as well as GyrB. No extensive in vitro data or in vivo efficacy or toxicity testing has been reported. It is unclear what the fate of this program is, since Johnson \& Johnson has greatly curtailed its antibacterial discovery programs in the United States.

The natural product aminocoumarins novobiocin, clorobiocin, and coumermycin are known inhibitors of GyrB (161). The activity of clorobiocin is about 10 -fold higher than that of novobiocin in an assay of DNA supercoiling by DNA gyrase. Interestingly, clorobiocin has very good activity in an assay of topoisomerase IV decatenation $\left(\mathrm{IC}_{50}, 0.17 \mu \mathrm{M}\right)$ compared to the activity of novobiocin against topoisomerase IV $(12 \mu \mathrm{M})$ 
(116). This is intriguing because they are so similar structurally. Engineered hybrids of the novobiocin and clorobiocin biosynthetic pathway were made in Streptomyces coelicolor and produced hybrid aminocoumarins (116). None were improved over clorobiocin itself.

A number of groups have undertaken projects designed to find balanced inhibitors of the B subunits of gyrase (GyrB) and topoisomerase IV (ParE), specifically to block the ATP binding site. The goal of discovering such balanced dual inhibitors was based on the finding by Vertex scientists that the activity of novobiocin against topoisomerase IV (ParC/ParE), which is normally very weak, can be increased 20 -fold by a single amino acid change in the enzyme (35). This was pursued at Vertex $(63,64,140,232)$ and resulted in the discovery of aminobenzimidazoles such as VX-752586 (Fig. 5F), which displays potent activity against both enzymes and antibacterial activity against Gram-positive organisms. Evidence for dual targeting at the cellular level was based on the effect of mutation in either GyrB, ParE, or both in $S$. aureus, S. pneumoniae, E. faecalis, and $H$. influenzae. VX-752586 showed a slight preference for GyrB in S. aureus, E. faecalis, and H. influenzae and for ParC in $S$. pneumoniae. As expected, the resistance frequency in E. faecalis was very low $\left(<5.2 \times 10^{-10}\right.$ at 4 and 8 times the MIC), owing to relatively balanced dual targeting. The progression of this compound toward the clinic is not clear, and the program is not listed on the company website. A number of other groups have reported on GyrB-ParE inhibitor programs, with less-detailed evidence for dual targeting at the antibacterial level. These include Prolysis/Evotec benzimidazoles (102) and Pfizer pyrimidinyl-imidazo-pyridines (353), which are similar to the Vertex compounds. Trius Pharmaceuticals was awarded a large National Institute of Allergy and Infectious Diseases (NIAID) contract in October 2008, for discovery of dual ParE-GyrB inhibitors targeting Gram-negative biodefense organisms. This is intriguing, though no data are available on the program, since other such dual inhibitors have had little Gram-negative activity.

Dual inhibitors of Gram-positive DNA polymerases. As noted in Table 3, anilino-uracils such as HpUra (hydroxyphenyluracil) and the more recent compounds HB-EMAU (hydroxybutyl-ethyl-methyl-anilinouracil) and EMAIPU (ethyl-methyphenyl-amino-isoxazolyl carbonyl-piperidinyl-methyluracil), target Gram-positive DNA polymerase IIIC (Pol IIIC). Purine (rather than pyrimidine)-based inhibitors that can inhibit both Grampositive DNA Pol IIIC and IIIE have been described and patented (391, 392). A number of $7 N$-alkyl-substituted dichlorobenzylguanines (DCBGs), such as 7-morpholinobutyl-DCBG (Fig. $5 \mathrm{G})$, demonstrate balanced potent $(\sim 50 \mathrm{nM})$ inhibition of both enzymes and have good antibacterial activity (MIC against MRSA $=1 \mu \mathrm{g} / \mathrm{ml})$. No data were presented on whole-cell mechanism of action, selectivity of enzyme inhibition (i.e., activity against mammalian DNA polymerases), toxicity, resistance determination, or in vivo activity. The possibility of unwanted activity against the mammalian polymerases is real, since dichlorophenylguanines have shown activity against mammalian polymerases and other DNA enzymes (79). Further structural and mechanistic studies on the DNA polymerases, both bacterial and human, might help to disentangle overlapping susceptibilities.

$\boldsymbol{\beta}$-Ketoacyl-ACP synthases of FAS II. FabF and FabH of $S$. aureus and FabB of E. coli are sensitive to inhibition by thio- lactomycin (300) (Fig. 5H), a natural product discovered by empirical screening (Table 4). Discovered in 1982 (259, 274), thiolactomycin was shown to have only moderate in vitro activity $\left(50 \%\right.$ effective doses $\left[\mathrm{ED}_{50} \mathrm{~s}\right.$ ] of 25 to $200 \mu \mathrm{g} / \mathrm{ml}$ against Serratia marcescens, K. pneumoniae, and E. coli) but was active in vivo by subcutaneous (s.c.) dosing against pyelonephritis systemic infection by intraperitoneal injection, with $\mathrm{ED}_{50} \mathrm{~s}$ of $\leq 1.6$ to $4.3 \mathrm{mg} / \mathrm{mouse}$ in all but the highest-inoculum infections, where the $\mathrm{ED}_{50}$ was $7.4 \mathrm{mg} /$ mouse (259). Since mice weighed 20 to $30 \mathrm{~g}$, a dose of $4 \mathrm{mg} / \mathrm{mouse}$ was 200 to $300 \mathrm{mg} / \mathrm{kg}$, a high dose. Efficacy may have been limited by rapid clearance. Oral dosing was tested and showed about $25 \%$ of s.c. efficacy against systemic infection. Little work seems to have been done on thiolactomycin, until recently, when antimycobacterial activity was studied. The antimycobacterial activity of thiolactomycin is due to inhibition of the KasA and KasB enzymes in $M$. tuberculosis, which are $\beta$-ketoacyl-acyl carrier protein (ACP) synthases involved in mycolic acid synthesis, and this impelled efforts toward improvement of its anti-M. tuberculosis activity, which was reviewed recently (183). No efficacious inhibitors have yet been reported.

Phenotypic screening of actinomycete fermentation broths with an $S$. aureus strain sensitized to FabF inhibitors by upregulation of FabF antisense RNA led to the discovery of phomalenic acid and platensimycin (Table 4) and to rediscovery of thiolactomycin $(381,399)$. Another inhibitor from that screen, platencin (Fig. 5I), was shown to inhibit both FabF and FabH (380). This dual inhibition would be expected to lead to decreased resistance potential, but unfortunately, no resistance data have been published for either platensimycin or platencin. Although both platensimycin and platencin showed some in vivo activity, the usefulness of this target in Gram-positive organisms is in question due to the ability of exogenous unsaturated fatty acids to remediate FAS II inhibition, as mentioned above. Platensimycin was recently shown to be active against M. tuberculosis due to inhibition of mycolic acid synthesis and to inhibit both KasA and -B, providing a new lead for antituberculosis drug design (51).

\section{Targeting Substrates and Cofactors}

Lipid II and other specific cell wall substrates. Lipid II, the carrier lipid-linked muramyl pentapeptide substrate of peptidoglycan transglycosylation and transpeptidation, is the antibacterial target of a number of natural products. Vancomycin, which targets the terminal D-Ala-D-Ala of the muramyl pentapeptide portion of lipid II, was very long lived in the clinic before any resistance to it arose through HGT. Single-step, target-based resistance to vancomycin does not occur because its target is an essential structure that is the end product of many synthetic steps. Changing the structure of the target would require substantial alteration of both substrate recognition by and regulation of pathway enzymes. In fact, horizontally transmitted vancomycin resistance (of the VanA and VanB types seen in enterococci) is due to import of an operon of several genes whose products alter the peptidoglycan pathway to produce a different product that can substitute for normal lipid II but does not bind vancomycin (296).

Remodeling cell walls to raise vancomycin MIC levels (as in vancomycin-intermediate $S$. aureus [VISA] strains) appears to 
be an endogenous multistep process. Similar to lipid II, both the phosphate and pyrophosphate forms of the carrier lipid itself, bactoprenol, are targets. This field has been reviewed very recently $(44,238,322,323)$ and is not covered here except to note that a number of natural product inhibitors and derivatives that act by sequestering lipid II or bactoprenol-P from the action of enzymes catalyzing their use have been near or under development. These include telavancin (registered) and oritavancin (back to phase III trials after a sortie at the FDA), which are active due to their lipid II binding. A derivative of plectasin, a Gram-positive organism-specific antibacterial peptide entering development, was recently shown to act by lipid II binding as well (321). Friulimycin B (dropped after phase I trials due to unfavorable pharmacokinetics) and the amphomycin derivative MX-2401 (preclinical) bind to bactoprenol-P, preventing its use by MraY $(317,320,373)$.

A vitamin cofactor as target. Nitazoxanide (NTZ) (Fig. 5J), a nitrothiazolide, is approved for treatment of amitochondrial parasites such as Giardia intestinalis, Trichomonas vaginalis, and Cryptosporidium parvum. It is also active against many anaerobic and microaerophilic bacteria, including $C$. difficile and $H$. pylori, and is being studied for its antiviral activity as well (94). NTZ is not cross resistant with metronidazole, although their spectra against parasites and anaerobic bacteria are similar, and resistance to NTZ was not selected in $H$. pylori in vitro or in a clinical trial (251). Due to its anti- $C$. difficile activity and good safety and tolerability profile in humans, NTZ has been studied for the treatment of CDAD $(266,267)$.

Reduction of NTZ and metronidazole by nitroreductases is required for their activity against bacterial anaerobes. The antibacterial activity of metronidazole is apparently due to those reduction products (which interact with DNA), but for NTZ, it may be that the nitroreductases themselves are the targets. Using $H$. pylori as a model organism, Hoffman et al. (159) showed that NTZ can inhibit pyruvate:ferredoxin oxidoreductase (PFOR), an enzyme which oxidatively decarboxylates pyruvate to form acetyl-CoA from $\mathrm{CoA}$. Indeed, all of the anaerobic bacteria (and $H$. pylori) and parasites in the NTZ spectrum rely on PFOR for pyruvate oxidation. Thus, PFOR is a good candidate as the antibacterial target of NTZ.

The mechanism of inhibition by NTZ appears to be interference with formation of the reaction intermediate C-2- $\alpha$ lactylthiamine-pyrophosphate, which is formed from the substrate pyruvate and the vitamin cofactor thiamine-pyrophosphate (TPP). NTZ, in its anionic form, abstracts a proton from TPP, thus inactivating itself and preventing the resolution of the intermediate and donation of the acetyl group to $\mathrm{CoA}$ (159). Thus, NTZ appears to interact with an activated cofactor rather than with the PFOR enzyme itself. The lack of resistance development to NTZ seen in $H$. pylori (251) may well be due to its targeting a cofactor (the product of a synthetic pathway) rather than an enzyme (the product of a single gene).

NTZ also inhibits other enzymes that use TPP, such as pyruvate dehydrogenase of $E$. coli, and shows some inhibition of $E$. coli in glucose minimal medium (159). Additionally, it was reported recently that NTZ is active in killing both growing and nongrowing $M$. tuberculosis, which does not have a PFOR enzyme (87). The authors of that study found that no NTZresistant mutants could be selected in $M$. tuberculosis, leading them to speculate that NTZ may have multiple targets in $M$. tuberculosis. While, as noted above, the nitro group is required for activity against bacterial anaerobes, it has been shown that compounds lacking the nitro group still show activity against Neospora caninum (an apicomplexan protozoan, as is C. parvum) (108), where protein-disulfide isomerase may be a target (264). Non-nitro-containing derivatives have also been found to have broad activity against many viruses (NTZ is in clinical trials for treatment of chronic hepatitis $\mathrm{C}$ and influenza) (315).

Thus, it appears that NTZ can inhibit a variety of enzymes, and in some cases (the nitroreductases), this is likely to be mediated by interaction with an activated TPP cofactor. It has not been proven that PFOR (or, more precisely, the TPP intermediate) is the sole target in $H$. pylori and $C$. difficile; thus, the low level of resistance seen cannot be attributed absolutely to interaction with the cofactor (and might be attributed to more standard multitargeting). However, the concept of targeting cofactors for reduced resistance potential should certainly be explored further.

\section{Hybrid Molecules: Dual Pharmacophore, Multiple Targets}

As an alternative to the single-pharmacophore, multipletarget approach to avoiding resistance selection, hybrid molecules may provide a more general method for attacking two cellular targets simultaneously_by tethering separate inhibitors or pharmacophores together to form a single molecule. This approach has been reviewed recently $(27,43)$ and is discussed here only in passing.

Early exemplars of this approach were $\beta$-lactam-FQ hybrids in which lactam ring opening would lead to expulsion of the FQ, with its subsequent entry into the cytoplasm. The raison d'être was to bring both components to the cell simultaneously (essentially matching their PKs) and cause FQ release by dint of the activity of the $\beta$-lactam on its target PBPs, leading to ring opening, or by $\beta$-lactamases attacking and hydrolyzing the lactam. In the latter case, $\beta$-lactam resistance due to $\beta$-lactamases would be overcome by the released FQ. It is hard to see how such hybrids would be expected to have emergent properties, i.e., properties different from those of a combination of the parent compounds. No compounds of this type were developed.

More recently, hybrids have been designed to keep both pharmacophores together in order to work in the same cellular compartment (or outside the cell) and to address the problem of resistance by (i) slowing the development of resistance to one or the other of the components, especially if each was single targeted, or (ii) presenting 2 possible warheads which could overcome preexisting resistance to either one. In the first case, where both components are single targeted, resistance selection to the hybrid should be much reduced over that seen with either of the single components as long as sufficient concentrations are maintained. It is not clear whether this would be better than a combination of the two, except that PKs are matched. However, the pharmacodynamics of the two components would also have to be compatible, which might be difficult. Furthermore, the fixed concentration of the components might lead to dose limitation due to toxicity of one of the components, which might be addressed better by separate administration. 


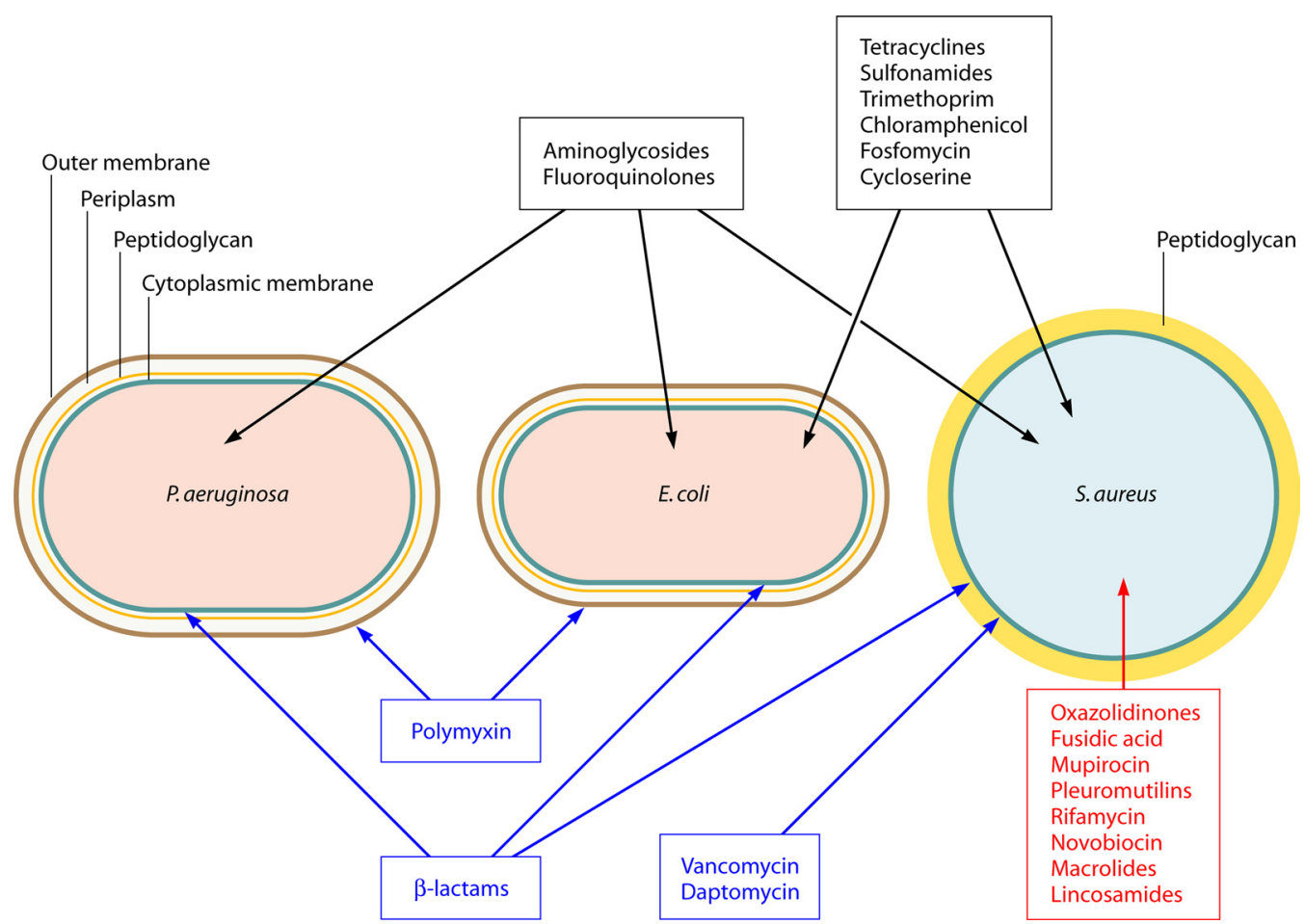

FIG. 6. Spectra and target locations of antibacterials. Drugs in red are active against Gram-positive organisms only and have cytoplasmic targets. Drugs in black are broad-spectrum cytoplasmic agents. Drugs in blue act extracellularly. Only 4 classes are currently useful against $P$. aeruginosa, with 2 acting outside the CM (polymyxin B and the $\beta$-lactams) and 2 being cytoplasmic (aminoglycosides and the FQs).

A number of hybrids of FQs with drugs such as oxazolidinones and DNA polymerase inhibitors have been disclosed $(58,167)$. These hybrids had the desired qualities of acting on strains resistant to either component and displaying very slow resistance selection. No clinical candidate emerged from these studies, presumably indicating PK, absorption, distribution, metabolism, and excretion (ADME), or toxicity difficulties. One hybrid that reached the clinic was Cumbre's CBR-2092, a rifamycin-FQ (strictly speaking, 2-pyridone instead of an FQ) hybrid that displayed both mechanisms of intracellular action and had the desired characteristics of much lowered resistance selection relative to those of its components and activity on strains with preexisting resistance to a component (313). Two phase I trials were completed by 2008, but no public reports were issued, and the company soon went out of business. Thus, this project met its preclinical marks but failed in the clinic. In terms of this review, even if we do not know the precise cause of this failure, it would seem to be something like toxicity or poor pharmacokinetics, things that are common to all human drug discovery and not a challenge unique to antibacterial discovery. Thus, if standard drug discovery challenges can be met, the hybrid antibacterial concept should be viable.

\section{CHEMISTRY}

\section{Spectrum Is Due to Permeability as Well as Target Distribution}

Net permeability, the product of entry and efflux, is a critical determinant of intrinsic sensitivity of bacterial species to antibacterials, along with the presence of targets and degradative mechanisms (such as $\beta$-lactamases), and contributes significantly to the spectrum of antibacterials as well as to resistance development.

Figure 6 shows the spectra of the classes of antibacterials in clinical use and the locations of their targets, external to the cell or in the cytoplasm. As illustrated and discussed below, Gram-negative bacteria have a second membrane which acts as a permeability barrier. In general, the currently used classes of drugs useful on E. coli are a subset of the classes of drugs active on $S$. aureus. In turn, the classes of useful antipseudomonals are a subset of E. coli drug classes. Exceptions exist, in that polymyxins have a Gram-negative spectrum, as do certain members of these classes, specifically the monobactams and nalidixic acid; some preclinical compounds, such as the LpxC inhibitors, may have Gram-negative organism-specific targets. However, since almost all targets of the antibacterials in clinical use are present in all three organisms, it follows that the antibacterial spectra of these drugs are determined largely by the ability of the drug to reach that target in sufficient concentration. Most of the synthetic inhibitors in Table 3 have antibacterial activity against Gram-positive species only, although most targets are functionally present in Gram-negative organisms. This was shown in many cases by demonstration of activity of Gram-positive organism-selective compounds on permeable or efflux-deficient, but not wild-type, E. coli (for example, see references $3,10,31,38,234$, and 380). The few exceptions include the benzoxaborole LeuRS inhibitors, which were optimized for Gram-negative activity, and the inhibitors of the Gram-negative organism-specific targets LpxC, LptD, and ClpXP (essential only in Caulobacter crescentus). If inhibitors of many E. coli enzymes 
are not active against the whole organism but are active against $S$. aureus, it would seem that finding new intracellular targets in MDR Gram-negative organisms is not a useful enterprise, as target identification is not rate limiting.

\section{Chemical Libraries Are Limiting}

The success of antibacterial screening, whether against single enzymes or by whole-cell empirical or phenotypic means, is dependent upon the quality of the chemicals assayed. As noted above, the search for antibacterials among natural products was initially very successful, presumably because that source contains compounds selected for their interaction with bacterial targetswhether as weapons or as signaling molecules $(83,91)$ — and their ability to reach those targets (338). Chemical libraries, however, have proven less useful for antibacterial screening.

In their review of a GSK screening initiative in which 67 essential genes were targeted in HTS campaigns using the Smith Kline compound collection (up to 530,000 compounds), Payne et al. (293) reveal that only 16 targets yielded hits (compounds defined as being chemically tractable and having low micromolar potency against the enzyme, with $10 \times$ selectivity for bacterial over mammalian enzymes), and only 5 of those yielded leads (compounds which, in addition to having "hit" qualities, were shown to have antibacterial activity proven to be due to inhibition of the in vitro-targeted enzyme). None of the initial hits were of "lead" quality.

In addition to HTS targeted screening, the GSK group screened empirically for whole-cell growth-inhibitory activity, with the intention of secondarily identifying the mechanism of action (reverse genetics). There were no progressable hits from a screen for $E$. coli inhibitors and 300 hits from an $S$. aureus screen that had activity against at least one other Gram-positive or Gram-negative organism. Most of the $S$. aureus hits were due to nuisance compounds, largely nonspecific membrane-active and cytotoxic compounds. One compound, a thiazolidinedione, was not membrane active, but no mechanism of action could be discerned for it and it was dropped. (Perhaps the compound had promiscuous activity and inhibited multiple processes.)

Screening for novel antibacterials was abandoned at GSK, but programs continued in the optimization of previously described classes, such as the pleuromutilins, eventually yielding retapamulin. Payne et al. concluded that the main reason for failure of both the target-directed and empirical screening campaigns was "insufficient or improper molecular diversity of the compounds screened" (293). It should be emphasized that the GSK experience, though one of the few tales of program failure recounted in the literature, is not unique in the industry-as can be gleaned by tracking publications of various companies through their elucidation of novel targets and through the trickling of reports of discovery programs that have so far not produced clinical candidates.

A recent report of an empirical screen of a library of 150,000 compounds for inhibitors of $E$. coli or $P$. aeruginosa growth identified several classes of compounds with reasonable potency: a large nitrofuran class, followed by naphthalimide, salicylanilide, bipyridinium, and quinoazolinediamine chemical classes (90). There was some SAR within the classes, but no mechanisms have yet been determined. While this seems to be a better result for Gram-negative activity than that seen by
GSK, a major caveat is that these hits were not reported to have been counterscreened for cytotoxicity.

The unsuccessful GSK experience with antibacterial HTS screening was mainly a result of the nature of the chemical library. Big Pharma chemical collections are generally aimed at size rather than designed for diversity or quality. They have been made up largely of series of compounds synthesized for all of the therapeutic areas covered by the companies. These compounds were synthesized, in the main, as agonists/antagonists of $\mathrm{G}$ protein-coupled receptors (GPCRs), kinases, proteases, ion channels, or nuclear receptors. Libraries designed to hit such targets contain "privileged structures," which often have some promiscuous character. It should be noted that most of these industrial nonantibacterial targets (except for the kinases and proteases) are not enzymes, while enzymes have been the targets of most antibacterial screening campaigns. The paper describing the GSK initiative (293) includes a graph showing the difference in some chemical properties between antibacterial agents and other drug classes (further illustrated below). Clearly, the libraries were not diverse in the types of structures they contained (as the authors note). In order to make HTS worthwhile, the size of the library should not be as much of a concern as what it contains. Proposals toward increasing diversity and biological relevance of libraries have been made by the Shoichet and Schreiber groups, among many others $(56,156,346)$.

A number of papers have discussed compounds that are falsely positive in many in vitro enzyme assays. Libraries are rife with aggregating $(248,249)$, reactive (311), and PAIN (18) compounds and, as the GSK group found, with membraneactive agents. Pfizer chemists recently analyzed physicochemical parameters of chemicals that are associated with toxicity (169). The main finding was that higher toxicity is associated with higher lipophilicity $(\log P>3)$ and lower polarity, as measured by total polar surface area (TPSA $<75 \AA^{2}$ ). This is hypothesized to be due to the higher promiscuity of high-log $P /$ low-TPSA compounds in off-target binding. It is clear that for any HTS effort, chemical libraries, especially those for antibacterials, must be improved by removal of interfering and potentially toxic compounds and by increasing diversity far beyond that directed at common therapeutic targets.

Thus, there are two main chemistry-related challenges exemplified in the GSK work and shown in Table 3: (i) the need for better chemical libraries which are more diverse and minimized with regard to interfering, cytotoxic, and membranelytic compounds; and (ii) the need for chemicals which are active against Gram-negative organisms.

\section{Barriers to Intracellular Accumulation in Gram-Negative Organisms}

Cytoplasmic and outer membranes have orthogonal sieving properties. The outer membrane of Gram-negative organisms provides a formidable additional barrier to the cytoplasmic membrane $(\mathrm{CM})$ present in all bacteria and, furthermore, synergizes the effect of efflux pumps in Gram-negative organisms. The difficulty in discovering new Gram-negative organism-specific drugs is a function of these Gram-negative barriers to entry, not to a paucity of targets exploited. Gram-negative permeability barriers 
have been reviewed often (for example, see references 270, 285, and 338) and are outlined only briefly here.

While all bacteria are bounded by a symmetric lipid bilayer $\mathrm{CM}$, Gram-negative organisms have a second, OM barrier, an asymmetric bilayer whose outer layer is composed of LPS. The periplasm lies between the $\mathrm{CM}$ and the $\mathrm{OM}$. This is pictured in Fig. 6. To oversimplify the nature of the barriers, the $\mathrm{CM}$ is permeable to uncharged, lipophilic molecules that can readily diffuse through the bilayer, with charged hydrophilic molecules crossing by active transport via solute-specific carriers and permeases. The bulk of the OM is largely impermeable, but molecules can transit through water-filled channels, called porins, that prefer hydrophilic, charged solutes with upper limits for molecular weight (MW); the cutoff for E. coli is an MW of 600 . Aside from the generalized porins, there are solute-specific facilitated diffusion channels through the $\mathrm{OM}$ into the periplasm which allow such solutes to bypass the porin-specific size and charge requirements. The specificities of $\mathrm{CM}$ active transport and $\mathrm{OM}$ facilitated diffusion are for nutrients and other materials that are necessary for cell growth under certain conditions. While some natural product antibiotics take advantage of these solute-specific routes, most antibacterial drugs do not (338). Thus, nonnutrient hydrophilic and charged molecules that transit the $\mathrm{OM}$ via porins are poorly suited for passage across the $\mathrm{CM}$ into the cytoplasm. As discussed in more detail below, there are exceptions to these general statements. Overall, however, it seems that compounds entering the Gram-negative cytoplasm should have both charged and uncharged species at physiological $\mathrm{pH}$.

RND efflux pumps. Relatively nonselective efflux pumps play an important role in establishing the net accumulation of compounds in the cytoplasm in Gram-negative organisms, where their effect is synergized by the presence of the $\mathrm{OM}(41,271)$. The basis of substrate recognition of the RND pumps (with MexAB-OprM and AcrAB-TolC being the major constitutive pumps in $P$. aeruginosa and $E$. coli, respectively) was initially unclear and appeared to be a "hydrophobic" region of the solute (drug) that permitted its interaction with the outer leaflet of the CM and access to the pump via the lipid phase (269, 404). Recent structural studies of the AcrAB/TolC pump of $E$. coli by Murakami and coworkers led to a model of pump action and to a better understanding of substrate recognition sites (265). In the model of Murakami et al., a drug enters one of the AcrB trimers directly from the periplasm. The substrate binding site is a large pocket rich in amino acids with aromatic side chains, lending themselves to hydrophobic interactions with solutes, although there are some polar side chains present. Minocycline and doxorubicin binding was localized to this region by crystallographic studies. Based on the recognition of the minocycline binding site, Takatsuka and colleagues (358) recently reported modeling studies of binding within AcrB with 30 diverse compounds. Their results indicated two main areas to which different compounds appeared to bind, namely, a "groove" (where minocycline binds) and a "cave." Competition experiments were used to test some of the predictions, i.e., groove binders generally competed with groove binders and not cave binders and vice versa. This elegant work can provide a path forward toward understanding substrate recognition of pumps, and perhaps how to avoid them.

Thus, in order for potential drugs to enter the Gram-nega- tive cytoplasm, they must have all the physicochemical properties required to cross the $\mathrm{OM}$ and diffuse through the $\mathrm{CM}$ without first being swept up from the periplasm by efflux. No wonder it is so hard to find compounds that enter Gramnegative organisms. Indeed, as noted above for the GSK study (293), there were no progressable E. coli hits of interest in the GSK chemical library.

\section{Formulation of Rules for Intracellular Accumulation}

The emphasis here is on Gram-negative organisms due to the growing problem of antibacterial resistance in such pathogens. Furthermore, inhibitors accumulating in the Gram-negative cytoplasm should also enter Gram-positive organisms, and hence, as long as the target is broadly distributed, these should be broad-spectrum agents. Which physicochemical characteristics are required, then, in order to design libraries for antibacterial screening and to inform the design and optimization of enzyme inhibitor leads in order to accumulate in Gram-positive organisms (requiring diffusion through, but not lysis of, the $\mathrm{CM}$ ) and Gram-negative organisms (requiring passage through the CM and OM and avoidance of RND pumps)? Is it possible to devise a set of chemical descriptors, analogous to Lipinski's Rule of 5 (215), that roughly define the characteristics for accumulation in the Gram-negative cytoplasm? To derive the Rule of 5, the rules generally describing orally bioavailable compounds, Lipinksi and colleagues chose a set of 2,245 drugs that had progressed into phase II development (and thus were likely to have good physicochemical properties) from a database (the World Drug Index [WDI]) of 50,427 biologically active molecules, including marketed and investigational drugs. They then chose chemical descriptors that they considered might be related to intestinal absorption and membrane permeability and compared the values of these parameters for the 2,245-drug subset with those for the WDI. In other words, they defined a subset or "bin" of interest and looked for its distinguishing characteristics.

Binning for SAR of antibacterials. O'Shea and Moser (284) undertook to define some physicochemical properties of marketed antibacterials by comparing three bins: (i) nonantibacterial drugs, (ii) antibacterial drugs whose spectrum included E. coli, and (iii) drugs active against Gram-positive organisms only, as represented by $S$. aureus. They found that drugs active against Gram-negative organisms are smaller, with an upper molecular mass of $600 \mathrm{Da}$, as would be expected from the known porin size cutoff for $E$. coli, and they had, on average, a larger polar surface area (PSA). Figure 7A is a plot of the distribution of lipophilicities of the drugs, as measured by clog $D_{7.4}$, (the calculated $\log$ of the oil-water coefficient based on the distribution of charged and uncharged microspecies of the compound at $\mathrm{pH}$ 7.4). It illustrates that drugs active against Gram-negative organisms are more polar (less lipophilic) than Gram-positive organism-specific drugs. In turn, Gram-positive organism-active drugs are more polar than nonantibacterial drugs. Gram-negative organism-active drugs also tend to be charged at $\mathrm{pH}$ 7.4. This is approximated by comparing the clog $D_{7.4}$ with $\operatorname{clog} P$ (calculated $\log$ of the oil-water partition coefficient of a neutral form of the compound). This binning scheme, however, does not differentiate between those drugs entering the cytoplasm of Gram-negative organisms from 
A. Binned by spectrum

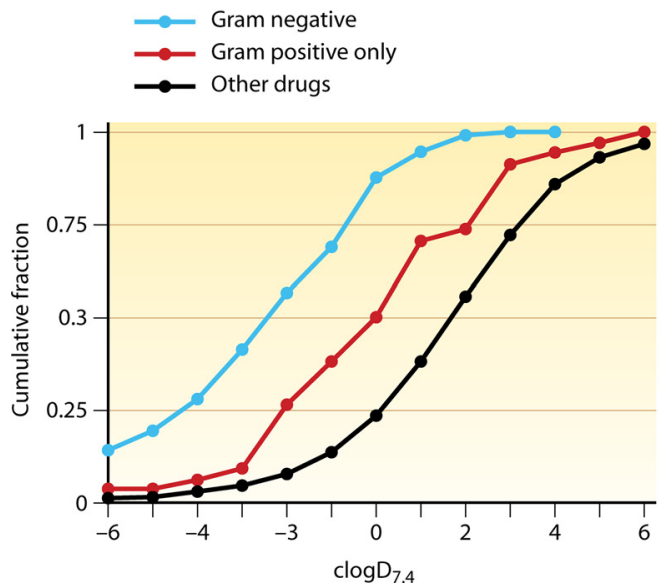

B. Binned by target location
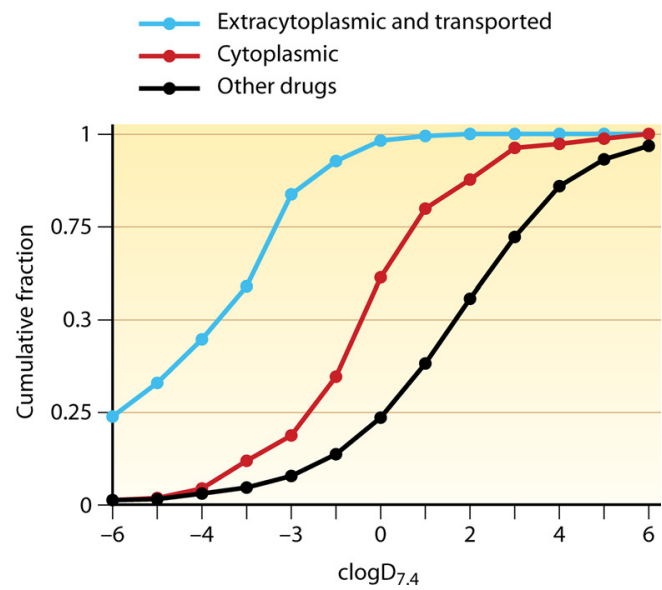

FIG. 7. Binning of antibacterials. (A) Binning by spectrum. (B) Binning by target location. The "extracytoplasmic and transported" set includes 70 compounds from 7 classes: $\beta$-lactams, glycopeptides, daptomycin, polymyxin B, gramicidin, fosfomycin, and the aminoglycosides. Cytoplasmic compounds comprise 77 compounds from 14 classes: FQs, tetracyclines, sulfonamides, macrolides, streptogramins, trimethoprims, rifamycins, lincosamides, oxazolidinones, mupirocin, fusidic acid, novobiocin, triclosan, and chloramphenicol. The set of other drugs includes 4,623 nonantibacterials. (Adapted from reference 284 with permission of the publisher. Copyright 2008 American Chemical Society.)

those drugs, such as the $\beta$-lactams, that need only traverse the OM to reach their targets. For Fig. $7 \mathrm{~B}$, the data were replotted using the following bins, based on the locations of the drug targets and the method of reaching those targets: (i) all drugs (active against either Gram-positive or Gram-negative organisms) acting extracytoplasmically plus "specially transported" drugs (those known to be transported actively via permeases plus the aminoglycosides, whose transport is energy dependent [257]), (ii) drugs entering the cytoplasm by passive diffusion, and (iii) nonantibacterial drugs. A different picture emerges. The extracytoplasmic and transported drugs are much more polar than those that diffuse into the cytoplasm. A previous review (338) graphically evaluated 90 cytoplasmically targeted antibacterial drugs (comprising 17 chemical classes), using 3 bins: (i) Gram-negative organism-active drugs entering by diffusion, (ii) Gram-positive organism-specific drugs entering by diffusion, and (iii) specially transported drugs (as defined above). The 57 cytoplasmically targeted Gram-negative organism-active agents (6 chemical classes) were shown to have narrower ranges of molecular mass (337 to $586 \mathrm{Da}$ ) and $\operatorname{clog} P$ values $(-1.5$ to 3.0$)$ than the other groups. The transported drugs were much more polar; the drugs active against Grampositive organisms had higher MW and higher average lipophilicity. Structures of representatives of the classes of compounds entering the $E$. coli cytoplasm by passive diffusion are shown in Fig. 8. It should be noted that of the 9 classes represented, only 2 (tetracycline and chloramphenicol) are natural products, while the rest are synthetics. Thus, for cytoplasmically targeted, passively diffused Gram-negative organism-active agents, natural products, so far, have no advantage.

Binning compounds in this way should provide a start toward understanding the requirements for entry into the Gramnegative cytoplasm. However, a much larger training set is required for the Gram-negative cytoplasmic bin, and more descriptors must be used. One variable to be considered is charge.
Charge. While $\log P$ is a major determining factor in the uptake of neutral molecules across biological membranes, with ionizable molecules the distribution of charged and uncharged species at physiological $\mathrm{pH}$-which is determined by the $\mathrm{pK}_{\mathrm{a}}(\mathrm{s})$ of the protonatable site(s) of the molecule - takes on importance. Weak acids and bases will have a significant neutral species at $\mathrm{pH} 7.4$, and that species will freely diffuse through the membrane, depending on its degree of lipophilicity, according to Fick's first law of diffusion. The clog $D_{7.4}$ takes charge distribution into account. The lipophilicity (and thus the rate of diffusion) of charged molecules is around 1,000-fold less than that of uncharged molecules $(287,366)$, so their partitioning into the membrane is usually discounted. They can, however, traverse the cytoplasmic membrane, driven by the electrochemical potential (proton motive force [PMF]) of biological membranes (366).

Recent modeling studies by Trapp and coauthors have approached the flux of neutral and ionic compounds into plants and animal cells and organelles by using a dynamic cell model based on the "Fick-Nernst-Planck" equation (a combination of Fick's first law and the Nernst-Planck equation describing the electrochemical potential) (162, 365-367). Adapting and enhancing this model, Zarfl and colleagues simulated accumulation in cells of a group of antibacterial sulfonamides based on various assumptions about the permeating capability of the anionic species of the compounds (402). Since the anionic species of the sulfonamides is the one thought to inhibit the target enzyme, dihydropteroate synthase, MICs should indicate the net accumulation of that species. The model for overall accumulation of the intracellular anion based on the expected distribution of microspecies at internal and external $\mathrm{pHs}$ agreed well with the MICs. Unfortunately, not enough compounds showed any sensitivity to the permeability assumptions for anion diffusion to determine their validity. Nevertheless, the dynamic models of Trapp, Zarfl, and their colleagues 
A<smiles>CN(C)C1C(O)=C(C(N)=O)C(=O)C2(O)C(O)=C3C(=O)c4c(O)cccc4C(C)(O)C3CC12</smiles>

C<smiles>O=C(O)C1CN(C2CC2)c2cc(N3CCNCC3)c(F)cc2C1=O</smiles>

F<smiles>O=C(CC(CO)C(O)c1ccc([N+](=O)[O-])c(O)c1)C(Cl)Cl</smiles>

H<smiles>Nc1ccc(S(=O)(=O)Nc2ccon2)cc1O</smiles>

B<smiles>COc1cc(Cc2cnc(N)nc2N)cc(OC)c1OC</smiles>

D<smiles>O=C1CN(/N=C/c2ccc([N+](=O)[O-])o2)C(=O)N1</smiles>

E<smiles>O=[N+]([O-])c1cncn1CCO</smiles>

G<smiles>CCCc1cc(C2=N[C@@H](C(=O)NO)CO2)cc(OC)c1OC</smiles>

I<smiles>NCC1OB(O)c2cccc(F)c21</smiles>

FIG. 8. Compounds that passively diffuse into the Gram-negative cytoplasm. (A) Tetracycline; (B) trimethoprim; (C) ciprofloxacin; (D) nitrofurantoin; (E) metronidazole; (F) chloramphenicol; (G) L-161,240 (inhibitor of LpxC); (H) sulfamethoxazole; (I) ABX (inhibitor of LeuRS).

seem an excellent starting point for further analysis of the uptake of ionizable antibacterials.

Methods for expanding the database. There are a limited number of marketed classes of antibacterials that accumulate in the Gram-negative cytoplasm. More Gram-negative organism-specific antibacterial classes can be gleaned from the literature, but that requires assurance that such compounds actually reach the cytoplasm and are not antibacterial through action outside it. With a given series of cytoplasmic enzyme inhibitors showing some antibacterial activity against $E$. coli (or $P$. aeruginosa), it would be possible to measure the enzyme inhibition and MIC on wild-type and isogenic tolC and LPSdeficient (lpxC or lptD [imp]) strains to develop quantifiable biological parameters (ratios of each $\mathrm{MIC}$ to the enzyme $\mathrm{IC}_{50}$ ) that may be related to physicochemical parameters of the compounds. Demanding enzyme inhibition without secondary (possibly extracytoplasmic) effects with a modicum of activity against $E$. coli limits starting materials for such a study. A more broadly applicable goal is to measure intracellular accumulation in cells of compounds with no biological activity. For example, a recent paper explored methods for measuring accumulation of ciprofloxacin in the cytoplasm of wild-type and efflux-deficient $P$. aeruginosa (60) and validated (at least for ciprofloxacin) a liquid chromatography-mass spectrometry (LC-MS) method for doing so. It should be noted that net accumulation of compounds will most likely be influenced by the presence of an intracellular binding sink, for which a spe- cific target may play a role. Thus, activity-blind measurement of accumulation will have some drawbacks.

\section{Dealing with Efflux}

It is not clear whether the binding characteristics of effluxed compounds will be related to their structure or their distribution of hydrophobic (and hydrophilic) regions. With mechanisms for measuring accumulation in the cytoplasm without demanding antibacterial activity, it might be possible to empirically establish characteristics that avoid efflux. Perhaps the overall higher charge of Gram-negative agents-including those acting in the periplasm-is "due" to the requirement for charged hydrophilic species both for porin entry and to avoid the hydrophobicity required for efflux. For agents acting in the cytoplasm, polarity is less extreme, and a membrane-permeant species, preferentially neutral but possibly weakly charged, is required.

It may be that there are no widely applicable rules for entering the CM of $P$. aeruginosa, as efflux pumps play a major role in intrinsic and endogenous resistance. In that case, efflux pump inhibitors (EPIs) would be highly desirable. There have been attempts at finding developable inhibitors of the RND efflux pumps of $P$. aeruginosa $(218,228,286)$. Workers at Microcide, in a program partnered with Daiichi, described MC-201,101, which showed good in vivo efficacy but was not developed due to toxicity (218). The program continued at 
Mpex, and an Mpex inhibitor, MP-601,205, was reported to be in phase II trials in combination with ciprofloxacin in an aerosolized formulation for treatment of cystic fibrosis exacerbations (218), but no results have appeared. The structure of MP-601,205 has not been disclosed specifically, but it is covered in a patent (with many structural classes) for use in combinations for ophthalmic and otic diseases. Mpex is now partnered with GSK for the EPI program. An interesting finding that warrants further study in light of the modeling experiments on drug binding sites within AcrB described above is the identification of trimethoprim as a pump-dependent synergist of antibiotics and a fluorescent dye in a screen for EPIs of AcrB (299).

\section{A BRIEF PRESCRIPTION FOR NATURAL PRODUCT SCREENING}

As noted above, the prime requirement for screening natural products is to find novelty. This can be promoted by investigating rare sources and niches, by selective isolation methods, or by cultivating previously "uncultivable" organisms $(21,180$, $210)$. But even rare organisms are likely to produce a large majority of previously seen compounds. Thus, the screening paradigm should focus on methods of seeing what had previously not been seen. This can be accomplished by use of wholecell screens designed to detect activities at levels below the MIC. Such hypersensitive screens have been used successfully to detect novel activities, although none has as yet led to a development candidate. As described above, a screen in which upregulation of an antisense RNA complementary to a specific gene hypersensitized the strain to inhibitors of that gene product (inhibited growth at concentrations below the normal MIC) was used to discover the FabF inhibitors platensimycin and platencin in fermentation broths of Streptomyces platensis, a standard actinomycete (399). While a single hypersensitization screen ostensibly is narrowly targeted, an array of such screens can be run in parallel. In "reporter" screens, a reporter gene, such as the green fluorescent protein gene, the $\beta$-galactosidase gene, or the lux operon, is placed under the control of a promoter which will be induced in response to specific stressors or the inhibition of a specific gene product. Such screens are generally run at sub-MIC levels, since total inhibition would likely inhibit reporter expression as well. One set of useful reporter strains was described by Urban and coworkers, who identified five promoters that responded to inhibition of the five major pathways of macromolecular synthesis (371). Synergy screens, such as the one described above for synergy of a carbapenem against MRSA (166), can find inhibitors at levels below that which would show frank inhibition of growth. Hence, all of these hypersensitized screens should be useful in finding potent but otherwise overlooked activities among natural products.

\section{CONCLUSIONS}

It appears that although rational, target-based screening has produced hits and leads (despite the questionable quality of some chemical libraries), none have yet been developed. The few that have entered clinical trials have not yet exited successfully. It is tempting to return to the days of "irrational" screening! The main thrusts of this review have been 2-fold, that the emphasis on finding inhibitors of novel, underexploited single-enzyme targets may be a "catch 22" that has occupied the greater part of the antibacterial discovery effort, to the detriment of other avenues, and that the chemical collections available for screening are less than optimal for antibacterial agents. On top of these antibacterial-specific problems are the standard, and considerable, pharmacological problems involved in the development of all types of drugs for human therapy.

The target problem is due mainly to the prospectively untested, but thus far reasonably well supported, hypothesis that single-target inhibitors will fall prey to rapid resistance development upon entry into clinical use. It may be that reduced fitness of resistant mutants will so compromise their survival that any such resistant clones will be lost rapidly from the population in the absence of selection. However, minimization of the possible portents of in vitro resistance frequencies is probably unwise due to the possibility that compensatory mutation will arise to restore fitness. The Pdf and FabI inhibitors that might have tested the hypothesis have not and may never pass phase I trials. Novel agents should be tested in standardized animal models to see whether resistance and compensatory mutations arise in predictable ways in vivo. Perhaps there is a chance that 50 of 100 such agents will not fall to resistance in such models, giving impetus to proceed with programs that may have been deprioritized due to in vitro resistance concerns. This seems unlikely, but the experiment is important.

"Multitargets" have also been pursued, although the number of these is rather limited; however, recent strides that have been made toward predicting polypharmacology should be applicable to identification of more bacterial multitargets. A variety of gyrase/topoisomerase IV inhibitors have been reported that show promise but have not yet reached development. They are almost all directed toward Gram-positive organisms. It may be that the spectrum has limited their development: perhaps the perception in marketing departments is that the need for Gram-positive organism-specific drugs has waned or that in future there would be regulatory problems for drugs where there is not a clear clinical need. What is clear is that there is a need for drugs targeted toward Gram-negative organisms, especially the multidrug-resistant strains. Industry and academe are quite aware of this, but finding such agents is very hard.

This underlines the chemical challenges to antibacterial discovery. Chemical libraries, and even natural products, do not have a wealth of interesting compounds that show novel activity against Gram-negative organisms. It seems that an attempt to derive rules for Gram-negative entry and to endow chemical libraries with those qualities can provide one avenue toward solving the problem. Rather than optimization of one compound class at a time, information could be pooled usefully and the database expanded. Unfortunately, there has not been much support (or interest?) by either academe or industry for such an endeavor. A collaborative approach with government or nonprofit funding might be undertaken. Efflux could be addressed by similar recognition of the structural and physicochemical bases of efflux pumps and by use of pump inhibitors. The general problem of "improper" chemical diversity in chemical libraries, with a predominance of lytic, promiscuous, and unleadlike compounds, must be addressed. Even a micro- 
biologist such as myself can see the "ugliness" of many of the compounds that have turned up by screening, although that quality has not been emphasized here for the sake of politeness. If chemical libraries can be improved by removing interfering compounds, increasing diversity, and incorporating rules for bacterial cell entry (especially for Gram-negative organisms), then whole-cell phenotypic or even empirical screening might again be productive (as it was with nalidixic acid and the oxazolidinones). Rather than screening with a small set of targets, library screening might be approached with arrays of targets, as suggested above for natural product screening. Rational SBDD approaches can use virtual libraries for in silico screening and thereby limit false-positive results. Such rational methods could be applied to existing multitargets and those still to be defined by bioinformatic techniques. Finally, natural products should not be left out of the equation. Judiciously attacked, they should once again provide for serendipitous "irrationality."

\section{REFERENCES}

1. Ackermann, B. L., B. T. Regg, L. Colombo, S. Stella, and J. E. Coutan. 1996 Rapid analysis of antibiotic-containing mixtures from fermentation broths by using liquid chromatography-electrospray ionization-mass spectrometry and matrix-assisted laser desorption ionization-time-of-flight-mass spectrometry. J. Am. Soc. Mass Spectrom. 7:1227-1237.

2. Adamek, R. J., S. Suerbaum, B. Pfaffenbach, and W. Opferkuch. 1998. Primary and acquired Helicobacter pylori resistance to clarithromycin, metronidazole, and amoxicillin-influence on treatment outcome. Am. J. Gastroenterol. 93:386-389.

3. Agarwal, A., S. Louise-May, J. A. Thanassi, S. D. Podos, J. Cheng, C. Thoma, C. Liu, J. A. Wiles, D. M. Nelson, A. S. Phadke, B. J. Bradbury, M. S. Deshpande, and M. J. Pucci. 2007. Small molecule inhibitors of E. coli primase, a novel bacterial target. Bioorg. Med. Chem. Lett. 17:2807-2810.

4. Ali, A., G. E. Taylor, K. Ellsworth, G. Harris, R. Painter, L. L. Silver, and K. Young. 2003. Novel pyrazolo[3,4-d]pyrimidine-based inhibitors of Staphylococcus aureus DNA polymerase III: design, synthesis, and biological evaluation. J. Med. Chem. 46:1824-1830.

5. Allen, N. E. 2010. From vancomycin to oritavancin: the discovery and development of a novel lipoglycopeptide antibiotic. Anti Infect. Agents Med. Chem. 9:23-47.

6. Allsop, A. E. 1998. New antibiotic discovery, novel screens, novel targets and impact of microbial genomics. Curr. Opin. Microbiol. 1:530-534.

7. Anderle, C., M. Stieger, M. Burrell, S. Reinelt, A. Maxwell, M. Page, and L. Heide. 2008. Biological activities of novel gyrase inhibitors of the aminocoumarin class. Antimicrob. Agents Chemother. 52:1982-1990.

8. Andersson, D. I. 2006. The biological cost of mutational antibiotic resistance: any practical conclusions? Curr. Opin. Microbiol. 9:461-465.

9. Andersson, D. I., and B. R. Levin. 1999. The biological cost of antibiotic resistance. Curr. Opin. Microbiol. 2:489-493.

10. Andre, E., L. Bastide, S. Michaux-Charachon, A. Gouby, P. Villain-Guillot, J. Latouche, A. Bouchet, M. Gualtieri, and J. P. Leonetti. 2006. Novel synthetic molecules targeting the bacterial RNA polymerase assembly. J. Antimicrob. Chemother. 57:245-251.

11. Andres, C. J., J. J. Bronson, S. V. D'Andrea, M. S. Deshpande, P. J. Falk, K. A. Grant-Young, W. E. Harte, H. T. Ho, P. F. Misco, J. G. Robertson, D. Stock, Y. Sun, and A. W. Walsh. 2000. 4-Thiazolidinones: novel inhibitors of the bacterial enzyme MurB. Bioorg. Med. Chem. Lett. 10:715-717.

12. Antane, S., C. E. Caufield, W. Hu, D. Keeney, P. Labthavikul, K. Morris, S. M. Naughton, P. J. Petersen, B. A. Rasmussen, G. Singh, and Y. Yang 2006. Pulvinones as bacterial cell wall biosynthesis inhibitors. Bioorg. Med. Chem. Lett. 16:176-180.

13. Apfel, C. M., H. Locher, S. Evers, B. Takacs, C. Hubschwerlen, W. Pirson, M. G. P. Page, and W. Keck. 2001. Peptide deformylase as an antibacteria drug target: target validation and resistance development. Antimicrob. Agents Chemother. 45:1058-1064.

14. Arhin, F., O. Belanger, S. Ciblat, M. Dehbi, D. Delorme, E. Dietrich, D. Dixit, Y. Lafontaine, D. Lehoux, J. Liu, G. A. McKay, G. Moeck, R. Reddy, Y. Rose, R. Srikumar, K. S. Tanaka, D. M. Williams, P. Gros, J. Pelletier, T. R. Parr, Jr., and A. R. Far. 2006. A new class of small molecule RNA polymerase inhibitors with activity against rifampicin-resistant Staphylococcus aureus. Bioorg. Med. Chem. 14:5812-5832.

15. Artsimovitch, I., C. Chu, A. S. Lynch, and R. Landick. 2003. A new class of bacterial RNA polymerase inhibitor affects nucleotide addition. Science 302:650-654.

16. Athanasellis, G., O. Igglessi-Markopoulou, and J. Markopoulos. 2010. Tet- ramic and tetronic acids as scaffolds in bioinorganic and bioorganic chemistry. Bioinorg. Chem. Appl. [Epub ahead of print.] doi:10.1155/2010/ 315056.

17. Aubry-Damon, H., C.-J. Soussy, and P. Courvalin. 1998. Characterization of mutations in the rpoB gene that confer rifampin resistance in Staphylococcus aureus. Antimicrob. Agents Chemother. 42:2590-2594.

18. Baell, J. B., and G. A. Holloway. 2010. New substructure filters for removal of pan assay interference compounds (PAINS) from screening libraries and for their exclusion in bioassays. J. Med. Chem. 53:2719-2740.

19. Bajorath, J. 2008. Computational analysis of ligand relationships within target families. Curr. Opin. Chem. Biol. 12:352-358.

20. Balemans, W., N. Lounis, R. Gilissen, J. Guillemont, K. Simmen, K. Andries, and A. Koul. 2010. Essentiality of FASII pathway for Staphylococcus aureus. Nature 463:E3.

21. Baltz, R. 2006. Marcel Faber Roundtable: is our antibiotic pipeline unproductive because of starvation, constipation or lack of inspiration? J. Ind Microbiol. Biotechnol. 33:507-513.

22. Baltz, R. H. 2005. Antibiotic discovery from Actinomycetes: will a renaissance follow the decline and fall. SIM News 55:186-196.

23. Bandow, J. E., H. Brotz, L. I. Leichert, H. Labischinski, and M. Hecker. 2003. Proteomic approach to understanding antibiotic action. Antimicrob. Agents Chemother. 47:948-955.

24. Bandow, J. E., and M. Hecker. 2007. Proteomic profiling of cellular stresses in Bacillus subtilis reveals cellular networks and assists in elucidating antibiotic mechanisms of action. Prog. Drug Res. 64:79, 81-101.

25. Barb, A. W., T. M. Leavy, L. I. Robins, Z. Guan, D. A. Six, P. Zhou, M. J. Hangauer, C. R. Bertozzi, and C. R. Raetz. 2009. Uridine-based inhibitors as new leads for antibiotics targeting Escherichia coli LpxC. Biochemistry 48:3068-3077.

26. Barb, A. W., A. L. McClerren, K. Snehelatha, C. M. Reynolds, P. Zhou, and C. R. Raetz. 2007. Inhibition of lipid A biosynthesis as the primary mechanism of CHIR-090 antibiotic activity in Escherichia coli. Biochemistry 46:3793-3802.

27. Barbachyn, M. R., and E. M. John. 2008. Recent advances in the discovery of hybrid antibacterial agents. Annu. Rep. Med. Chem. 43:281-290.

28. Barbosa, M. D., G. Yang, J. Fang, M. G. Kurilla, and D. L. Pompliano. 2002. Development of a whole-cell assay for peptidoglycan biosynthesis inhibitors. Antimicrob. Agents Chemother. 46:943-946.

29. Barker, J. J. 2006. Antibacterial drug discovery and structure-based design. Drug Discov. Today 11:391-404.

30. Baum, E. Z., S. M. Crespo-Carbone, D. Abbanat, B. Foleno, A. Maden, R. Goldschmidt, and K. Bush. 2006. Utility of muropeptide ligase for identification of inhibitors of the cell wall biosynthesis enzyme MurF. Antimicrob. Agents Chemother. 50:230-236.

31. Baum, E. Z., S. M. Crespo-Carbone, B. D. Foleno, L. D. Simon, J. Guillemont, M. Macielag, and K. Bush. 2009. MurF inhibitors with antibacterial activity: effect on muropeptide levels. Antimicrob. Agents Chemother. 53: 3240-3247.

32. Baum, E. Z., S. M. Crespo-Carbone, A. Klinger, B. D. Foleno, I. Turchi, M. Macielag, and K. Bush. 2007. A MurF inhibitor that disrupts cell wall biosynthesis in Escherichia coli. Antimicrob. Agents Chemother. 51:44204426.

33. Baum, E. Z., D. A. Montenegro, L. Licata, I. Turchi, G. C. Webb, B. D. Foleno, and K. Bush. 2001. Identification and characterization of new inhibitors of the Escherichia coli MurA enzyme. Antimicrob. Agents Chemother. 45:3182-3188.

34. Beise, F., H. Labischinski, and P. Giesbrecht. 1988. Selective inhibition of penicillin-binding proteins and its effects on growth and architecture of Staphylococcus aureus. FEMS Microbiol. Lett. 55:195-202.

35. Bellon, S., J. D. Parsons, Y. Wei, K. Hayakawa, L. L. Swenson, P. S. Charifson, J. A. Lippke, R. Aldape, and C. H. Gross. 2004. Crystal structures of Escherichia coli topoisomerase IV ParE subunit (24 and 43 kilodaltons): a single residue dictates differences in novobiocin potency against topoisomerase IV and DNA gyrase. Antimicrob. Agents Chemother. 48: $1856-1864$.

36. Bercovier, H., O. Kafri, and S. Sela. 1986. Mycobacteria possess a surprisingly small number of ribosomal RNA genes in relation to the size of their genome. Biochem. Biophys. Res. Commun. 136:1136-1141.

37. Beuria, T. K., M. K. Santra, and D. Panda. 2005. Sanguinarine blocks cytokinesis in bacteria by inhibiting FtsZ assembly and bundling. Biochemistry 44:16584-16593.

38. Beyer, D., H. P. Kroll, R. Endermann, G. Schiffer, S. Siegel, M. Bauser, J. Pohlmann, M. Brands, K. Ziegelbauer, D. Haebich, C. Eymann, and H. Brotz-Oesterhelt. 2004. New class of bacterial phenylalanyl-tRNA synthetase inhibitors with high potency and broad-spectrum activity. Antimicrob. Agents Chemother. 48:525-532.

39. Bjorkman, J., I. Nagaev, O. G. Berg, D. Hughes, and D. I. Andersson. 2000. Effects of environment on compensatory mutations to ameliorate costs of antibiotic resistance. Science 287:1479-1482.

40. Black, M. T., T. Stachyra, D. Platel, A. M. Girard, M. Claudon, J. M. Bruneau, and C. Miossec. 2008. Mechanism of action of the antibiotic 
NXL101, a novel nonfluoroquinolone inhibitor of bacterial type II topoisomerases. Antimicrob. Agents Chemother. 52:3339-3349.

41. Blair, J. M., and L. J. Piddock. 2009. Structure, function and inhibition of RND efflux pumps in Gram-negative bacteria: an update. Curr. Opin. Microbiol. 12:512-519.

42. Bradbury, B. J., and M. J. Pucci. 2008. Recent advances in bacterial topoisomerase inhibitors. Curr. Opin. Pharmacol. 8:574-581.

43. Bremner, J. B., J. I. Ambrus, and S. Samosorn. 2007. Dual action-based approaches to antibacterial agents. Curr. Med. Chem. 14:1459-1477.

44. Breukink, E., and B. de Kruijff. 2006. Lipid II as a target for antibiotics. Nat. Rev. Drug Discov. 5:321-323.

45. Brickner, S. J., D. K. Hutchinson, M. R. Barbachyn, P. R. Manninen, D. A Ulanowicz, S. A. Garmon, K. C. Grega, S. K. Hendges, D. S. Toops, C. W. Ford, and G. E. Zurenko. 1996. Synthesis and antibacterial activity of U-100592 and U-100766, two oxazolidinone antibacterial agents for the potential treatment of multidrug-resistant Gram-positive bacterial infections. J. Med. Chem. 39:673-679.

46. Brinster, S., G. Lamberet, B. Staels, P. Trieu-Cuot, A. Gruss, and C Poyart. 2009. Type II fatty acid synthesis is not a suitable antibiotic target for Gram-positive pathogens. Nature 458:83-86.

47. Brinster, S., G. Lamberet, B. Staels, P. Trieu-Cuot, A. Gruss, and C. Poyart. 2010. Letter. Nature 463:E4.

48. Bronson, J. J., K. L. DenBleyker, P. J. Falk, R. A. Mate, H. T. Ho, M. J. Pucci, and L. B. Snyder. 2003. Discovery of the first antibacterial small molecule inhibitors of MurB. Bioorg. Med. Chem. Lett. 13:873-875.

49. Brötz-Oesterhelt, H., J. E. Bandow, and H. Labischinski. 2005. Bacterial proteomics and its role in antibacterial drug discovery. Mass. Spectrom. Rev. 24:549-565.

50. Brötz-Oesterhelt, H., and N. A. Brunner. 2008. How many modes of action should an antibiotic have? Curr. Opin. Pharmacol. 8:564-573.

51. Brown, A. K., R. C. Taylor, A. Bhatt, K. Fatterer, and G. S. Besra. 2009 Platensimycin activity against mycobacterial $\beta$-ketoacyl-ACP synthases. PLoS One 4:e6306.

52. Brown, D. W. 2010. The evolution of a fosfomycin resistance enzyme, FosA, from $P$. aeruginosa and the development of a high throughput screen for the discovery of bioactive inhibitors. Ph.D. thesis. Vanderbilt University, Nashville, TN.

53. Brown, G. M. 1962. The biosynthesis of folic acid. II. Inhibition by sulfonamides. J. Biol. Chem. 237:536-540.

54. Bryan, L. E. 1989. Two forms of antimicrobial resistance: bacterial persistence and positive function resistance. J. Antimicrob. Chemother. 23:817820 .

55. Bukanov, N. O., and D. E. Berg. 1994. Ordered cosmid library and highresolution physical-genetic map of Helicobacter pylori strain NCTC11638 Mol. Microbiol. 11:509-523.

56. Burke, M. D., E. M. Berger, and S. L. Schreiber. 2003. Generating diverse skeletons of small molecules combinatorially. Science 302:613-618.

57. Bushby, S. R., and G. H. Hitchings. 1968. Trimethoprim, a sulphonamide potentiator. Br. J. Pharmacol. Chemother. 33:72-90.

58. Butler, M. M., W. A. LaMarr, K. A. Foster, M. H. Barnes, D. J. Skow, P. T. Lyden, L. M. Kustigian, C. Zhi, N. C. Brown, G. E. Wright, and T. L. Bowlin. 2007. Antibacterial activity and mechanism of action of a nove anilinouracil:fluoroquinolone hybrid compound. Antimicrob. Agents Chemother. 51:119-127.

59. Butler, M. M., D. J. Skow, R. O. Stephenson, P. T. Lyden, W. A. LaMarr, and K. A. Foster. 2002. Low frequencies of resistance among Staphylococ cus and Enterococcus species to the bactericidal DNA polymerase inhibitor $N$ (3)-hydroxybutyl 6-(3'-ethyl-4'-methylanilino) uracil. Antimicrob. Agents Chemother. 46:3770-3775.

60. Cai, H., K. Rose, L. H. Liang, S. Dunham, and C. Stover. 2009. Development of a liquid chromatography/mass spectrometry-based drug accumulation assay in Pseudomonas aeruginosa. Anal. Biochem. 385:321-325.

61. Cassell, G. H., and J. Mekalanos. 2001. Development of antimicrobial agents in the era of new and reemerging infectious diseases and increasing antibiotic resistance. JAMA 285:601-605.

62. Chang, S. Y., E. C. McGary, and S. Chang. 1989. Methionine aminopeptidase gene of Escherichia coli is essential for cell growth. J. Bacteriol 171:4071-4072

63. Charifson, P. S., A. L. Grillot, T. H. Grossman, J. D. Parsons, M. Badia, S. Bellon, D. D. Deininger, J. E. Drumm, C. H. Gross, A. LeTiran, Y. Liao, N. Mani, D. P. Nicolau, E. Perola, S. Ronkin, D. Shannon, L. L. Swenson, Q. Tang, P. R. Tessier, S. K. Tian, M. Trudeau, T. Wang, Y. Wei, H. Zhang, and D. Stamos. 2008. Novel dual-targeting benzimidazole urea inhibitors of DNA gyrase and topoisomerase IV possessing potent antibacterial activity: intelligent design and evolution through the judicious use of structureguided design and structure-activity relationships. J. Med. Chem. 51:52435263.

64. Charifson, P. S., T. H. Grossman, and P. Mueller. 2009. The use of structure-guided design to discover new anti-microbial agents: focus on antibacterial resistance. Anti Infect. Med. Chem. 8:73-86.

65. Chen, C. R., M. Malik, M. Snyder, and K. Drlica. 1996. DNA gyrase and topoisomerase IV on the bacterial chromosome: quinolone-induced DNA cleavage. J. Mol. Biol. 258:627-637.

66. Chen, D., C. Hackbarth, Z. J. Ni, C. Wu, W. Wang, R. Jain, Y. He, K Bracken, B. Weidmann, D. V. Patel, J. Trias, R. J. White, and Z. Yuan. 2004. Peptide deformylase inhibitors as antibacterial agents: identification of VRC3375, a proline-3-alkylsuccinyl hydroxamate derivative, by using an integrated combinatorial and medicinal chemistry approach. Antimicrob. Agents Chemother. 48:250-261.

67. Chen, D., C. Rosenow, J. Trias, R. J. White, and Z. Yuan. 1998. Pathway screening: novel technology for identifying inhibitors of MurA-F in a single incubation, abstr. 273. Abstr. 38th Intersci. Conf. Antimicrob. Agents Che mother., San Diego, CA. American Society for Microbiology, Washington, DC

68. Chen, D. Z., D. V. Patel, C. J. Hackbarth, W. Wang, G. Dreyer, D. C. Young, P. S. Margolis, C. Wu, Z. J. Ni, J. Trias, R. J. White, and Z. Yuan. 2000 Actinonin, a naturally occurring antibacterial agent, is a potent deformylase inhibitor. Biochemistry 39:1256-1262.

69. Cheng, J., J. A. Thanassi, C. L. Thoma, B. J. Bradbury, M. Deshpande, and M. J. Pucci. 2007. Dual targeting of DNA gyrase and topoisomerase IV: target interactions of heteroaryl isothiazolones in Staphylococcus aureus. Antimicrob. Agents Chemother. 51:2445-2453.

70. Cheng, L., T. A. Naumann, A. R. Horswill, S.-J. Hong, B. J. Venters, J. W. Tomsho, S. J. Benkovic, and K. C. Keiler. 2007. Discovery of antibacteria cyclic peptides that inhibit the ClpXP protease. Protein Sci. 16:1535-1542.

71. Chopra, I. 2000. New drugs for the superbugs. Microbiol. Today 27:4-6.

72. Chopra, I. 2007. Bacterial RNA polymerase: a promising target for the discovery of new antimicrobial agents. Curr. Opin. Invest. Drugs 8:600-607.

73. Chopra, I., L. Hesse, and A. J. O'Neill. 2002. Exploiting current understanding of antibiotic action for discovery of new drugs. J. Appl. Microbiol. 92:4S-15S.

74. Choudhry, A. E., T. L. Mandichak, J. P. Broskey, R. W. Egolf, C. Kinsland, T. P. Begley, M. A. Seefeld, T. W. Ku, J. R. Brown, M. Zalacain, and K. Ratnam. 2003. Inhibitors of pantothenate kinase: novel antibiotics for staphylococcal infections. Antimicrob. Agents Chemother. 47:2051-2055.

75. Clements, J. M., R. P. Beckett, A. Brown, G. Catlin, M. Lobell, S. Palan, W Thomas, M. Whittaker, S. Wood, S. Salama, P. J. Baker, H. F. Rodgers, V. Barynin, D. W. Rice, and M. G. Hunter. 2001. Antibiotic activity and characterization of BB-3497, a novel peptide deformylase inhibitor. Antimicrob. Agents Chemother. 45:563-570.

76. Clements, J. M., F. Coignard, I. Johnson, S. Chandler, S. Palan, A. Waller, J. Wijkmans, and M. G. Hunter. 2002. Antibacterial activities and characterization of novel inhibitors of LpxC. Antimicrob. Agents Chemother. 46:1793-1799.

77. Cohen, S. S. 1977. A strategy for the chemotherapy of infectious disease. Science 197:431-432.

78. Courvalin, P. 2008. Predictable and unpredictable evolution of antibiotic resistance. J. Intern. Med. 264:4-16.

79. Crute, J., I. Lehman, J. Gambino, T.-F. Yang, P. Medveczky, M. Medveczky, N. Khan, C. Mulder, J. Monroe, and G. Wright. 1995. Inhibition of herpes simplex virus type 1 helicase-primase by (dichloroanilino) purines and pyrimidines. J. Med. Chem. 38:1820-1825.

80. Cuny, G. D. 2009. A new class of UDP-3- $O$-( $R$-3-hydroxymyristol)- $N$-acetylglucosamine deacetylase (LpxC) inhibitors for the treatment of Gramnegative infections: PCT application WO 2008027466. Expert Opin. Ther Pat. 19:893-899.

81. Czaplewski, L. G., I. Collins, E. A. Boyd, D. Brown, S. P. East, M. Gardiner, R. Fletcher, D. J. Haydon, V. Henstock, P. Ingram, C. Jones, C. Noula, L. Kennison, C. Rockley, V. Rose, H. B. Thomaides-Brears, R. Ure, M. Whittaker, and N. R. Stokes. 2009. Antibacterial alkoxybenzamide inhibitors of the essential bacterial cell division protein FtsZ. Bioorg. Med. Chem. Lett. 19:524-527.

82. Davies, J. 1994. Inactivation of antibiotics and the dissemination of resistance genes. Science 264:375-382.

83. Davies, J. 2006. Are antibiotics naturally antibiotics? J. Ind. Microbiol. Biotechnol. 33:496-499.

84. D'Costa, V. M., E. Griffiths, and G. D. Wright. 2007. Expanding the soil antibiotic resistome: exploring environmental diversity. Curr. Opin. Microbiol. 10:481-489.

85. D'Costa, V. M., K. M. McGrann, D. W. Hughes, and G. D. Wright. 2006 Sampling the antibiotic resistome. Science 311:374-377.

86. Debono, M., M. Barnhart, C. B. Carrell, J. A. Hoffmann, J. L. Occolowitz B. J. Abbott, D. S. Fukuda, R. L. Hamill, K. Biemann, and W. C. Herlihy 1987. A21978C, a complex of new acidic peptide antibiotics: isolation, chemistry, and mass spectral structure elucidation. J. Antibiot. (Tokyo) 40:761-777.

87. de Carvalho, L. P. S., G. Lin, X. Jiang, and C. Nathan. 2009. Nitazoxanide kills replicating and nonreplicating Mycobacterium tuberculosis and evades resistance. J. Med. Chem. 52:5789-5792.

88. de Dios, A., L. Prieto, J. A. Martin, A. Rubio, J. Ezquerra, M. Tebbe, B Lopez de Uralde, J. Martin, A. Sanchez, D. L. LeTourneau, J. E. McGee, C. Boylan, T. R. Parr, and M. C. Smith. 2002. 4-Substituted D-glutamic acid 
analogues: the first potent inhibitors of glutamate racemase (MurI) enzyme with antibacterial activity. J. Med. Chem. 45:4559-4570.

89. de Jonge, B. L. M., A. Kutschke, M. Uria-Nickelsen, H. D. Kamp, and S. D. Mills. 2009. Pyrazolopyrimidinediones are selective agents for Helicobacter pylori that suppress growth through inhibition of glutamate racemase (MurI). Antimicrob. Agents Chemother. 53:3331-3336.

90. De La Fuente, R., N. D. Sonawane, D. Arumainayagam, and A. S. Verkman. 2006. Small molecules with antimicrobial activity against $E$. coli and $P$. aeruginosa identified by high-throughput screening. Br. J. Pharmacol. 149: 551-559.

91. Demain, A. L., and A. Fang. 2000. The natural functions of secondary metabolites. Adv. Biochem. Eng. Biotechnol. 69:1-39.

92. Denis, A., F. Faivre, Y. Bonvin, V. Gerusz, S. Briet, N. Desroy, M. Oxoby, C. Soulama, S. Floquet, J. Genevard, C. Oliveira, F. Moreau, and S. Escaich. 2008. Design, synthesis and antibacterial properties of new poten aryloxy-phenol FabI inhibitors, abstr. F1-330. Abstr. 48th Intersci. Conf. Antimicrob. Agents Chemother., Washington, DC. American Society for Microbiology, Washington, DC

93. Denome, S. A., P. K. Elf, T. A. Henderson, D. E. Nelson, and K. D. Young 1999. Escherichia coli mutants lacking all possible combinations of eight penicillin binding proteins: viability, characteristics, and implications for peptidoglycan synthesis. J. Bacteriol. 181:3981-3993.

94. Devasahayam, G., W. M. Scheld, and P. S. Hoffman. 2010. Newer antibacterial drugs for a new century. Expert Opin. Invest. Drugs 19:215-234.

95. DeVito, J. A., J. A. Mills, V. G. Liu, A. Agarwal, C. F. Sizemore, Z. Yao, D. M. Stoughton, M. G. Cappiello, M. D. Barbosa, L. A. Foster, and D. L. Pompliano. 2002. An array of target-specific screening strains for antibacterial discovery. Nat. Biotechnol. 20:478-483.

96. Donald, R. G., S. Skwish, R. A. Forsyth, J. W. Anderson, T. Zhong, C Burns, S. Lee, X. Meng, L. LoCastro, L. W. Jarantow, J. Martin, S. H. Lee, I. Taylor, D. Robbins, C. Malone, L. Wang, C. S. Zamudio, P. J. Youngman, and J. W. Phillips. 2009. A Staphylococcus aureus fitness test platform for mechanism-based profiling of antibacterial compounds. Chem. Biol. 16: $826-836$.

97. Douthwaite, S. 2001. Structure-activity relationships of ketolides vs. macrolides. Clin. Microbiol. Infect. 7:11-17.

98. Drlica, K. 2001. A strategy for fighting antibiotic resistance. ASM News 67:27-33.

99. Drusano, G. L., A. Louie, M. Deziel, and T. Gumbo. 2006. The crisis of resistance: identifying drug exposures to suppress amplification of resistant mutant subpopulations. Clin. Infect. Dis. 42:525-532.

100. Dubrac, S., and T. Msadek. 2008. Tearing down the wall: peptidoglycan metabolism and the WalK/WalR (YycG/YycF) essential two-component system, p. 214-228. In R. Utsumi (ed.), Bacterial signal transduction: networks and drug targets. Springer, New York, NY.

101. Durrant, J. D., R. E. Amaro, L. Xie, M. D. Urbaniak, M. A. J. Ferguson, A Haapalainen, Z. Chen, A. M. Di Guilmi, F. Wunder, P. E. Bourne, and J. A McCammon. 2010. A multidimensional strategy to detect polypharmacological targets in the absence of structural and sequence homology. PLoS Comput. Biol. 6:e1000648.

102. East, S. P., C. B. White, O. Barker, S. Barker, J. Bennett, D. Brown, E. A Boyd, C. Brennan, C. Chowdhury, I. Collins, E. Convers-Reignier, B. W. Dymock, R. Fletcher, D. J. Haydon, M. Gardiner, S. Hatcher, P. Ingram, P. Lancett, P. Mortenson, K. Papadopoulos, C. Smee, H. B. ThomaidesBrears, H. Tye, J. Workman, and L. G. Czaplewski. 2009. DNA gyrase (GyrB)/topoisomerase IV (ParE) inhibitors: synthesis and antibacterial activity. Bioorg. Med. Chem. Lett. 19:894-899.

103. Ehmann, D. E., J. E. Demeritt, K. G. Hull, and S. L. Fisher. 2004. Biochemical characterization of an inhibitor of Escherichia coli UDP- $N$-acetylmuramyl-L-alanine ligase. Biochim. Biophys. Acta 1698:167-174.

104. Elespuru, R. K., and R. J. White. 1983. Biochemical prophage induction assay: a rapid test for antitumor agents that interact with DNA. Cancer Res. 43:2819-2830.

105. El Zoeiby, A., F. Sanschagrin, A. Darveau, J. R. Brisson, and R. C Levesque. 2003. Identification of novel inhibitors of Pseudomonas aeruginosa MurC enzyme derived from phage-displayed peptide libraries. J. Antimicrob. Chemother. 51:531-543.

106. Escaich, S., L. Prouvensier, M. Saccomani, L. Durant, A. Denis, C. Soulama, F. Faivre, Y. Bonvin, V. Gerusz, and M. Oxoby. 2008. MUT37307 FabI inhibitor: in vitro and in vivo antibacterial activity against $S$. aureus, abstr. F1-333. Abstr. 48th Intersci. Conf. Antimicrob. Agents Chemother., Washington, DC. American Society for Microbiology, Washington, DC.

107. Eschenburg, S., M. A. Priestman, F. A. Abdul-Latif, C. Delachaume, F Fassy, and E. Schonbrunn. 2005. A novel inhibitor that suspends the induced fit mechanism of UDP- $N$-acetylglucosamine enolpyruvyl transferase (MurA). J. Biol. Chem. 280:14070-14075

108. Esposito, M., R. Stettler, S. L. Moores, C. Pidathala, N. Muller, A. Stachulski, N. G. Berry, J.-F. Rossignol, and A. Hemphill. 2005. In vitro efficacies of nitazoxanide and other thiazolides against Neospora caninum tachyzoites reveal antiparasitic activity independent of the nitro group. Antimicrob. Agents Chemother. 49:3715-3723.

109. Evdokimov, A., M. Pokross, R. L. Walter, M. Mekel, B. L. Barnett, J. Am- burgey, W. L. Seibel, S. J. Soper, J. F. Djung, N. Fairweather, C. Diven, V. Rastogi, L. Grinius, C. Klanke, R. Siehnel, T. Twinem, R. Andrews, and A. Curnow. 2007. Serendipitous discovery of novel bacterial methionine aminopeptidase inhibitors. Proteins 66:538-546.

110. Eveland, S. S., D. L. Pompliano, and M. S. Anderson. 1997. Conditionally lethal Escherichia coli murein mutants contain point defects that map to regions conserved among murein and folyl poly- $\gamma$-glutamate ligases: identification of a ligase superfamily. Biochemistry 36:6223-6229.

111. Fernandes, P. 2006. Antibacterial discovery and development-the failure of success? Nat. Biotechnol. 24:1497-1503.

112. Ferrero, L., B. Cameron, B. Manse, D. Lagneaux, J. Crouzet, A. Famechon, and F. Blanche. 1994. Cloning and primary structure of Staphylococcus aureus DNA topoisomerase IV: a primary target of fluoroquinolones. Mol. Microbiol. 13:641-653.

113. Fillgrove, K. L., S. Pakhomova, M. E. Newcomer, and R. N. Armstrong. 2003. Mechanistic diversity of fosfomycin resistance in pathogenic microorganisms. J. Am. Chem. Soc. 125:15730-15731.

114. Finegold, S. M., D. Molitoris, M.-L. Vaisanen, Y. Song, C. Liu, and M. Bolanos. 2004. In vitro activities of OPT-80 and comparator drugs against intestinal bacteria. Antimicrob. Agents Chemother. 48:4898-4902.

115. Fischbach, M. A., and C. T. Walsh. 2009. Antibiotics for emerging pathogens. Science 325:1089-1093.

116. Flatman, R. H., A. Eustaquio, S. M. Li, L. Heide, and A. Maxwell. 2006. Structure-activity relationships of aminocoumarin-type gyrase and topoisomerase IV inhibitors obtained by combinatorial biosynthesis. Antimicrob. Agents Chemother. 50:1136-1142.

117. Flipo, M., J. Charton, A. Hocine, S. Dassonneville, B. Deprez, and R. Deprez-Poulain. 2009. Hydroxamates: relationships between structure and plasma stability. J. Med. Chem. 52:6790-6802.

118. Forsyth, R. A., R. J. Haselbeck, K. L. Ohlsen, R. T. Yamamoto, H. Xu, J. D. Trawick, D. Wall, L. Wang, V. Brown-Driver, J. M. Froelich, G. C. Kedar, P. King, M. McCarthy, C. Malone, B. Misiner, D. Robbins, Z. Tan, Z. Y. Zhu Zy, G. Carr, D. A. Mosca, C. Zamudio, J. G. Foulkes, and J. W. Zyskind. 2002. A genome-wide strategy for the identification of essential genes in Staphylococcus aureus. Mol. Microbiol. 43:1387-1400.

119. Francisco, G. D., Z. Li, J. D. Albright, N. H. Eudy, A. H. Katz, P. J. Petersen, P. Labthavikul, G. Singh, Y. Yang, B. A. Rasmussen, Y. I. Lin, and T. S. Mansour. 2004. Phenyl thiazolyl urea and carbamate derivatives as new inhibitors of bacterial cell-wall biosynthesis. Bioorg. Med. Chem. Lett. 14:235-238.

120. Freiberg, C., N. A. Brunner, G. Schiffer, T. Lampe, J. Pohlmann, M. Brands, M. Raabe, D. Habich, and K. Ziegelbauer. 2004. Identification and characterization of the first class of potent bacterial acetyl-CoA carboxylase inhibitors with antibacterial activity. J. Biol. Chem. 279:26066-26073.

121. Freiberg, C., H. P. Fischer, and N. A. Brunner. 2005. Discovering the mechanism of action of novel antibacterial agents through transcriptional profiling of conditional mutants. Antimicrob. Agents Chemother. 49:749759.

122. Freiberg, C., J. Pohlmann, P. G. Nell, R. Endermann, J. Schuhmacher, B. Newton, M. Otteneder, T. Lampe, D. Habich, and K. Ziegelbauer. 2006. Novel bacterial acetyl coenzyme A carboxylase inhibitors with antibiotic efficacy in vivo. Antimicrob. Agents Chemother. 50:2707-2712.

123. Freund, Y., R. Kimura, S. J. Baker, R. E. Mendes, D. J. Biedenbach, N. L. Simon, P. L. Demarsh, A. O'Leary, and M. R. K. Alley. 2009. In vitro activity and in vivo efficacy of $(S)$-3(aminomethyl)benzo[c][1,2]oxaborol$1(3 \mathrm{H})$-ol hydrochloride compound: a Gram-negative antimicrobial, abstr. F1-1223a. Abstr. 49th Intersci. Conf. Antimicrob. Agents Chemother., San Francisco, CA. American Society for Microbiology, Washington, DC.

124. Fugitt, R., and R. Luckenbaugh. December 1978. 5-Halomethyl-3-phenylu2-oxazolidinones. U.S. patent 4,128,654.

125. Fulmer, T. 2009. Not so FAS. Sci. Bus. Exchange doi:10.1038/scibx.2009.430.

126. Gadebusch, H. H., E. O. Stapley, and S. B. Zimmerman. 1992. The discovery of cell wall active antibacterial antibiotics. Crit. Rev. Biotechnol. 12: $225-243$.

127. Gegnas, L. D., S. T. Waddell, R. M. Chabin, S. Reddy, and K. K. Wong. 1998. Inhibitors of the bacterial cell wall biosynthesis enzyme MurD Bioorg. Med. Chem. Lett. 8:1643-1648.

128. Gellert, M., K. Mizuuchi, M. H. O’Dea, and H. A. Nash. 1976. DNA gyrase: an enzyme that introduces superhelical turns into DNA. Proc. Natl. Acad. Sci. U. S. A. 73:3872-3876.

129. Geng, B., G. Basarab, J. Comita-Prevoir, M. Gowravaram, P. Hill, A. Kiely, J. Loch, L. MacPherson, M. Morningstar, G. Mullen, E. Osimboni, A. Satz, C. Eyermann, and T. Lundqvist. 2009. Potent and selective inhibitors of Helicobacter pylori glutamate racemase (MurI): pyridodiazepine amines. Bioorg. Med. Chem. Lett. 19:930-936.

130. Georgopapadakou, N. H., and F. Y. Liu. 1980. Penicillin-binding proteins in bacteria. Antimicrob. Agents Chemother. 18:148-157.

131. Gillespie, S. 2002. Evolution of drug resistance in Mycobacterium tuberculosis: clinical and molecular perspective. Antimicrob. Agents Chemother. 46:267-274.

132. Gilmour, R., J. E. Foster, Q. Sheng, J. R. McClain, A. Riley, P. M. Sun, W. L. Ng, D. Yan, T. I. Nicas, K. Henry, and M. E. Winkler. 2005. New class 
of competitive inhibitor of bacterial histidine kinases. J. Bacteriol. 187: 8196-8200.

133. Golan, Y., K. Mullane, M. Miller, K. Weiss, A. Lentnek, P. Sears, Y. Shue, S. Gorbach, and T. Louie. 2009. Low recurrence rate among patients (Pts) with $C$. difficile infection (CDI) treated with fidaxomicin (FDX), abstr L1-1639. Abstr. 49th Intersci. Conf. Antimicrob. Agents Chemother., San Francisco, CA. American Society for Microbiology, Washington, DC.

134. Goldstein, E., D. Citro, P. Sears, F. Babakhani, and D. Gerding. 2009 Comparative fidaxomicin susceptibilities of isolates collected at baseline, failure, and recurrence from patients in a phase III trial of Clostridium difficile infection (CDI), abstr. L1-1641. Abstr. 49th Intersci. Conf. Antimicrob. Agents Chemother., San Francisco, CA. American Society for Microbiology, Washington, DC

135. Gomez, L., M. D. Hack, J. Wu, J. J. Wiener, H. Venkatesan, A. Santillan, Jr., D. J. Pippel, N. Mani, B. J. Morrow, S. T. Motley, K. J. Shaw, R. Wolin, C. A. Grice, and T. K. Jones. 2007. Novel pyrazole derivatives as poten inhibitors of type II topoisomerases. 1. Synthesis and preliminary SAR analysis. Bioorg. Med. Chem. Lett. 17:2723-2727.

136. Gomez, M., C. Hackbarth, N. Rafanan, A. Kubo, W. Wang, V. Tembe, P. Margolis, D. Chen, H. O'Dowd, B. Raju, Z. Yuan, D. Patel, R. White, and J. Trias. 2002. VRC5264, a new inhibitor of LpxC, an essential Gramnegative metalloenzyme, abstr. F-2034. Abstr. 42nd Intersci. Conf. Antimicrob. Agents Chemother., San Diego, CA. American Society for Microbiology, Washington, DC.

137. Goss, W. A., W. H. Deitz, and T. M. Cook. 1964. Mechanism of action of nalidixic acid on Escherichia coli. J. Bacteriol. 88:1112-1118.

138. Gould, C. V., P. D. Sniegowski, M. Shchepetov, J. P. Metlay, and J. N. Weiser. 2007. Identifying mutator phenotypes among fluoroquinolone-resistant strains of Streptococcus pneumoniae using fluctuation analysis. Antimicrob. Agents Chemother. 51:3225-3229.

139. Green, L. S., J. M. Bullard, W. Ribble, F. Dean, D. F. Ayers, U. A. Ochsner, N. Janjic, and T. C. Jarvis. 2009. Inhibition of methionyl-tRNA synthetase by REP8839 and effects of resistance mutations on enzyme activity. Antimicrob. Agents Chemother. 53:86-94.

140. Grossman, T. H., D. J. Bartels, S. Mullin, C. H. Gross, J. D. Parsons, Y Liao, A. L. Grillot, D. Stamos, E. R. Olson, P. S. Charifson, and N. Mani 2007. Dual targeting of GyrB and ParE by a novel aminobenzimidazole class of antibacterial compounds. Antimicrob. Agents Chemother. 51:657666.

141. Gu, Y. G., A. S. Florjancic, R. F. Clark, T. Zhang, C. S. Cooper, D. D. Anderson, C. G. Lerner, J. O. McCall, Y. Cai, C. L. Black-Schaefer, G. F. Stamper, P. J. Hajduk, and B. A. Beutel. 2004. Structure-activity relationships of novel potent MurF inhibitors. Bioorg. Med. Chem. Lett. 14:267270.

142. Gualtieri, M., P. Villain-Guillot, J. Latouche, J.-P. Leonetti, and L. Bastide. 2006. Mutation in the Bacillus subtilis RNA polymerase $\beta$ subunit confers resistance to lipiarmycin. Antimicrob. Agents Chemother. 50:401-402.

143. Guay, D. R. 2007. Drug forecast-the peptide deformylase inhibitors as antibacterial agents. Ther. Clin. Risk Manage. 3:513-525.

144. Gumbo, T., A. Louie, M. R. Deziel, and G. L. Drusano. 2005. Pharmacodynamic evidence that ciprofloxacin failure against tuberculosis is not due to poor microbial kill but to rapid emergence of resistance. Antimicrob. Agents Chemother. 49:3178-3181.

145. Hackbarth, C. J., D. Z. Chen, J. G. Lewis, K. Clark, J. B. Mangold, J. A Cramer, P. S. Margolis, W. Wang, J. Koehn, C. Wu, S. Lopez, G. Withers III, H. Gu, E. Dunn, R. Kulathila, S. H. Pan, W. L. Porter, J. Jacobs, J. Trias, D. V. Patel, B. Weidmann, R. J. White, and Z. Yuan. 2002. N-Alkyl urea hydroxamic acids as a new class of peptide deformylase inhibitors with antibacterial activity. Antimicrob. Agents Chemother. 46:2752-2764.

146. Hall, L. M. C., and S. K. Henderson-Begg. 2006. Hypermutable bacteria isolated from humans-a critical analysis. Microbiology 152:2505-2514.

147. Hamilton-Miller, J. M. T. 1990. The emergence of antibiotic resistance: myths and facts in clinical practice. Intensive Care Med. 16:S206-S211.

148. Hann, M. M., and T. I. Oprea. 2004. Pursuing the leadlikeness concept in pharmaceutical research. Curr. Opin. Chem. Biol. 8:255-263.

149. Hawser, S., S. Lociuro, and K. Islam. 2006. Dihydrofolate reductase inhibitors as antibacterial agents. Biochem. Pharmacol. 71:941-948.

150. Haydon, D. J., J. M. Bennett, D. Brown, I. Collins, G. Galbraith, P. Lancett R. Macdonald, N. R. Stokes, P. K. Chauhan, J. K. Sutariya, N. Nayal, A Srivastava, J. Beanland, R. Hall, V. Henstock, C. Noula, C. Rockley, and L. Czaplewski. 2010. Creating an antibacterial with in vivo efficacy: synthesis and characterization of potent inhibitors of the bacterial cell division protein FtsZ with improved pharmaceutical properties. J. Med. Chem. 53: 3927-3936.

151. Haydon, D. J., N. R. Stokes, R. Ure, G. Galbraith, J. M. Bennett, D. R Brown, P. J. Baker, V. V. Barynin, D. W. Rice, S. E. Sedelnikova, J. R. Heal, J. M. Sheridan, S. T. Aiwale, P. K. Chauhan, A. Srivastava, A. Taneja, I. Collins, J. Errington, and L. G. Czaplewski. 2008. An inhibitor of FtsZ with potent and selective anti-staphylococcal activity. Science 321:1673-1675.

152. Heath, R. J., and C. O. Rock. 2000. Microbiology: a triclosan-resistant bacterial enzyme. Nature 406:145-146.

153. Heath, R. J., N. Su, C. K. Murphy, and C. O. Rock. 2000. The enoyl-[acyl- carrier-protein] reductases FabI and FabL from Bacillus subtilis. J. Biol Chem. 275:40128-40133

154. Heerding, D. A., G. Chan, W. E. DeWolf, A. P. Fosberry, C. A. Janson, D. D. Jaworski, E. McManus, W. H. Miller, T. D. Moore, D. J. Payne, X. Qiu, S. F. Rittenhouse, C. Slater-Radosti, W. Smith, D. T. Takata, K. S. Vaidya, C. C. Yuan, and W. F. Huffman. 2001. 1,4-Disubstituted imidazoles are potential antibacterial agents functioning as inhibitors of enoyl acyl carrier protein reductase (FabI). Bioorg. Med. Chem. Lett. 11:2061-2065.

155. Hendlin, D., E. O. Stapley, M. Jackson, H. Wallick, A. K. Miller, F. J. Wolf, T. W. Miller, L. Chaiet, F. M. Kahan, E. L. Foltz, H. B. Woodruff, J. M. Mata, S. Hernandez, and S. Mochales. 1969. Phosphonomycin, a new antibiotic produced by strains of Streptomyces. Science 166:122-123.

156. Hert, J., J. J. Irwin, C. Laggner, M. J. Keiser, and B. K. Shoichet. 2009 Quantifying biogenic bias in screening libraries. Nat. Chem. Biol. 5:479483.

157. Hill, J., J. Finn, X. Yu, Z. Wang, J. Silverman, N. Oliver, P. Gallant, P. Wendler, and D. Keith. 2001. Synthesis and activity of spirocyclic tetrahydrofurans as inhibitors of phenylalanine tRNA synthetase, abstr. F-1707. Abstr. 41st Intersci. Conf. Antimicrob. Agents Chemother., Chicago, IL. American Society for Microbiology, Washington, DC

158. Hitchings, G. H., E. A. Falco, H. Vanderwerff, P. B. Russell, and G. B. Elion. 1952. Antagonists of nucleic acid derivatives. VII. 2,4-Diaminopyrimidines. J. Biol. Chem. 199:43-56.

159. Hoffman, P. S., G. Sisson, M. A. Croxen, K. Welch, W. D. Harman, N. Cremades, and M. G. Morash. 2007. Antiparasitic drug nitazoxanide inhibits the pyruvate oxidoreductases of Helicobacter pylori, selected anaerobic bacteria and parasites, and Campylobacter jejuni. Antimicrob. Agents Chemother. 51:868-876.

160. Hooper, D. C. 1999. Mode of action of fluoroquinolones. Drugs 58:6-10.

161. Hooper, D. C., J. S. Wolfson, G. L. McHugh, M. B. Winters, and M. N. Swartz. 1982. Effects of novobiocin, coumermycin A1, clorobiocin, and their analogs on Escherichia coli DNA gyrase and bacterial growth. Antimicrob. Agents Chemother. 22:662-671.

162. Horobin, R. W., S. Trapp, and V. Weissig. 2007. Mitochondriotropics: a review of their mode of action, and their applications for drug and DNA delivery to mammalian mitochondria. J. Control. Release 121:125-136.

163. Hu, Y., J. S. Helm, L. Chen, C. Ginsberg, B. Gross, B. Kraybill, K. Tiyanont, X. Fang, T. Wu, and S. Walker. 2004. Identification of selective inhibitors for the glycosyltransferase MurG via high-throughput screening. Chem. Biol. 11:703-711.

164. Huang, Q., F. Kirikae, T. Kirikae, A. Pepe, A. Amin, L. Respicio, R. A Slayden, P. J. Tonge, and I. Ojima. 2006. Targeting FtsZ for antituberculosis drug discovery: noncytotoxic taxanes as novel antituberculosis agents. J. Med. Chem. 49:463-466.

165. Huband, M. D., M. A. Cohen, M. Zurack, D. L. Hanna, L. A. Skerlos, M. C Sulavik, G. W. Gibson, J. W. Gage, E. Ellsworth, M. A. Stier, and S. J. Gracheck. 2007. In vitro and in vivo activities of PD 0305970 and PD 0326448, new bacterial gyrase/topoisomerase inhibitors with potent antibacterial activities versus multidrug-resistant Gram-positive and fastidious organism groups. Antimicrob. Agents Chemother. 51:1191-1201.

166. Huber, J., R. G. K. Donald, S. H. Lee, L. W. Jarantow, M. J. Salvatore, X. Meng, R. Painter, R. H. Onishi, J. Occi, K. Dorso, K. Young, Y. W. Park, S. Skwish, M. J. Szymonifka, T. S. Waddell, L. Miesel, J. W. Phillips, and T. Roemer. 2009. Chemical genetic identification of peptidoglycan inhibitors potentiating carbapenem activity against methicillin-resistant Staphylococcus aureus. Chem. Biol. 16:837-848.

167. Hubschwerlen, C., J.-L. Specklin, C. Sigwalt, S. Schroeder, and H. H. Locher. 2003. Design, synthesis and biological evaluation of oxazolidinonequinolone hybrids. Bioorg. Med. Chem. 11:2313-2319.

168. Hughes, D. 2003. Exploiting genomics, genetics and chemistry to combat antibiotic resistance. Nat. Rev. Genet. 4:432-441.

169. Hughes, J. D., J. Blagg, D. A. Price, S. Bailey, G. A. Decrescenzo, R. V. Devraj, E. Ellsworth, Y. M. Fobian, M. E. Gibbs, R. W. Gilles, N. Greene E. Huang, T. Krieger-Burke, J. Loesel, T. Wager, L. Whiteley, and Y. Zhang. 2008. Physiochemical drug properties associated with in vivo toxicological outcomes. Bioorg. Med. Chem. Lett. 18:4872-4875.

170. Huovinen, P., L. Sundstrom, G. Swedberg, and O. Skold. 1995. Trimethoprim and sulfonamide resistance. Antimicrob. Agents Chemother. 39:279-289

171. Ince, D., and D. C. Hooper. 2000. Mechanisms and frequency of resistance to premafloxacin in Staphylococcus aureus: novel mutations suggest novel drug-target interactions. Antimicrob. Agents Chemother. 44:3344-3350.

172. Ince, D., and D. C. Hooper. 2003. Quinolone resistance due to reduced target enzyme expression. J. Bacteriol. 185:6883-6892.

173. Ito, H., A. Ura, Y. Oyamada, A. Tanitame, H. Yoshida, S. Yamada, M. Wachi, and J. Yamagishi. 2006. A 4-aminofurazan derivative-A189inhibits assembly of bacterial cell division protein FtsZ in vitro and in vivo. Microbiol. Immunol. 50:759-764.

174. Jackman, J. E., C. R. H. Raetz, and C. A. Fierke. 1999. UDP-3- $O-(R-3-$ hydroxymyristoyl)- $N$-acetylglucosamine deacetylase of Escherichia coli is a zinc metalloenzyme. Biochemistry 38:1902-1911.

175. Jarvest, R. L., J. M. Berge, V. Berry, H. F. Boyd, M. J. Brown, J. S. Elder, 
A. K. Forrest, A. P. Fosberry, D. R. Gentry, M. J. Hibbs, D. D. Jaworski, P. J. O'Hanlon, A. J. Pope, S. Rittenhouse, R. J. Sheppard, C. SlaterRadosti, and A. Worby. 2002. Nanomolar inhibitors of Staphylococcus aureus methionyl tRNA synthetase with potent antibacterial activity against Gram-positive pathogens. J. Med. Chem. 45:1959-1962.

176. Jayasekera, M. M. K., K. Onheiber, J. Keith, H. Venkatesan, A. Santillan, E. M. Stocking, L. Tang, J. Miller, L. Gomez, B. Rhead, T. Delcamp, S. Huang, R. Wolin, E. V. Bobkova, and K. J. Shaw. 2005. Identification of novel inhibitors of bacterial translation elongation factors. Antimicrob. Agents Chemother. 49:131-136.

177. Ji, Y., D. Yin, B. Fox, D. J. Holmes, D. Payne, and M. Rosenberg. 2004 Validation of antibacterial mechanism of action using regulated antisense RNA expression in Staphylococcus aureus. FEMS Microbiol. Lett. 231: $177-184$.

178. Jones, K. R., J.-H. Cha, and D. S. Merrell. 2008. Who's winning the war? Molecular mechanisms of antibiotic resistance in Helicobacter pylori. Curr. Drug Ther. 3:190-203.

179. Jones, R. N., T. R. Fritsche, K. Islam, S. Hawser, and H. S. Sader. 2007. Antimicrobial activity of a novel dihydrofolate reductase inhibitor, iclaprim, tested against clinical strains of Enterobacteriaceae (ENT): results from the International Study of Iclaprim Susceptibility (ISIS), abstr. E-909. Abstr. 47th Intersci. Conf. Antimicrob. Agents Chemother., Chicago, IL. American Society for Microbiology, Washington, DC

180. Kaeberlein, T., K. Lewis, and S. S. Epstein. 2002. Isolating "uncultivable" microorganisms in pure culture in a simulated natural environment. Science 296:1127-1129.

181. Kahan, F. M., J. S. Kahan, P. J. Cassidy, and H. Kropp. 1974. The mechanism of action of fosfomycin (phosphonomycin). Ann. N. Y. Acad. Sci. 235:364-386.

182. Kaldor, S. W., V. J. Kalish, J. F. Davies, B. V. Shetty, J. E. Fritz, K. Appelt, J. A. Burgess, K. M. Campanale, N. Y. Chirgadze, D. K. Clawson, B. A Dressman, S. D. Hatch, D. A. Khalil, M. B. Kosa, P. P. Lubbehusen, M. A. Muesing, A. K. Patick, S. H. Reich, K. S. Su, and J. H. Tatlock. 1997 Viracept (nelfinavir mesylate, AG1343): a potent, orally bioavailable inhibitor of HIV-1 protease. J. Med. Chem. 40:3979-3985.

183. Kamal, A., S. Azeeza, M. S. Malik, A. A. Shaik, and M. V. Rao. 2008. Efforts towards the development of new antitubercular agents: potential for thiolactomycin based compounds. J. Pharm. Pharm. Sci. 11:56s-80s.

184. Karlowsky, J. A., N. Kaplan, B. Hafkin, D. J. Hoban, and G. G. Zhanel. 2009. AFN-1252, a FabI inhibitor, demonstrates a Staphylococcus-specific spectrum of activity. Antimicrob. Agents Chemother. 53:3544-3548.

185. Karlowsky, J. A., N. M. Laing, T. Baudry, N. Kaplan, D. Vaughan, D. J. Hoban, and G. G. Zhanel. 2007. In vitro activity of API-1252, a novel FabI inhibitor, against clinical isolates of Staphylococcus aureus and Staphylococcus epidermidis. Antimicrob. Agents Chemother. 51:1580-1581.

186. Katz, M. L., L. V. Mueller, M. Polyakov, and S. F. Weinstock. 2006. Where have all the antibiotic patents gone? Nat. Biotechnol. 24:1529-1531.

187. Keiser, M. J., B. L. Roth, B. N. Armbruster, P. Ernsberger, J. J. Irwin, and B. K. Shoichet. 2007. Relating protein pharmacology by ligand chemistry. Nat. Biotechnol. 25:197-206.

188. Kempsell, K. E., Y. E. Ji, I. C. Estrada, M. J. Colston, and R. A. Cox. 1992 The nucleotide sequence of the promoter, 16S rRNA and spacer region of the ribosomal RNA operon of Mycobacterium tuberculosis and comparison with Mycobacterium leprae precursor rRNA. J. Gen. Microbiol. 138:17171727.

189. Khodursky, A. B., E. L. Zechiedrich, and N. R. Cozzarelli. 1995. Topoisomerase IV is a target of quinolones in Escherichia coli. Proc. Natl. Acad. Sci. U. S. A. 92:11801-11805.

190. Kim, D. H., W. J. Lees, K. E. Kempsell, W. S. Lane, K. Duncan, and C. T. Walsh. 1996. Characterization of a Cys115 to Asp substitution in the Esch erichia coli cell wall biosynthetic enzyme UDP-GlcNAc enolpyruvyl transferase (MurA) that confers resistance to inactivation by the antibiotic fosfomycin. Biochemistry 35:4923-4928.

191. Kirby, W. M. M. 1944. Extraction of a highly potent penicillin inactivator from penicillin resistant staphylococci. Science 99:452-453.

192. Kirby, W. M. M., D. G. Hudson, and W. D. Noyes. 1956. Clinical and laboratory studies of novobiocin, a new antibiotic. Arch. Intern. Med. 98: $1-7$.

193. Kitagawa, H., T. Ozawa, S. Takahata, M. Iida, J. Saito, and M. Yamada. 2007. Phenylimidazole derivatives of 4-pyridone as dual inhibitors of bacterial enoyl-acyl carrier protein reductases FabI and FabK. J. Med. Chem. 50:4710-4720.

194. Kitamoto, O., N. Kasai, K. Fukuya, and A. Kawashima. 1956. Drug sensitivity of the Shigella strains isolated in 1955. J. Jpn. Assoc. Infect. Dis. 30:403-404.

195. Kocagoz, T., C. Hackbarth, I. Unsal, E. Rosenberg, H. Nikaido, and H. Chambers. 1996. Gyrase mutations in laboratory-selected, fluoroquinolone-resistant mutants of Mycobacterium tuberculosis H37Ra. Antimicrob. Agents Chemother. 40:1768-1774.

196. Kotnik, M., P. S. Anderluh, and A. Prezelj. 2007. Development of novel inhibitors targeting intracellular steps of peptidoglycan biosynthesis. Curr. Pharm. Des. 13:2283-2309.
197. Kraus, C. N. 2008. Low hanging fruit in infectious disease drug development. Curr. Opin. Microbiol. 11:434-438.

198. Kugelberg, E., S. Lofmark, B. Wretlind, and D. I. Andersson. 2005. Reduction of the fitness burden of quinolone resistance in Pseudomonas aeruginosa. J. Antimicrob. Chemother. 55:22-30.

199. Kuhl, A., N. Svenstrup, C. Ladel, M. Otteneder, A. Binas, G. Schiffer, M. Brands, T. Lampe, K. Ziegelbauer, H. Rubsamen-Waigmann, D. Haebich, and K. Ehlert. 2005. Biological characterization of novel inhibitors of the Gram-positive DNA polymerase IIIC enzyme. Antimicrob. Agents Chemother. 49:987-995.

200. Kurosu, M., P. Narayanasamy, K. Biswas, R. Dhiman, and D. C. Crick. 2007. Discovery of 1,4-dihydroxy-2-naphthoate prenyltransferase inhibitors: new drug leads for multidrug-resistant Gram-positive pathogens. J. Med. Chem. 50:3973-3975.

201. Kutterer, K. M., J. M. Davis, G. Singh, Y. Yang, W. Hu, A. Severin, B. A. Rasmussen, G. Krishnamurthy, A. Failli, and A. H. Katz. 2005. 4-Alkyl and 4,4'-dialkyl 1,2-bis(4-chlorophenyl)pyrazolidine-3,5-dione derivatives as new inhibitors of bacterial cell wall biosynthesis. Bioorg. Med. Chem. Lett. 15:2527-2531.

202. Kuzuyama, T., T. Shimizu, S. Takahashi, and H. Seto. 1998. Fosmidomycin, a specific inhibitor of 1-deoxy-D-xylulose 5-phosphate reductoisomerase in the nonmevalonate pathway for terpenoid biosynthesis. Tetrahedron Lett. 39:7913-7916.

203. Kwon, Y. J., Y. Fang, G. H. Xu, and W. G. Kim. 2009. Aquastatin A, a new inhibitor of enoyl-acyl carrier protein reductase from Sporothrix sp. FN611. Biol. Pharm. Bull. 32:2061-2064.

204. Lange, R. P., H. H. Locher, P. C. Wyss, and R. L. Then. 2007. The targets of currently used antibacterial agents: lessons for drug discovery. Curr. Pharm. Des. 13:3140-3154.

205. Langsdorf, E. F., A. Malikzay, W. A. Lamarr, D. Daubaras, C. Kravec, R. Zhang, R. Hart, F. Monsma, T. Black, C. C. Ozbal, L. Miesel, and C. A. Lunn. 2009. Screening for antibacterial inhibitors of the UDP-3-O-(R-3hydroxymyristoyl) $-N$-acetylglucosamine deacetylase (LpxC) using a highthroughput mass spectrometry assay. J. Biomol. Screen. doi:10.1177/ 1087057109355319.

206. Leclercq, R., E. Derlot, M. Weber, J. Duval, and P. Courvalin. 1989. Transferable vancomycin and teicoplanin resistance in Enterococcus faecium. Antimicrob. Agents Chemother. 33:10-15.

207. Lee, L. V., B. Granda, K. Dean, J. Tao, E. Liu, R. Zhang, S. Peukert, S. Wattanasin, X. Xie, N. S. Ryder, R. Tommasi, and G. Deng. 2010. Biophysical investigation of mode of inhibition of tetramic acids, the allosteric inhibitors of undecaprenyl pyrophosphate synthase. Biochemistry 49:53665376

208. Lee, M. D., Y. She, M. J. Soskis, C. P. Borella, J. R. Gardner, P. A. Hayes, B. M. Dy, M. L. Heaney, M. R. Philips, W. G. Bornmann, F. M. Sirotnak, and D. A. Scheinberg. 2004. Human mitochondrial peptide deformylase, a new anticancer target of actinonin-based antibiotics. J. Clin. Invest. 114: $1107-1116$.

209. Leeds, J. A., and C. R. Dean. 2006. Peptide deformylase as an antibacterial target: a critical assessment. Curr. Opin. Pharmacol. 8:8.

210. Leeds, J. A., E. K. Schmitt, and P. Krastel. 2006. Recent developments in antibacterial drug discovery: microbe-derived natural products-from collection to the clinic. Expert Opin. Invest. Drugs 15:211-226.

211. Li, X., M. Zolli-Juran, J. D. Cechetto, D. M. Daigle, G. D. Wright, and E. D. Brown. 2004. Multicopy suppressors for novel antibacterial compounds reveal targets and drug efflux susceptibility. Chem. Biol. 11:1423-1430.

212. Li, Z., G. D. Francisco, W. Hu, P. Labthavikul, P. J. Petersen, A. Severin, G. Singh, Y. Yang, B. A. Rasmussen, Y. I. Lin, J. S. Skotnicki, and T. S. Mansour. 2003. 2-Phenyl-5,6-dihydro-2H-thieno[3,2-c]pyrazol-3-ol derivatives as new inhibitors of bacterial cell wall biosynthesis. Bioorg. Med. Chem. Lett. 13:2591-2594.

213. Liebscher, M., G. Jahreis, C. Lucke, S. Grabley, S. Raina, and C. SchieneFischer. 2007. Fatty acyl benzamido antibacterials based on inhibition of DnaK-catalyzed protein folding. J. Biol. Chem. 282:4437-4446.

214. Ling, L. L., J. Xian, S. Ali, B. Geng, J. Fan, D. M. Mills, A. C. Arvanites, H. Orgueira, M. A. Ashwell, G. Carmel, Y. Xiang, and D. T. Moir. 2004 Identification and characterization of inhibitors of bacterial enoyl-acyl carrier protein reductase. Antimicrob. Agents Chemother. 48:1541-1547.

215. Lipinski, C., F. Lombardo, B. Dominy, and P. Feeney. 1997. Experimental and computational approaches to estimate solubility and permeability in drug discovery and development settings. Adv. Drug Deliv. Rev. 23:3-25.

216. Liu, M., T. S. Hanks, J. Zhang, M. J. McClure, D. W. Siemsen, J. L. Elser, M. T. Quinn, and B. Lei. 2006. Defects in ex vivo and in vivo growth and sensitivity to osmotic stress of group A streptococcus caused by interruption of response regulator gene vicR. Microbiology 152:967-978.

217. Lock, R. L., and E. J. Harry. 2008. Cell-division inhibitors: new insights for future antibiotics. Nat. Rev. Drug Discov. 7:324-338.

218. Lomovskaya, O., and K. A. Bostian. 2006. Practical applications and feasibility of efflux pump inhibitors in the clinic - a vision for applied use Biochem. Pharmacol. 71:910-918.

219. Long, K. S., J. Poehlsgaard, C. Kehrenberg, S. Schwarz, and B. Vester. 2006. The Cfr rRNA methyltransferase confers resistance to phenicols, 
lincosamides, oxazolidinones, pleuromutilins, and streptogramin A antibiotics. Antimicrob. Agents Chemother. 50:2500-2505.

220. Louie, A., M. R. Deziel, W. Liu, and G. L. Drusano. 2007. Impact of resistance selection and mutant growth fitness on the relative efficacies of streptomycin and levofloxacin for plague therapy. Antimicrob. Agents Chemother. 51:2661-2667.

221. Love, E., D. D'Ambrosio, and N. C. Brown. 1976. Mapping of the gene specifying DNA polymerase III of Bacillus subtilis. Mol. Gen. Genet. 144: 313-321.

222. Lu, H., and P. J. Tonge. 2008. Inhibitors of FabI, an enzyme drug target in the bacterial fatty acid biosynthesis pathway. Acc. Chem. Res. 41:11-20.

223. Lugtenberg, E. J., L. De Haas-Menger, and W. H. Ruyters. 1972. Murein synthesis and identification of cell wall precursors of temperature-sensitive lysis mutants of Escherichia coli. J. Bacteriol. 109:326-335.

224. Lugtenberg, E. J., and A. van Schijndel-van Dam. 1972. Temperaturesensitive mutants of Escherichia coli $\mathrm{K}-12$ with low activities of the L-alanine adding enzyme and the D-alanyl-D-alanine adding enzyme. J. Bacteriol. 110:35-40.

225. Lugtenberg, E. J., and A. van Schijndel-van Dam. 1972. Temperaturesensitive mutants of Escherichia coli K-12 with low activity of the diaminopimelic acid adding enzyme. J. Bacteriol. 110:41-46.

226. Lugtenberg, E. J., and A. van Schijndel-van Dam. 1973. Temperaturesensitive mutant of Escherichia coli K-12 with an impaired D-alanine:Dalanine ligase. J. Bacteriol. 113:96-104.

227. Luria, S. E., and M. Delbruck. 1943. Mutations of bacteria from virus sensitivity to virus resistance. Genetics 28:491-511.

228. Lynch, A. S. 2006. Efflux systems in bacterial pathogens: an opportunity for therapeutic intervention? An industry view. Biochem. Pharmacol. 71:949956.

229. Ma, Z., C. Lienhardt, H. McIlleron, A. J. Nunn, and X. Wang. 2010. Global tuberculosis drug development pipeline: the need and the reality. Lancet 375:2100-2109.

230. Maisnier-Patin, S., O. G. Berg, L. Liljas, and D. I. Andersson. 2002. Compensatory adaptation to the deleterious effect of antibiotic resistance in Salmonella typhimurium. Mol. Microbiol. 46:355-366.

231. Maisnier-Patin, S., W. Paulander, A. Pennhag, and D. I. Andersson. 2007 Compensatory evolution reveals functional interactions between ribosomal proteins S12, L14 and L19. J. Mol. Biol. 366:207-215.

232. Mani, N., C. H. Gross, J. D. Parsons, B. Hanzelka, U. Muh, S. Mullin, Y Liao, A.-L. Grillot, D. Stamos, P. S. Charifson, and T. H. Grossman. 2006 In vitro characterization of the antibacterial spectrum of novel bacterial type II topoisomerase inhibitors of the aminobenzimidazole class. Antimicrob. Agents Chemother. 50:1228-1237.

233. Mann, B. S., J. R. Johnson, M. H. Cohen, R. Justice, and R. Pazdur. 2007 FDA approval summary: vorinostat for treatment of advanced primary cutaneous T-cell lymphoma. Oncologist 12:1247-1252.

234. Mansour, T. S., C. E. Caufield, B. Rasmussen, R. Chopra, G. Krishnamurthy, K. M. Morris, K. Svenson, J. Bard, C. Smeltzer, S. Naughton, S. Antane, Y. Yang, A. Severin, D. Quagliato, P. J. Petersen, and G. Singh. 2007. Naphthyl tetronic acids as multi-target inhibitors of bacterial peptidoglycan biosynthesis. ChemMedChem 28:28.

235. Mao, E. F., L. Lane, J. Lee, and J. H. Miller. 1997. Proliferation of mutators in A cell population. J. Bacteriol. 179:417-422.

236. Margalit, D. N., L. Romberg, R. B. Mets, A. M. Hebert, T. J. Mitchison, M. W. Kirschner, and D. RayChaudhuri. 2004. Targeting cell division: small-molecule inhibitors of FtsZ GTPase perturb cytokinetic ring assembly and induce bacterial lethality. Proc. Natl. Acad. Sci. U. S. A. 101:1182111826 .

237. Marshall, S. H., C. J. Donskey, R. Hutton-Thomas, R. A. Salata, and L. B. Rice. 2002. Gene dosage and linezolid resistance in Enterococcus faecium and Enterococcus faecalis. Antimicrob. Agents Chemother. 46:3334-3336.

238. Martin, N. I., and E. Breukink. 2007. Expanding role of lipid II as a target for lantibiotics. Future Microbiol. 2:513-525.

239. Martinez, J. L. 2009. The role of natural environments in the evolution of resistance traits in pathogenic bacteria. Proc. Biol. Sci. 276:2521-2530.

240. Martinez, J. L., and F. Baquero. 2000. Mutation frequencies and antibiotic resistance. Antimicrob. Agents Chemother. 44:1771-1777.

241. Martinez, J. L., F. Baquero, and D. I. Andersson. 2007. Predicting antibiotic resistance. Nat. Rev. Microbiol. 5:958-965.

242. Martínez-Martínez, L., A. Pascual, and G. A. Jacoby. 1998. Quinolone resistance from a transferable plasmid. Lancet 351:797-799.

243. Massengo-Tiassé, R., and J. Cronan. 2009. Diversity in enoyl-acyl carrier protein reductases. Cell. Mol. Life Sci. 66:1507-1517.

244. Massengo-Tiassé, R. P., and J. E. Cronan. 2008. Vibrio cholerae FabV defines a new class of enoyl-acyl carrier protein reductase. J. Biol. Chem. 283:1308-1316.

245. Mazel, D., S. Pochet, and P. Marliere. 1994. Genetic characterization of polypeptide deformylase, a distinctive enzyme of eubacterial translation. EMBO J. 13:914-923

246. Mazumder, A., K. Raghavan, J. Weinstein, K. W. Kohn, and Y. Pommier. 1995. Inhibition of human immunodeficiency virus type-1 integrase by curcumin. Biochem. Pharmacol. 49:1165-1170.
247. McClerren, A. L., S. Endsley, J. L. Bowman, N. H. Andersen, Z. Guan, J. Rudolph, and C. R. Raetz. 2005. A slow, tight-binding inhibitor of the zinc-dependent deacetylase LpxC of lipid A biosynthesis with antibiotic activity comparable to ciprofloxacin. Biochemistry 44:16574-16583.

248. McGovern, S. L., E. Caselli, N. Grigorieff, and B. K. Shoichet. 2002. A common mechanism underlying promiscuous inhibitors from virtual and high-throughput screening. J. Med. Chem. 45:1712-1722.

249. McGovern, S. L., B. T. Helfand, B. Feng, and B. K. Shoichet. 2003. A specific mechanism of nonspecific inhibition. J. Med. Chem. 46:4265-4272.

250. McMurry, L. M., M. Oethinger, and S. B. Levy. 1998. Triclosan targets lipid synthesis. Nature 394:531-532.

251. Mégraud, F., A. Occhialini, and J. F. Rossignol. 1998. Nitazoxanide, a potential drug for eradication of Helicobacter pylori with no cross-resistance to metronidazole. Antimicrob. Agents Chemother. 42:2836-2840.

252. Mendoza, C., J. M. Garcia, J. Llaneza, F. J. Mendez, C. Hardisson, and J. M. Ortiz. 1980. Plasmid-determined resistance to fosfomycin in Serratia marcescens. Antimicrob. Agents Chemother. 18:215-219.

253. Miesel, L., J. Greene, and T. A. Black. 2003. Genetic strategies for antibacterial drug discovery. Nat. Rev. Genet. 4:442-456.

254. Miller, D. J., S. M. Hammond, D. Anderluzzi, and T. D. Bugg. 1998 Aminoalkylphosphinate inhibitors of D-Ala-D-Ala adding enzyme. J. Chem. Soc. Perkin 1 1:131-142

255. Miller, J. R., S. Dunham, I. Mochalkin, C. Banotai, M. Bowman, S. Buist, B. Dunkle, D. Hanna, H. J. Harwood, M. D. Huband, A. Karnovsky, M. Kuhn, C. Limberakis, J. Y. Liu, S. Mehrens, W. T. Mueller, L. Narasimhan, A. Ogden, J. Ohren, J. V. N. V. Prasad, J. A. Shelly, L. Skerlos, M. Sulavik, V. H. Thomas, S. VanderRoest, L. Wang, Z. Wang, A. Whitton, T. Zhu, and C. K. Stover. 2009. A class of selective antibacterials derived from a protein kinase inhibitor pharmacophore. Proc. Natl. Acad. Sci. U. S. A. 106:17371742.

256. Miller, K., A. J. O'Neill, and I. Chopra. 2002. Response of Escherichia coli hypermutators to selection pressure with antimicrobial agents from different classes. J. Antimicrob. Chemother. 49:925-934

257. Miller, M. 1995. Aminoglycoside transport, p. 175-219. In N. Georgopapdakou (ed.), Drug transport in antimicrobial and anticancer chemotherapy. Marcel Dekker, Inc., New York, NY.

258. Miller, W. H., M. A. Seefeld, K. A. Newlander, I. N. Uzinskas, W. J. Burgess, D. A. Heerding, C. C. Yuan, M. S. Head, D. J. Payne, S. F. Rittenhouse, T. D. Moore, S. C. Pearson, V. Berry, W. E. DeWolf, Jr., P. M. Keller, B. J. Polizzi, X. Qiu, C. A. Janson, and W. F. Huffman. 2002 Discovery of aminopyridine-based inhibitors of bacterial enoyl-ACP reductase (FabI). J. Med. Chem. 45:3246-3256.

259. Miyakawa, S., K. Suzuki, T. Noto, Y. Harada, and H. Okazaki. 1982 Thiolactomycin, a new antibiotic. IV. Biological properties and chemotherapeutic activity in mice. J. Antibiot. (Tokyo) 35:411-419.

260. Mohan, S., T. M. Kelly, S. S. Eveland, C. R. Raetz, and M. S. Anderson. 1994. An Escherichia coli gene (FabZ) encoding (3R)-hydroxymyristoyl acyl carrier protein dehydrase. Relation to $f a b A$ and suppression of mutations in lipid A biosynthesis. J. Biol. Chem. 269:32896-32903.

261. Molteni, V., X. He, J. Nabakka, K. Yang, A. Kreusch, P. Gordon, B. Bursulaya, I. Warner, T. Shin, T. Biorac, N. S. Ryder, R. Goldberg, J. Doughty, and Y. He. 2004. Identification of novel potent bicyclic peptide deformylase inhibitors. Bioorg. Med. Chem. Lett. 14:1477-1481.

262. Morris, S., G. H. Bai, P. Suffys, L. Portillo-Gomez, M. Fairchok, and D. Rouse. 1995. Molecular mechanisms of multiple drug resistance in clinical isolates of Mycobacterium tuberculosis. J. Infect. Dis. 171:954-960.

263. Mott, J. E., B. A. Shaw, J. F. Smith, P. D. Bonin, D. L. Romero, K. R. Marotti, and A. A. Miller. 2008. Resistance mapping and mode of action of a novel class of antibacterial anthranilic acids: evidence for disruption of cell wall biosynthesis. J. Antimicrob. Chemother. 62:720-729.

264. Müller, J., A. Naguleswaran, N. Müller, and A. Hemphill. 2008. Neospora caninum: functional inhibition of protein disulfide isomerase by the broadspectrum anti-parasitic drug nitazoxanide and other thiazolides. Exp. Parasitol. 118:80-88.

265. Murakami, S., R. Nakashima, E. Yamashita, T. Matsumoto, and A. Yamaguchi. 2006. Crystal structures of a multidrug transporter reveal a functionally rotating mechanism. Nature 443:173-179.

266. Musher, D. M., N. Logan, R. J. Hamill, H. L. DuPont, A. Lentnek, A. Gupta, and J. F. Rossignol. 2006. Nitazoxanide for the treatment of Clos tridium difficile colitis. Clin. Infect. Dis. 43:421-427.

267. Musher, D. M., N. Logan, V. Mehendiratta, N. A. Melgarejo, S. Garud, and R. J. Hamill. 2007. Clostridium difficile colitis that fails conventional metronidazole therapy: response to nitazoxanide. J. Antimicrob. Chemother. 59:705-710.

268. Nagaev, I., J. Bjorkman, D. I. Andersson, and D. Hughes. 2001. Biological cost and compensatory evolution in fusidic acid-resistant Staphylococcus aureus. Mol. Microbiol. 40:433-439.

269. Nikaido, H. 1996. Multidrug efflux pumps of Gram-negative bacteria. J. Bacteriol. 178:5853-5859.

270. Nikaido, H. 2003. Molecular basis of bacterial outer membrane permeability revisited. Microbiol. Mol. Biol. Rev. 67:593-656. 
271. Nikaido, H., and Y. Takatsuka. 2009. Mechanisms of RND multidrug efflux pumps. Biochim. Biophys. Acta 1794:769-781.

272. Nilsson, A. I., O. G. Berg, O. Aspevall, G. Kahlmeter, and D. I. Andersson. 2003. Biological costs and mechanisms of fosfomycin resistance in Escherichia coli. Antimicrob. Agents Chemother. 47:2850-2858

273. Nilsson, A. I., A. Zorzet, A. Kanth, S. Dahlstram, O. G. Berg, and D. I. Andersson. 2006. Reducing the fitness cost of antibiotic resistance by amplification of initiator tRNA genes. Proc. Natl. Acad. Sci. U. S. A. 103: 6976-6981.

274. Noto, T., S. Miyakawa, H. Oishi, H. Endo, and H. Okazaki. 1982. Thiolactomycin, a new antibiotic. III. In vitro antibacterial activity. J. Antibiot. (Tokyo) 35:401-410.

275. Novak, R., and D. M. Shlaes. 2010. The pleuromutilin antibiotics: a new class for human use. Curr. Opin. Invest. Drugs 11:182-191.

276. Oblak, M., M. Kotnik, and T. Solmajer. 2007. Discovery and development of ATPase inhibitors of DNA gyrase as antibacterial agents. Curr. Med. Chem. 14:2033-2047.

277. Ohashi, Y., Y. Chijiiwa, K. Suzuki, K. Takahashi, H. Nanamiya, T. Sato, Y. Hosoya, K. Ochi, and F. Kawamura. 1999. The lethal effect of a benzamide derivative, 3-methoxybenzamide, can be suppressed by mutations within a cell division gene, ftsZ, in Bacillus subtilis. J. Bacteriol. 181:1348-1351.

278. Oiwa, R. 1992. Antibacterial agents, p. 1-29. In S. Omura (ed.), The search for bioactive compounds from microorganisms. Springer-Verlag, New York, NY

279. Okuhara, M., Y. Kuroda, T. Goto, M. Okamoto, H. Terano, M. Kohsaka, H. Aoki, and H. Imanaka. 1980. Studies on new phosphonic acid antibiotics. III. Isolation and characterization of FR-31564, FR-32863 and FR-33289. J. Antibiot. (Tokyo) 33:24-28.

280. O'Neill, A. J. 2008. New antibacterial agents for treating infections caused by multi-drug resistant Gram-negative bacteria. Expert Opin. Invest. Drugs 17:297-302.

281. O'Neill, A. J., and I. Chopra. 2004. Preclinical evaluation of novel antibacterial agents by microbiological and molecular techniques. Expert Opin. Invest. Drugs 13:1045-1063.

282. O'Neill, A. J., I. Chopra, J. L. Martinez, and F. Baquero. 2001. Use of mutator strains for characterization of novel antimicrobial agents. Antimicrob. Agents Chemother. 45:1599-1600.

283. Onishi, H. R., B. A. Pelak, L. S. Gerckens, L. L. Silver, F. M. Kahan, M.-H Chen, A. A. Patchett, S. M. Galloway, S. A. Hyland, M. S. Anderson, and C. R. H. Raetz. 1996. Antibacterial agents that inhibit lipid A biosynthesis. Science 274:980-982.

284. O'Shea, R. O., and H. E. Moser. 2008. Physicochemical properties of antibacterial compounds: implications for drug discovery. J. Med. Chem. 51:2871-2878.

285. Pagès, J.-M., C. E. James, and M. Winterhalter. 2008. The porin and the permeating antibiotic: a selective diffusion barrier in Gram-negative bacteria. Nat. Rev. Microbiol. 6:893-903.

286. Pages, J. M., M. Masi, and J. Barbe. 2005. Inhibitors of efflux pumps in Gram-negative bacteria. Trends Mol. Med. 11:382-389.

287. Pagliara, A., P. A. Carrupt, G. Caron, P. Gaillard, and B. Testa. 1997 Lipophilicity profiles of ampholytes. Chem. Rev. 97:3385-3400.

288. Pan, X.-S., K. A. Gould, and L. M. Fisher. 2009. Probing the differential interactions of quinazolinedione PD 0305970 and quinolones with gyrase and topoisomerase IV. Antimicrob. Agents Chemother. 53:3822-3831.

289. Parenti, F., H. Pagani, and G. Beretta. 1975. Lipiarmycin, a new antibiotic from Actinoplanes. I. Description of the producer strain and fermentation studies. J. Antibiot. (Tokyo) 28:247-252.

290. Park, H. S., Y. M. Yoon, S. J. Jung, C. M. Kim, J. M. Kim, and J.-H. Kwak 2007. Antistaphylococcal activities of CG400549, a new bacterial enoyl-acyl carrier protein reductase (FabI) inhibitor. J. Antimicrob. Chemother. 60: 568-574.

291. Parmeggiani, A., and P. Nissen. 2006. Elongation factor Tu-targeted antibiotics: four different structures, two mechanisms of action. FEBS Lett 580:4576-4581.

292. Paulander, W., D. I. Andersson, and S. E. Maisnier-Patin. 2010. Amplification of the gene for isoleucyl-tRNA synthetase facilitates adaptation to the fitness cost of mupirocin resistance in Salmonella enterica. Genetics 185:305-312.

293. Payne, D. J., M. N. Gwynn, D. J. Holmes, and D. L. Pompliano. 2007. Drugs for bad bugs: confronting the challenges of antibacterial discovery. Nat. Rev. Drug Discov. 6:29-40.

294. Payne, D. J., W. H. Miller, V. Berry, J. Brosky, W. J. Burgess, E. Chen, W. E. DeWolf, Jr., A. P. Fosberry, R. Greenwood, M. S. Head, D. A. Heerding, C. A. Janson, D. D. Jaworski, P. M. Keller, P. J. Manley, T. D. Moore, K. A. Newlander, S. Pearson, B. J. Polizzi, X. Qiu, S. F. Rittenhouse, C. SlaterRadosti, K. L. Salyers, M. A. Seefeld, M. G. Smyth, D. T. Takata, I. N Uzinskas, K. Vaidya, N. G. Wallis, S. B. Winram, C. C. K. Yuan, and W. F. Huffman. 2002. Discovery of a novel and potent class of FabI-directed antibacterial agents. Antimicrob. Agents Chemother. 46:3118-3124.

295. Payne, D. J., P. V. Warren, D. J. Holmes, Y. Ji, and J. T. Lonsdale. 2001 Bacterial fatty-acid biosynthesis: a genomics-driven target for antibacterial drug discovery. Drug Discov. Today 6:537-544.
296. Périchon, B., and P. Courvalin. 2009. Glycopeptide resistance in enterococci, p. 229-240. In D. L. Mayers (ed.), Antimicrobial drug resistance. Humana Press, Totowa, NJ.

297. Peukert, S., Y. Sun, R. Zhang, B. Hurley, M. Sabio, X. Shen, C. Gray, J. Dzink-Fox, J. Tao, R. Cebula, and S. Wattanasin. 2008. Design and structure-activity relationships of potent and selective inhibitors of undecapreny pyrophosphate synthase (UPPS): tetramic, tetronic acids and dihydropyridin-2-ones. Bioorg. Med. Chem. Lett. 18:1840-1844.

298. Pichota, A., J. Duraiswamy, Z. Yin, T. H. Keller, J. Alam, S. Liung, G. Lee, M. Ding, G. Wang, W. L. Chan, M. Schreiber, I. Ma, D. Beer, X. Ngew, K. Mukherjee, M. Nanjundappa, J. W. P. Teo, P. Thayalan, A. Yap, T. Dick, W. Meng, M. Xu, J. Koehn, S.-H. Pan, K. Clark, X. Xie, C. Shoen, and M. Cynamon. 2008. Peptide deformylase inhibitors of Mycobacterium tuberculosis: synthesis, structural investigations, and biological results. Bioorg. Med. Chem. Lett. 18:6568-6572.

299. Piddock, L. J. V., M. I. Garvey, M. M. Rahman, and S. Gibbons. 2010. Natural and synthetic compounds such as trimethoprim behave as inhibitors of efflux in Gram-negative bacteria. J. Antimicrob. Chemother. 65: 1215-1223.

300. Price, A. C., K. H. Choi, R. J. Heath, Z. Li, S. W. White, and C. O. Rock. 2001. Inhibition of beta-ketoacyl-acyl carrier protein synthases by thiolactomycin and cerulenin. Structure and mechanism. J. Biol. Chem. 276:65516559

301. Projan, S. J. 2003. Why is Big Pharma getting out of antibacterial drug discovery? Curr. Opin. Microbiol. 6:427-430.

302. Projan, S. J., and P. A. Bradford. 2007. Late stage antibacterial drugs in the clinical pipeline. Curr. Opin. Microbiol. 10:441-446.

303. Projan, S. J., and D. M. Shlaes. 2004. Antibacterial drug discovery: is it all downhill from here? Clin. Microbiol. Infect. 10:18-22.

304. Pucci, M. J., J. Cheng, S. D. Podos, C. L. Thoma, J. A. Thanassi, D. D. Buechter, G. Mushtaq, G. A. Vigliotti, Jr., B. J. Bradbury, and M. Deshpande. 2007. In vitro and in vivo antibacterial activities of heteroaryl isothiazolones against resistant Gram-positive pathogens. Antimicrob. Agents Chemother. 51:1259-1267.

305. Qin, Z., J. Zhang, B. Xu, L. Chen, Y. Wu, X. Yang, X. Shen, S. Molin, A. Danchin, H. Jiang, and D. Qu. 2006. Structure-based discovery of inhibitors of the YycG histidine kinase: new chemical leads to combat Staphylococcus epidermidis infections. BMC Microbiol. 6:96.

306. Reference deleted.

307. Rai, D., J. K. Singh, N. Roy, and D. Panda. 2008. Curcumin inhibits FtsZ assembly: an attractive mechanism for its antibacterial activity. Biochem. J. 410:147-155

308. Rajeswari, A., and M. Sabesan. 2008. Inhibition of monoamine oxidase-B by the polyphenolic compound, curcumin and its metabolite tetrahydrocurcumin, in a model of Parkinson's disease induced by MPTP neurodegeneration in mice. Inflammopharmacology 16:96-99.

309. Ramanathan-Girish, S., J. McColm, J. M. Clements, P. Taupin, S. Barrowcliffe, J. Hevizi, S. Safrin, C. Moore, G. Patou, H. Moser, A. Gadd, U. Hoch, V. Jiang, D. Lofland, and K. W. Johnson. 2004. Pharmacokinetics in animals and humans of a first-in-class peptide deformylase inhibitor. Antimicrob. Agents Chemother. 48:4835-4842.

310. Reck, F., S. Marmor, S. Fisher, and M. A. Wuonola. 2001. Inhibitors of the bacterial cell wall biosynthesis enzyme MurC. Bioorg. Med. Chem. Lett. 11:1451-1454.

311. Rishton, G. M. 1997. Reactive compounds and in vitro false positives in HTS. Drug Discov. Today 2:382-384.

312. Rishton, G. M. 2003. Nonleadlikeness and leadlikeness in biochemical screening. Drug Discov. Today 8:86-96.

313. Robertson, G. T., E. J. Bonventre, T. B. Doyle, Q. Du, L. Duncan, T. W. Morris, E. D. Roche, D. Yan, and A. S. Lynch. 2008. In vitro evaluation of CBR-2092, a novel rifamycin-quinolone hybrid antibiotic: studies of the mode of action in Staphylococcus aureus. Antimicrob. Agents Chemother. 52:2313-2323.

314. Rosche, W. A., and P. L. Foster. 2000. Determining mutation rates in bacterial populations. Methods 20:4-17.

315. Rossignol, J.-F. 2009. Thiazolides: a new class of antiviral drugs. Expert Opin. Drug Metab. Toxicol. 5:667-674.

316. Ruiz, N. 2008. Bioinformatics identification of MurJ (MviN) as the peptidoglycan lipid II flippase in Escherichia coli. Proc. Natl. Acad. Sci. U. S. A 105:15553-15557.

317. Ryder, N. S. 2009. Discontinued drugs in 2008: anti-infectives. Expert Opin. Invest. Drugs 19:1-21.

318. Saeki, T., M. Hori, and H. Umezawa. 1974. Kinetic studies on the inhibition of nucleoside diphosphate kinase by desdanine. J. Biochem. 76:623-629.

319. Santel, T., G. Pflug, N. Y. Hemdan, A. Schafer, M. Hollenbach, M. Buchold, A. Hintersdorf, I. Lindner, A. Otto, M. Bigl, I. Oerlecke, A. Hutschenreuter, U. Sack, K. Huse, M. Groth, C. Birkemeyer, W. Schellenberger, R. Gebhardt, M. Platzer, T. Weiss, M. A. Vijayalakshmi, M. Kruger, and G. Birkenmeier. 2008. Curcumin inhibits glyoxalase 1: a possible link to its anti-inflammatory and anti-tumor activity. PLoS One 3:e3508.

320. Schneider, T., K. Gries, M. Josten, I. Wiedemann, S. Pelzer, H. Labischinski, and H.-G. Sahl. 2009. The lipopeptide antibiotic friulimicin B inhibits 
cell wall biosynthesis through complex formation with bactoprenol phosphate. Antimicrob. Agents Chemother. 53:1610-1618.

321. Schneider, T., T. Kruse, R. Wimmer, I. Wiedemann, V. Sass, U. Pag, A Jansen, A. K. Nielsen, P. H. Mygind, D. S. Raventos, S. Neve, B. Ravn, A. M. Bonvin, L. De Maria, A. S. Andersen, L. K. Gammelgaard, H. G. Sahl, and H. H. Kristensen. 2010. Plectasin, a fungal defensin, targets the bacterial cell wall precursor lipid II. Science 328:1168-1172.

322. Schneider, T., and H. G. Sahl. 2010. Lipid II and other bactoprenol-bound cell wall precursors as drug targets. Curr. Opin. Invest. Drugs 11:157-164.

323. Schneider, T., and H. G. Sahl. 2010. An oldie but a goodie-cell wall biosynthesis as antibiotic target pathway. Int. J. Med. Microbiol. 300:161169.

324. Schwarz, S., C. Werckenthin, and C. Kehrenberg. 2000. Identification of plasmid-borne chloramphenicol-florfenicol resistance gene in Staphylococcus sciuri. Antimicrob. Agents Chemother. 44:2530-2533.

325. Sears, P., T. Louie, K. Mullane, M. Miller, and Y. K. Shue. 2009. Pharmacokinetics/pharmacodynamics (PK/PD) of fidaxomicin in treatment of Clos tridium difficile infection (CDI), abstr. A1-1949. Abstr. 49th Intersci. Conf Antimicrob. Agents Chemother., San Francisco, CA. American Society for Microbiology, Washington, DC

326. Segre, G., E. Bianchi, A. Cataldi, and G. Zannini. 1987. Pharmacokinetic profile of fosfomycin trometamol (Monuril). Eur. Urol. 13(Suppl. 1):56-63

327. Selva, E., N. Montanini, S. Stella, A. Soffientini, L. Gastaldo, and M Denaro. 1997. Targeted screening for elongation factor Tu binding antibiotics. J. Antibiot. (Tokyo) 50:22-26.

328. Sergio, S., G. Pirali, R. White, and F. Parenti. 1975. Lipiarmycin, a new antibiotic from Actinoplanes. III. Mechanism of action. J. Antibiot. (Tokyo) 28:543-549.

329. Sharma, A., G. K. Khuller, and S. Sharma. 2009. Peptide deformylase-a promising therapeutic target for tuberculosis and antibacterial drug discovery. Expert Opin. Ther. Targets 13:753-765.

330. Shen, R., M. C. Olcott, J. Kim, I. Rajagopal, and C. K. Mathews. 2004 Escherichia coli nucleoside diphosphate kinase interactions with T4 phage proteins of deoxyribonucleotide synthesis and possible regulatory functions. J. Biol. Chem. 279:32225-32232.

331. Shin, H., H. A. Gennadios, D. A. Whittington, and D. W. Christianson. 2007. Amphipathic benzoic acid derivatives: synthesis and binding in the hydrophobic tunnel of the zinc deacetylase LpxC. Bioorg. Med. Chem. 15:2617-2623.

332. Shryock, T. R., and F. A. Kapral. 1992. The production of bactericidal fatty acids from glycerides in staphylococcal abscesses. J. Med. Microbiol. 36: 288-292.

333. Silver, L. L. Rational approaches to antibacterial discovery: pre-genomic phenotypic and directed screening. In T. J. Dougherty and M. J. Pucci (ed.) Antibacterial discovery and development, in press. Springer, New York, NY.

334. Silver, L. L. 2003. Novel inhibitors of bacterial cell wall synthesis. Curr Opin. Microbiol. 6:431-438.

335. Silver, L. L. 2005. A retrospective on the failures and successes of antibacterial drug discovery. IDrugs 8:651-655.

336. Silver, L. L. 2006. Does the cell wall of bacteria remain a viable source of targets for novel antibiotics? Biochem. Pharmacol. 71:996-1005.

337. Silver, L. L. 2007. Multi-targeting by monotherapeutic antibacterials. Nat Rev. Drug Discov. 6:41-55.

338. Silver, L. L. 2008. Are natural products still the best source for antibacterial discovery? The bacterial entry factor. Expert Opin. Drug Discov. 3:487-500.

339. Silver, L. L., and K. A. Bostian. 1990. Screening of natural products for antimicrobial agents. Eur. J. Clin. Microbiol. Infect. Dis. 9:455-461.

340. Silver, L. L., and K. A. Bostian. 1993. Discovery and development of new antibiotics: the problem of antibiotic resistance. Antimicrob. Agents Chemother. 37:377-383.

341. Simmons, K. J., I. Chopra, and C. W. G. Fishwick. 2010. Structure-based discovery of antibacterial drugs. Nat. Rev. Microbiol. 8:501-510.

342. Skipper, H. E., J. R. Thomson, and M. Bell. 1954. Attempts at dual blocking of biochemical events in cancer chemotherapy. Cancer Res. 14:503-507.

343. Slade, D. A. 1963. A clinical trial of nalidixic acid (Negram, WIN. 18,320) in thirty-three patients with urinary infections treated in general practice. Br. J. Urol. 35:125-128.

344. Sonenshein, A. L., H. B. Alexander, D. M. Rothstein, and S. H. Fisher. 1977. Lipiarmycin-resistant ribonucleic acid polymerase mutants of Bacillus subtilis. J. Bacteriol. 132:73-79.

345. Spellberg, B., J. H. Powers, E. P. Brass, L. G. Miller, and J. E. Edwards, Jr. 2004. Trends in antimicrobial drug development: implications for the future. Clin. Infect. Dis. 38:1279-1286.

346. Spiegel, D. A., F. C. Schroeder, J. R. Duvall, and S. L. Schreiber. 2006. An oligomer-based approach to skeletal diversity in small-molecule synthesis. J. Am. Chem. Soc. 128:14766-14767.

347. Spratt, B. G. 1994. Resistance to antibiotics mediated by target alterations Science 264:388-393

348. Spratt, B. G., and K. D. Cromie. 1988. Penicillin-binding proteins of Gramnegative bacteria. Rev. Infect. Dis. 10:699-711.

349. Sreevatsan, S., X. Pan, K. E. Stockbauer, N. D. Connell, B. N. Kreiswirth,
T. S. Whittam, and J. M. Musser. 1997. Restricted structural gene polymorphism in the Mycobacterium tuberculosis complex indicates evolutionarily recent global dissemination. Proc. Natl. Acad. Sci. U. S. A. 94:98699874.

350. Srinivas, N., P. Jetter, B. J. Ueberbacher, M. Werneburg, K. Zerbe, J. Steinmann, B. Van der Meijden, F. Bernardini, A. Lederer, R. L. Dias, P. E. Misson, H. Henze, J. Zumbrunn, F. O. Gombert, D. Obrecht, P. Hunziker, S. Schauer, U. Ziegler, A. Kach, L. Eberl, K. Riedel, S. J. DeMarco, and J. A. Robinson. 2010. Peptidomimetic antibiotics target outer-membrane biogenesis in Pseudomonas aeruginosa. Science 327:1010-1013.

351. Stamper, G. F., K. L. Longenecker, E. H. Fry, C. G. Jakob, A. S. Florjancic, Y. G. Gu, D. D. Anderson, C. S. Cooper, T. Zhang, R. F. Clark, Y. Cia, C. L. Black-Schaefer, J. O. McCall, C. G. Lerner, P. J. Hajduk, B. A. Beutel, and V. S. Stoll. 2006. Structure-based optimization of MurF inhibitors. Chem. Biol. Drug Des. 67:58-65.

352. Stapley, E. O. 1958. Cross-resistance studies and antibiotic identification. Appl. Microbiol. 6:392-398.

353. Starr, J. T., R. J. Sciotti, D. L. Hanna, M. D. Huband, L. M. Mullins, H. Cai, J. W. Gage, M. Lockard, M. R. Rauckhorst, R. M. Owen, M. S. Lall, M. Tomilo, H. Chen, S. P. McCurdy, and M. R. Barbachyn. 2009. 5-(2 Pyrimidinyl)-imidazo[1,2-a]pyridines are antibacterial agents targeting the ATPase domains of DNA gyrase and topoisomerase IV. Bioorg. Med. Chem. Lett. 19:5302-5306.

354. Strahilevitz, J., and D. C. Hooper. 2005. Dual targeting of topoisomerase IV and gyrase to reduce mutant selection: direct testing of the paradigm by using WCK-1734, a new fluoroquinolone, and ciprofloxacin. Antimicrob. Agents Chemother. 49:1949-1956.

355. Strömbergsson, H., M. Lapins, G. J. Kleywegt, and J. E. Wikberg. 2010. Towards proteome-wide interaction models using the proteochemometrics approach. Mol. Infect. 29:499-508.

356. Swanson, R. N., D. J. Hardy, N. L. Shipkowitz, C. W. Hanson, N. C. Ramer, P. B. Fernandes, and J. J. Clement. 1991. In vitro and in vivo evaluation of tiacumicins B and $\mathrm{C}$ against Clostridium difficile. Antimicrob. Agents Chemother. 35:1108-1111.

357. Takahata, S., M. Iida, Y. Osaki, J. Saito, H. Kitagawa, T. Ozawa, T. Yoshida, and S. Hoshiko. 2006. AG205, a novel agent directed against FabK of Streptococcus pneumoniae. Antimicrob. Agents Chemother. 50: 2869-2871.

358. Takatsuka, Y., C. R. Chen, and H. Nikaido. 2010. Mechanism of recognition of compounds of diverse structures by the multidrug efflux pump AcrB of Escherichia coli. Proc. Natl. Acad. Sci. U. S. A. 107:6559-6565.

359. Tam, V. H., K. T. Chang, K. Abdelraouf, C. G. Brioso, M. Ameka, L. A. McCaskey, J. S. Weston, J. P. Caeiro, and K. W. Garey. 2010. Prevalence, resistance mechanisms, and susceptibility of multidrug-resistant bloodstream isolates of Pseudomonas aeruginosa. Antimicrob. Agents Chemother. 54:1160-1164

360. Tanitame, A., Y. Oyamada, K. Ofuji, M. Fujimoto, N. Iwai, Y. Hiyama, K. Suzuki, H. Ito, H. Terauchi, M. Kawasaki, K. Nagai, M. Wachi, and J. Yamagishi. 2004. Synthesis and antibacterial activity of a novel series of potent DNA gyrase inhibitors. Pyrazole derivatives. J. Med. Chem. 47: 3693-3696.

361. Tanitame, A., Y. Oyamada, K. Ofuji, H. Terauchi, M. Kawasaki, M. Wachi, and J. Yamagishi. 2005. Synthesis and antibacterial activity of a novel series of DNA gyrase inhibitors: 5-[(E)-2-arylvinyl]pyrazoles. Bioorg. Med. Chem. Lett. 15:4299-4303.

362. Tanner, M. E., S. Vaganay, J. van Heijenoort, and D. Blanot. 1996. Phosphinate inhibitors of the D-glutamic acid-adding enzyme of peptidoglycan biosynthesis. J. Org. Chem. 61:1756-1760.

363. Tomasic, T., N. Zidar, A. Kovac, S. Turk, M. Simcic, D. Blanot, M. MüllerPremru, M. Filipic, S. Golic Grdadolnik, A. Zega, M. Anderluh, S. Gobec, D. Kikelj, and L. P. Masic. 2009. 5-Benzylidenethiazolidin-4-ones as multitarget inhibitors of bacterial Mur ligases. ChemMedChem 5:286-295.

364. Tomasic, T., N. Zidar, V. Rupnik, A. Kovac, D. Blanot, S. Gobec, D. Kikelj, and L. P. Masic. 2009. Synthesis and biological evaluation of new glutamic acid-based inhibitors of MurD ligase. Bioorg. Med. Chem. Lett. 19:153157.

365. Trapp, S. 2009. Bioaccumulation of polar and ionizable compounds in plants, p. 299-353. In J. Devillers (ed.), Ecotoxicology modeling. Springer, New York, NY.

366. Trapp, S., and R. W. Horobin. 2005. A predictive model for the selective accumulation of chemicals in tumor cells. Eur. Biophys. J. 34:959-966.

367. Trapp, S., G. R. Rosania, R. W. Horobin, and J. Kornhuber. 2008. Quantitative modeling of selective lysosomal targeting for drug design. Eur. Biophys. J. 37:1317-1328.

368. Trias, J., and Z. Yuan. 1999. Mining bacterial cell wall biosynthesis with new tools: multitarget screens. Drug Resist. Updat. 2:358-362.

369. Tung, R. D. 2002. Design and synthesis of amprenavir, a novel HIV protease inhibitor. Infect. Dis. Ther. 25:101-118

370. Turk, S., A. Kovac, A. Boniface, J. M. Bostock, I. Chopra, D. Blanot, and S. Gobec. 2009. Discovery of new inhibitors of the bacterial peptidoglycan biosynthesis enzymes MurD and MurF by structure-based virtual screening. Bioorg. Med. Chem. 17:1884-1889. 
371. Urban, A., S. Eckermann, B. Fast, S. Metzger, M. Gehling, K. Ziegelbauer, H. Rubsamen-Waigmann, and C. Freiberg. 2007. Novel whole-cell antibiotic biosensors for compound discovery. Appl. Environ. Microbiol. 73: 6436-6443.

372. Urgaonkar, S., H. S. LaPierre, I. Meir, H. Lund, D. RayChaudhuri, and J. T. Shaw. 2005. Synthesis of antimicrobial natural products targeting FtsZ: (+/-)-dichamanetin and (+/-)-2' "-hydroxy-5' '-benzylisouvarinol-B. Org. Lett. 7:5609-5612.

373. Van Bambeke, F., M. P. Mingeot-Leclercq, M. J. Struelens, and P. M Tulkens. 2008. The bacterial envelope as a target for novel anti-MRSA antibiotics. Trends Pharmacol. Sci. 29:124-134.

374. van den Boogaard, J., G. S. Kibiki, E. R. Kisanga, M. J. Boeree, and R. E. Aarnoutse. 2009. New drugs against tuberculosis: problems, progress, and evaluation of agents in clinical development. Antimicrob. Agents Chemother. 53:849-862.

375. Van Miert, A. S. 1994. The sulfonamide-diaminopyrimidine story. J. Vet. Pharmacol. Ther. 17:309-316.

376. Versalovic, J., D. Shortridge, K. Kibler, M. V. Griffy, J. Beyer, R. K. Flamm, S. K. Tanaka, D. Y. Graham, and M. F. Go. 1996. Mutations in 23S rRNA are associated with clarithromycin resistance in Helicobacter pylori. Antimicrob. Agents Chemother. 40:477-480.

377. Villoutreix, B. O., R. Eudes, and M. A. Miteva. 2009. Structure-based virtual ligand screening: recent success stories. Comb. Chem. High Throughput Screen. 12:1000-1016.

378. Walsh, C. 2003. Where will new antibiotics come from? Nat. Rev. Microbiol. 1:65-70.

379. Wang, J., A. Galgoci, S. Kodali, K. B. Herath, H. Jayasuriya, K. Dorso, F. Vicente, A. Gonzalez, D. Cully, D. Bramhill, and S. Singh. 2003. Discovery of a small molecule that inhibits cell division by blocking FtsZ, a novel therapeutic target of antibiotics. J. Biol. Chem. 278:44424-44428.

380. Wang, J., S. Kodali, S. H. Lee, A. Galgoci, R. Painter, K. Dorso, F. Racine, M. Motyl, L. Hernandez, E. Tinney, S. L. Colletti, K. Herath, R. Cummings, O. Salazar, I. Gonzalez, A. Basilio, F. Vicente, O. Genilloud, F. Pelaez, H. Jayasuriya, K. Young, D. F. Cully, and S. B. Singh. 2007. Discovery of platencin, a dual FabF and FabH inhibitor with in vivo antibiotic properties. Proc. Natl. Acad. Sci. U. S. A. 104:7612-7616.

381. Wang, J., S. M. Soisson, K. Young, W. Shoop, S. Kodali, A. Galgoci, R. Painter, G. Parthasarathy, Y. S. Tang, R. Cummings, S. Ha, K. Dorso, M Motyl, H. Jayasuriya, J. Ondeyka, K. Herath, C. Zhang, L. Hernandez, J. Allocco, A. Basilio, J. R. Tormo, O. Genilloud, F. Vicente, F. Pelaez, L. Colwell, S. H. Lee, B. Michael, T. Felcetto, C. Gill, L. L. Silver, J. D. Hermes, K. Bartizal, J. Barrett, D. Schmatz, J. W. Becker, D. Cully, and S. B. Singh. 2006. Platensimycin is a selective FabF inhibitor with potent antibiotic properties. Nature 441:358-361.

382. Wang, W.-L., S. C. Chai, M. Huang, H.-Z. He, T. D. Hurley, and Q.-Z. Ye. 2008. Discovery of inhibitors of Escherichia coli methionine aminopeptidase with the Fe(II)-form selectivity and antibacterial activity. J. Med. Chem. 51:6110-6120.

383. Watanabe, T., Y. Hashimoto, K. Yamamoto, K. Hirao, A. Ishihama, M Hino, and R. Utsumi. 2003. Isolation and characterization of inhibitors of the essential histidine kinase, YycG in Bacillus subtilis and Staphylococcus aureus. J. Antibiot. (Tokyo) 56:1045-1052.

384. Weiss, W. J., B. Hafkin, N. Kaplan, M. Pulse, and P. Nguyen. 2008. Efficacy of AFN-1252 and vancomycin in the mouse subcutaneous abscess model with a methicillin-resistant $S$. aureus, abstr. F1-329. Abstr. 48th Intersci. Conf. Antimicrob. Agents Chemother., Washington, DC. American Society for Microbiology, Washington, DC.

385. Wiener, J. J., L. Gomez, H. Venkatesan, A. Santillan, Jr., B. D. Allison, K. L. Schwarz, S. Shinde, L. Tang, M. D. Hack, B. J. Morrow, S. T. Motley, R. M. Goldschmidt, K. J. Shaw, T. K. Jones, and C. A. Grice. 2007. Tetrahydroindazole inhibitors of bacterial type II topoisomerases. 2. SAR development and potency against multidrug-resistant strains. Bioorg. Med. Chem. Lett. 17:2718-2722.

386. Windau, A., S. Bajaksouzian, P. C. Appelbaum, and M. R. Jacobs. 2002
AR-100, a novel diaminopyrimidine compound: activity against Enterobacteriaceae, abstr. F-2025. Abstr. 42nd Intersci. Conf. Antimicrob. Agents Chemother., San Diego, CA. American Society for Microbiology, Washington, DC.

387. Wong, K., D. Kuo, R. Chabin, C. Fournier, L. Gegnas, S. Waddell, F. Marsilio, B. Leiting, and D. Pompliano. 1998. Engineering a cell-free murein biosynthetic pathway: combinatorial enzymology in drug discovery. J. Am. Chem. Soc. 120:13527-13528.

388. Woodford, N., and M. J. Ellington. 2007. The emergence of antibiotic resistance by mutation. Clin. Microbiol. Infect. 13:5-18.

389. Woodruff, H. B., J. M. Mata, S. Hernàndez, S. Mochales, A. Rodríguez, E. O. Stapley, H. Wallick, A. K. Miller, and D. Hendlin. 1977. Fosfomycin: laboratory studies. Chemotherapy 23:1-22.

390. Wright, G. D. 2007. The antibiotic resistome: the nexus of chemical and genetic diversity. Nat. Rev. Microbiol. 5:175-186.

391. Wright, G. E., N. C. Brown, W. C. Xu, Z. Y. Long, C. Zhi, J. J. Gambino, M. H. Barnes, and M. M. Butler. 2005. Active site directed inhibitors of replication-specific bacterial DNA polymerases. Bioorg. Med. Chem. Lett. 15:729-732.

392. Wright, G. E., W.-C. Xu, and N. C. Brown. 9 August 2005. Purine and isosteric antibacterial compounds. U.S. patent 6,926,763 B2.

393. Wu, H. C., and P. S. Venkateswaran. 1974. Fosfomycin-resistant mutant of Escherichia coli. Ann. N. Y. Acad. Sci. 235:587-592.

394. Xu, H. H., L. Real, and M. W. Bailey. 2006. An array of Escherichia coli clones over-expressing essential proteins: a new strategy of identifying cellular targets of potent antibacterial compounds. Biochem. Biophys. Res. Commun. 349:1250-1257.

395. Yang, Y., A. Severin, R. Chopra, G. Krishnamurthy, G. Singh, W. Hu, D. Keeney, K. Svenson, P. J. Petersen, P. Labthavikul, D. M. Shlaes, B. A. Rasmussen, A. A. Failli, J. S. Shumsky, K. M. K. Kutterer, A. Gilbert, and T. S. Mansour. 2006. 3,5-Dioxopyrazolidines, novel inhibitors of UDP- $N$ acetylenolpyruvylglucosamine reductase (MurB) with activity against Gram-positive bacteria. Antimicrob. Agents Chemother. 50:556-564.

396. Yao, J., Q. Zhang, J. Min, J. He, and Z. Yu. 2010. Novel enoyl-ACP reductase (FabI) potential inhibitors of Escherichia coli from Chinese medicine monomers. Bioorg. Med. Chem. Lett. 20:56-59.

397. Yeh, P., A. I. Tschumi, and R. Kishony. 2006. Functional classification of drugs by properties of their pairwise interactions. Nat. Genet. 38:489-494.

398. Yin, D., B. Fox, M. L. Lonetto, M. R. Etherton, D. J. Payne, D. J. Holmes, M. Rosenberg, and Y. Ji. 2004. Identification of antimicrobial targets using a comprehensive genomic approach. Pharmacogenomics 5:101-113.

399. Young, K., H. Jayasuriya, J. G. Ondeyka, K. Herath, C. Zhang, S. Kodali, A. Galgoci, R. Painter, V. Brown-Driver, R. Yamamoto, L. L. Silver, Y. Zheng, J. I. Ventura, J. Sigmund, S. Ha, A. Basilio, F. Vicente, J. R. Tormo, F. Pelaez, P. Youngman, D. Cully, J. F. Barrett, D. Schmatz, S. B. Singh, and J. Wang. 2006. Discovery of FabH/FabF inhibitors from natural products. Antimicrob. Agents Chemother. 50:519-526.

400. Young, K., and L. L. Silver. 1991. Leakage of periplasmic enzymes from envA1 strains of Escherichia coli. J. Bacteriol. 173:3609-3614.

401. Yuan, Z., and R. J. White. 2006. The evolution of peptide deformylase as a target: contribution of biochemistry, genetics and genomics. Biochem. Pharmacol. 71:1042-1047.

402. Zarfl, C., M. Matthies, and J. Klasmeier. 2008. A mechanistical model for the uptake of sulfonamides by bacteria. Chemosphere 70:753-760.

403. Zeng, B., K. Wong, D. Pompliano, S. Reddy, and M. Tanner. 1998. A phosphinate inhibitor of the mesodiaminopimelic acid-adding enzyme (MurE) of peptidoglycan biosynthesis. J. Org. Chem. 63:10081-10086.

404. Zgurskaya, H. I., and H. Nikaido. 2000. Multidrug resistance mechanisms: drug efflux across two membranes. Mol. Microbiol. 37:219-225.

405. Zhu, L., J. Lin, J. Ma, J. E. Cronan, and H. Wang. 2010. The triclosan resistance of Pseudomonas aeruginosa PAO1 is due to FabV, a triclosanresistant enoyl-acyl carrier protein reductase. Antimicrob. Agents Chemother. 54:689-698. 
Lynn Silver received her Ph.D. in Molecular Biology and Microbiology at Tufts University in 1975 and did postdoctoral work at the Université de Genève and at the NIH. In 1982, she joined Merck Research Laboratories, where she worked for 21 years in the antibacterial discovery area, screening for novel antibacterials in both natural products and chemical collections, supporting chemical synthetic projects on improved antibacterials, evaluating preclinical drug candi-

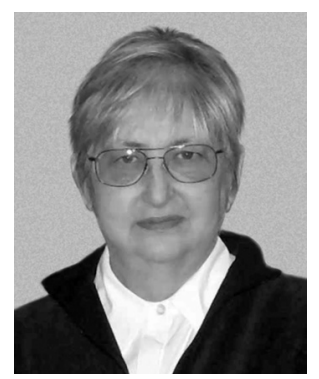
dates, and studying antibacterial resistance. She was a member of teams coordinating the advancement of Invanz through the regulatory process and evaluating licensing and collaboration opportunities. Since retiring from Merck in 2003, she has been a consultant in antibacterial discovery and preclinical development for pharmaceutical companies and venture capitalists. She is a member of the editorial board of Antimicrobial Agents and Chemotherapy (1997 to 2011), an ASM Branch Lecturer (2007 to 2009), and a member of several scientific advisory boards. 